University of Rhode Island

DigitalCommons@URI

Open Access Dissertations

2019

\title{
ALEXA OR ALEX? GENDERED TECHNOLOGY'S INFLUENCE ON CONSUMER JUDGMENTS
}

Jiyoon An

University of Rhode Island, marketingprofan@hotmail.com

Follow this and additional works at: https://digitalcommons.uri.edu/oa_diss

\section{Recommended Citation}

An, Jiyoon, "ALEXA OR ALEX? GENDERED TECHNOLOGY'S INFLUENCE ON CONSUMER JUDGMENTS" (2019). Open Access Dissertations. Paper 880.

https://digitalcommons.uri.edu/oa_diss/880

This Dissertation is brought to you for free and open access by DigitalCommons@URI. It has been accepted for inclusion in Open Access Dissertations by an authorized administrator of DigitalCommons@URI. For more information, please contact digitalcommons-group@uri.edu. 


\begin{abstract}
ALEXA OR ALEX?
GENDERED TECHNOLOGY'S INFLUENCE ON CONSUMER JUDGMENTS

BY

JIYOON AN
\end{abstract}

A DISSERTATION SUBMITTED IN PARTIAL FULFILLMENT OF THE

REQUIREMENTS FOR THE DEGREE OF

DOCTOR OF PHILOSOPHY

IN

BUSINESS ADMINISTRATION

UNIVERSITY OF RHODE ISLAND 


\title{
DOCTOR OF PHILOSOPHY DISSERTATION
}

\author{
$\mathrm{ON}$ \\ JIYOON AN
}

APPROVED:

Dissertation Committee:

\author{
Major Professor Ruby R. Dholakia \\ Christy Ashley \\ Seung K. Shin \\ Ian Reyes \\ Nasser Zawai \\ DEAN OF THE GRADUATE SCHOOL \\ UNIVERSITY OF RHODE ISLAND
}




\begin{abstract}
This research attempts to examine when technological products are seen as a gendered agent rather than an object. Based on a review of the literature on consumertechnology relationship and social cognition theory, this research addresses the conditions for gendering of technology, its process and outcomes by using multi-method empirical studies. The stereotype model tests the mediating and moderating hypotheses regarding gendering and its effects on consumer judgments. The disruption model attempts to disrupt the stereotyped gender effects by using a counter-stereotypical gendered cue. The research provides theoretical, managerial, and public policy insights.
\end{abstract}




\section{ACKNOWLEDGEMENTS}

I would like to thank the University of Rhode Island's College of Business faculty and community for encouraging my academic journey to become a marketing educator. In particular, I would like to thank Drs. Ruby R. Dholakia and Christy Ashley because they have helped me to become a well-rounded marketing scholar and to think of research from both a micro to a macro perspective.

I really appreciate Drs. Ruby R. Dholakia, Christy Ashley, Seung K. Shin, and Ian Reyes for their guidance as dissertation committee members. Drs. Ruby R. Dholakia and Christy Ashley have coached me consistently with in-depth knowledge and experience as well as warmth, respect and kindness. I want to thank Dr. Ruby for mentoring my dissertation. Without you, my unrefined idea would have never taken off for the scholarly journey. I want to express my gratitude to Dr. Christy for being my hands-on mentor to help me come through critical challenges. Thank you does not seem enough to express

my gratitude to my dissertation co-chairs. Also, I would like to thank Dr. Seung K. Shin for his guidance on both a professional and personal level. I appreciate Dr. Ian Reyes for his helpful insight from a critical, socio-cultural approach. Their patience, advice, and commitment have been so helpful throughout the journey in developing my research on the intersection of culture and technology.

My gratitude is to my family for believing in me during this long and challenging journey - my parents, Okhyang Na, Dongsu An, and my sister, Hyeyoon An. My parents have taught me to be resilient and not to give up on my academic journey and valued my potentials and intellectual curiosity. Also, I want to thank Hyeyoon for being the best 
friend and for being very supportive of my academic journey and to give a different perspective as a successful global business professional.

I have received support from many people including my committee members, University of Rhode Island's College of Business faculty and community, and family members. The completion of this dissertation represents was possible thanks to their help. Thank you. 


\section{TABLE OF CONTENTS}

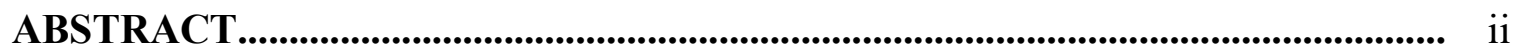

ACKNOWLEDGEMENTS................................................................................ ii

TABLE OF CONTENTS..................................................................................... v

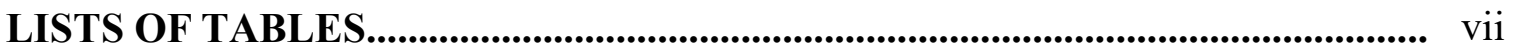

LISTS OF FIGURES........................................................................................................................ vii

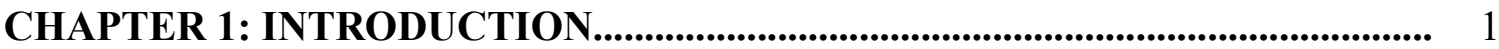

Contributions of the Research.............................................................................

Organization of the Dissertation.............................................................................

CHAPTER 2: THEORETICAL BACKGROUND..................................................... 6

Smart Technology and Consumer-Technology Relationship........................................ 7

Gender, Gendered Roles, and Gendering............................................................ 11

Social Cognition Theory and Alternatives on Consumer Judgments............................. 17

Gendering Effects on Consumer Judgments........................................................... 17

CHAPTER 3: RESEARCH FRAMEWORK AND HYPOTHESES.......................... 21

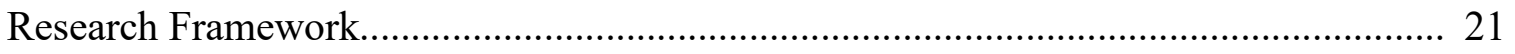

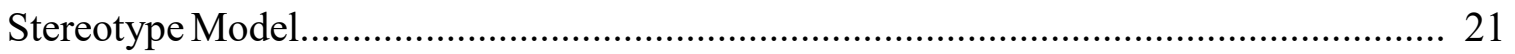

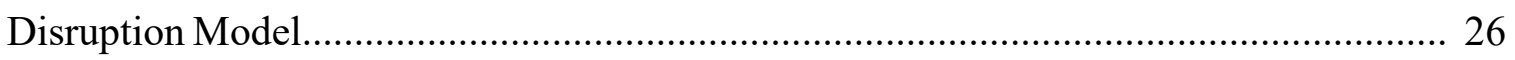

CHAPTER 4: METHODOLOGY, ANALYSIS, ANDFINDINGS........................... 29

Overview of Exploratory Studies............................................................................. 29

Exploratory Study 1 - Qualitative interview......................................................... 30

Exploratory Study 2 - Pet name exercise............................................................. 49

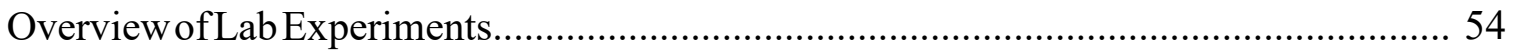

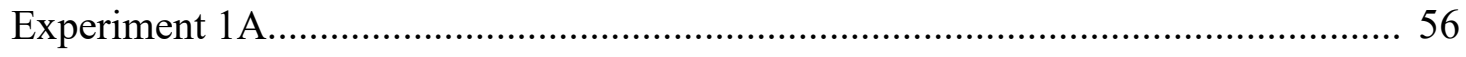




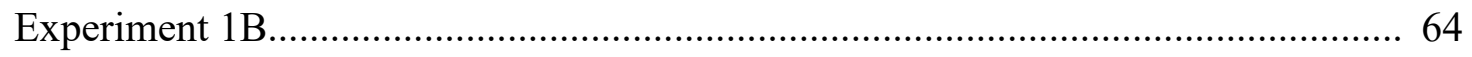

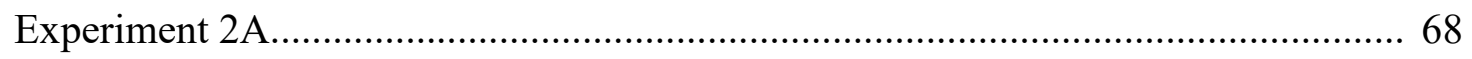

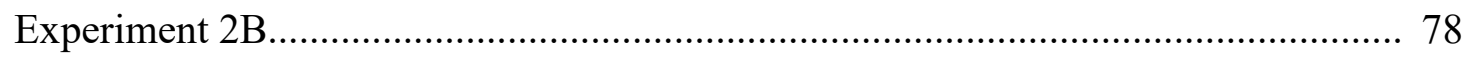

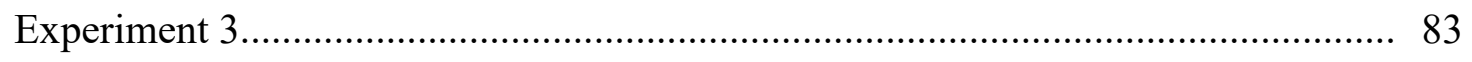

CHAPTER 5: DISCUSSION AND CONCLUSION.......................................... 90

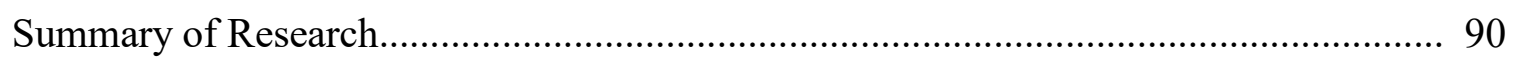

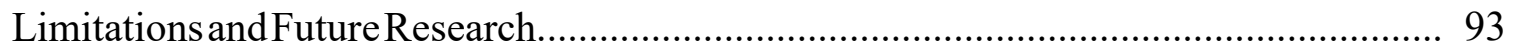

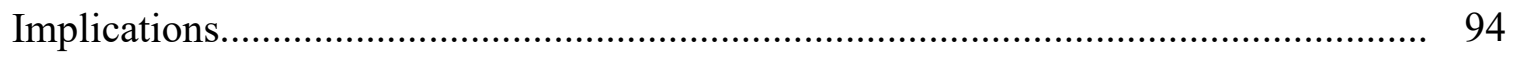

APPENDICES.............................................................................................................................. 98

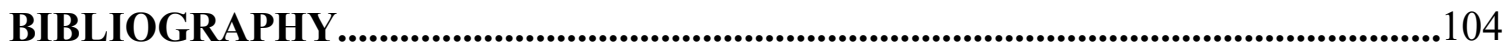




\section{LIST OF TABLES}

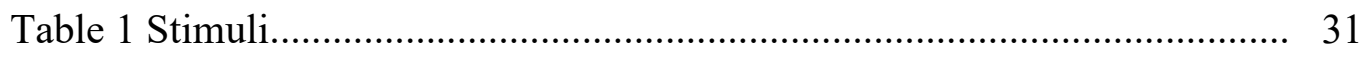

Table 2 Demographic Characteristics of Participants.................................. 33

Table 3 Fit indices.............................................................................. 36

Table 4 Two-dimensional Solution......................................................... 37

Table 5 Gender-implicit pet name task................................................. 52

Table 6 Gender-explicit categorization task......................................... 53

Table 7 Summary of Experiment Design................................................. 54

Table 8 Means of Experiment 1A....................................................... 58

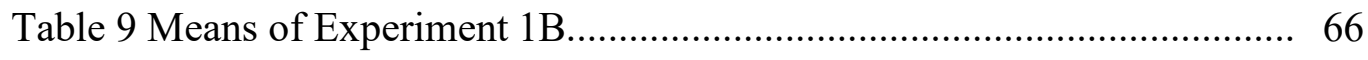

Table 10 Means of Experiment 2A.................................................... 71

Table 11 Means of Experiment 2B..................................................... 79

Table 12 Effects of perceived male-gendered role on consumer judgments $\quad 82$

Table 13 Means of Experiment 3 ..................................................... 84

Table 14 Direct effects of gendering and stereo-typicality of cues................ 89

Table 15 Summaries of Study Results..................................................... 92 


\section{LIST OF FIGURES}

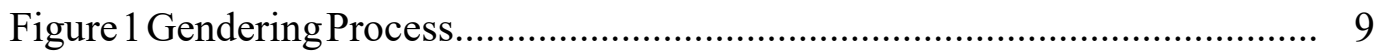

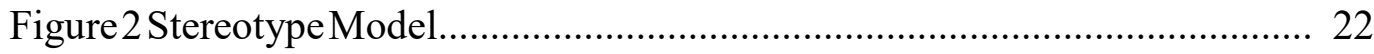

Figure 3 Stereotype Model with Hypotheses............................................... 26

Figure 4 Disruption Model with Hypotheses............................................ 28

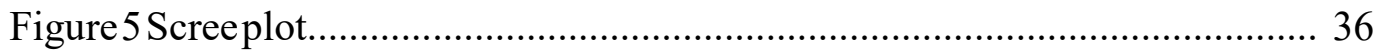

Figure 6 Two-Dimensional Multidimensional Scaling Perceptual Map........... 41

Figure 7 Accuracy of gender category-smart refrigerator associations.............. 59

Figure 8 Accessibilityof gender category-smart refrigerator associations......... 59

Figure 9 Experiment 1A's mediation analysis.......................................... 62

Figure 10 Perceived Gendered Roles in Jill and No Cue Condition................. 66

Figure 11 Accuracy of gender category-cooking robotassociations................. 72

Figure 12 Accessibility of gender category-cooking robot associations............. 73

Figure 13 Experiment 2A's moderated mediation analysis.............................. 76

Figure 14 Experiment 2B's mediation analysis......................................... 81

Figure 15 Accuracy of gender category-automowerassociations..................... 85

Figure 16 Accessibility of gender category-automower associations................ 86

Figure 17 Perceived Gendered Role ....................................................... 87

Figure 18 Effect of counter-stereotypical cue on perceived quality.................. 88

Figure 19 Effect of counter-stereotypical cue on persuasive effectiveness......... 88 


\section{CHPATER 1: INTRODUCTION}

From Alexa to Cortana, smart technologies have become a part of consumers' lives. A recent survey reports that $85 \%$ of American consumers currently use smart technologies, such as smart home devices and digital assistant services (New York Times 2018). Recent literature recognizes the nature of consumer-smart technology as relational and pseudo-interpersonal (Hoffman and Novak 2018). Smart technology is often represented with verbal, visual, auditory and other sensory cues to imbue humanlike characteristics (e.g., anthropomorphism). For example, consumers find human-like characteristics in smart technologies such as their names (e.g., Amazon's Alexa, Apple's Siri or Microsoft's Cortana) as well as the products' structures (e.g., audio and visual cues in the humanoid robot Sophia).

Smart technology is seen as alive, capable of forming pseudo-interpersonal relationships with other entities (e.g. Novak and Hoffman 2019). Mourey and colleagues (2017) note that smart products seem alive to consumers because the products are intelligent, interactive, responsive, and may even possess personalities. Consumers may form relationships with smart technology products that are not explained by the utility of the products and are different from relationships with other types of technological products.

To understand a technological agent as a potential partner, social cognition is used to inform our understanding of how people interact with smart technology. Social technology helps explain how people make inferences about other people based on social markers (Hoffman and Novak 2018). Rijsdijk and his collegues also note that technology products entail deliberative and reactive capacities (Rijsdijk et al. 2007). 
The deliberate capacity is characterized by analyzing data for decision making without interference by users (e.g., automation). The reactive capacity includes responding on interactive input (e.g., consumer's voice). For example, Amazon's Alexa is characterized by capacities to learn a consumer's behaviors (e.g., play preferred songs), make connections to other home gadgets (e.g., dim lights), and work with other technological products autonomously (e.g., monitor thermostats).

If consumers perceive smart technology devices as social agents, it is possible that the social markers that the consumer uses to categorize the technology and the roles associated with each of those markers will guide whether and how consumers interact with smart technology devices. If technology is interpreted as a social agent for social interactions, the properties used by consumers to make sense of social interactions may apply to the consumer-technology interaction with the smart object as well (Fiske and Haslam 1996; Haslam and Whelan 2008). Like interpersonal human interactions, a consumer uses the social categories that characterize another social agent (e.g., his/her age, race, national status, occupation or gender) to determine whether s/he is a threat and, if not, whether s/he is helpful (Haslam and Whelan 2008). Abele and Wojciszke (2013) note that a communal role (e.g., empathic, emotional, and dependent) and an agentic role (e.g., decisive, dominant, and aggressive) are femalegendered and male-gendered, respectively.

Extending social cognition theory to equate consumer technology relationship to interpersonal relationship, a smart technological product's humanlike characteristic is hypothesized to activate social norms and expectations which predict whether and how the consumer interacts with the smart technology (Fiske 2000; Wegner and Bargh 
1998). The focus of this dissertation is on gender as a social marker and the associated norms and expectations. Gender defines associations and expectations of men and women that govern characteristics and behaviors (Bourdieu 1998), which is important to understand meaning of gendered smart technology. Specifically, gendering, a mental model for favoring specific characteristics of, suited to, or biased toward one gender or the other (Wajcman 2010) is the core concept of this dissertation.

This dissertation specifically focuses on gender as an embedded cue within smart technology devices. Gender is seen as one of the important social membership categories (Haslam, Rothschild, and Ernst 2000). Previous studies suggest that when technology is viewed as an object for consumption, technology's associations with a specific gender signal asymmetrical quality (e.g., innovativeness with male consumers and kindness with female consumers; Dholakia and Chiang 2003). If gender cues that are embedded within the smart technology device affect its gendering, or the assignment of a specific gender to a device, it may influence consumer judgments regarding the device.

Understanding the gendering of smart technology devices is complicated by the existing culturally grounded associations between technology and masculinity (Gill and Grint 1995). Technology is often associated with males over females because men tend to develop technology from a male perspective and are perceived as lead users with a better understanding of technology (Dholakia 2012). Further, the use of smart technology in the home, where there may be cultural distinctions between women's and men's work, may affect both the gendering of smart objects and the impact of gendering on their evaluations (Gill and Grint 1995). The research context chosen for 
this dissertation is smart technological products for the home in our effortsto advance the scholarship of gendering and smart technology.

\section{Contributions of the Research}

Given the pervasive and growing consumer use of smart technologies, it is surprising that researchers have not addressed a consumer's interactions with smart technology when technology is seen as a social agent. This dissertation is designed to address this gap. Social cognition theory is used to examine the consumer-technology relationship. This perspective was developed from both social cognition literature and the research on consumer-technology relationships.

This research makes important contributions to consumer behavior theory and practice. Specifically, this research provides evidence on how gendering of technology affects consumer-technology interactions. Empirical findings reveal that due to gendering, a consumer assigns a congruent gendered role to the product, leading to favoring specific characteristics of, suited to, or biased toward one gender or the other. This contributes to current knowledge of technology's roles in consumer-technology relationships (Fournier 1998; Hoffman and Novak 2018, 2019; Mick and Fournier 1998). The theoretical contribution of this research is instructive to explain outstanding research questions of perceived capacities of technology: how technology becomes "ontologically indeterminate and emerging entities akin to life forms" (Zwick and Dholakia 2006, p. 57). In addition, this research has managerial implications for strategic use of gendered cues to influence consumer decision making and choices. 


\section{Organization of the Dissertation}

The dissertation is organized around five chapters. In Chapter 1, an overview of the dissertation is provided. Chapter 2 presents theoretical background on consumertechnology relationship, gender and gendering of technology and effects of gendering. Drawing upon literature on social cognition and consumer-technology relationships, Chapter 3 outlines the Stereotype and Disruption Model as the research framework. Specific hypotheses to examine the process, effect, and intervention of gendering in the lab experiments are discussed. Chapter 4 reports the empirical findings from two exploratory studies (e.g., card sort task and pet name exercise) and five lab experiments. The studies are designed to address questions on whether gendering occurs or not as a function of a gender cue, and whether gendering affects consumer judgments. The final chapter concludes with theoretical and managerial implications as well as limitations and directions for future research. 


\section{CHAPTER 2: THEORETICAL BACKGROUND}

This chapter introduces the theoretical background of the dissertation. Unlike other technological products, interactions with smart technological products can be social and relational because a consumer can find human-like cues. Smart technological products often entail names (e.g., Alexa, Siri, or Cortana) and are represented with verbal, visual, auditory and other sensory cues to imbue humanlike characteristics. Smart technology's human-like product cues have been wellreceived in the marketplace. Identification of humanlike cue (e.g., Erica: product name) activates a consumer's social cognition to perceive the smart product as a human-like social agent for interpersonal relationship.

A social category membership (e.g., age, gender, race, nationality, or occupation) is one of the defining characteristics of the agent used to make sense of interpersonal relationship. Gender is an important social category. A consumer can infer gendered roles (e.g., kindness) and make biased judgments by favoring or disfavoring inferred gendered roles. Despite its popularity, the influence of human-like cues embedded in smart technological products have received little attention. Theoretical explanations of biased judgments are lacking. Social cognition theory offers a theoretical explanation of smart technology as a social agent.

\section{Smart Technology and Consumer-Technology Relationship}

Humans have used various forms of technologies in their evolutionary journey. Over the years, the technologies have become more complex. Consumers are able to perform tasks such as cooking and cleaning with less and less human effort. The latest 
developments in these technologies are smart technologies with human-like capacities that work independently (autonomy), operate based on its own decisions (authority), and be connected to work with other technological products (agency) (Hoffman and Novak 2019). These human-like capacities make the technologies seem alive to consumers because the products are intelligent, interactive, responsive and may even possess personalities (Mourey, Olson and Yoon 2017). They facilitate development of pseudo-interpersonal relationship with consumers (Hoffman and Novak 2018).

Smart technologies differ from earlier technologies designed to perform the same consumer task. For instance, a smart vacuum cleaner might use voice cues to respond to a consumer's verbal request to clean a specific area. A non-smart vacuum cleaner, on the other hand, would interact with a consumer via the use of pictorial or numerical cues embedded in the device. The human-like characteristics of a smart technology are designed to create a consumer-technology relationship akin to interpersonal relationship (Hoffman and Novak 2018).

Nass and his colleague examined consumer responses to intelligent technological products (e.g., personal computer) (Nass and Steuer 1993). Through the lens of communication studies, the authors investigated social interactions between a technological product and humans and identified four characteristics: information modality (e.g., verbal or non-verbal - pictorial or numerical), human-sounding speech, performing social roles, and interactive input and output in a social context. Marketing scholars have provided empirical evidence that a smart technological product was perceived as alive (Mourey, Olson and Yoon 2017) and capable of developing pseudointerpersonal relationship with consumers. As smart technologies become more 
pervasive in the domestic setting of the home, the contemporary role of these technologies can be conceived of as a relational partner rather than merely as an object to act upon consumers' command and control.

\section{Gender, Gendered Roles, and Gendering}

Bristor and Fischer (1993) defined sex as a biological concept based on physiological characteristics but gender as a social concept based on psychological, sociological, or cultural heritage. Also, Bristor and Fischer (1993) defined gender identity as individual's identification on gender-relating characteristics (e.g., being gentle for women but strong for men). Fischer and Arnold (1990) investigated how gender identity shapes Christmas-giving rituals, leading individuals to behave in a gender identification- congruent manner. Yorkson and his colleague (2005) note that gender is a categorization marker (e.g., female) and its associated cognitive linguistic outcomes (e.g., kind), which makes individuals seek for congruency between the marker and outcomes.

Gendering is a mental model for favoring specific characteristics of, suited to, or biased toward one gender or the other (Wajcman 2010). In the context of smart domestic technologies, gendering is assumed to be a consumer's mental model to assign gender category to a smart device based on its human-like cues. According to insights from Yorkson and his colleague (2005), biological gender (e.g., male/female) activates its associated cognitive linguistic outcomes (e.g., masculinity/femininity). Figure 1 illustrates the gendering process. 
Figure 1 The Gendering Process

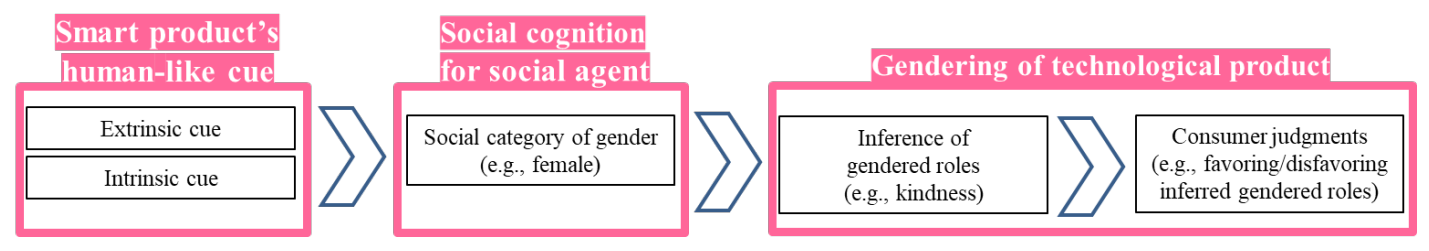

In the gendering process, gendered roles, norms and expectations of gender as a social category, serve an important role (Bem 1974; Luchs and Mooradian 2012). To illustrate, Dholakia and her colleague (2003) note a shopper's gender signals kindness with a female shopper and innovativeness with a male shopper. These gender sterotypes still exist as evidenced by a more recent Time Use Study (OECD 2018) which shows that women in the U.S. spent 1.62 times more in unpaid routine housework, shopping, and care for household members than men (243 vs 150 minutes/day). For OECD countries, women spent on average, 1.95 times more than men in unpaid domestic work.

Marketers tend to infuse product cues associated with gender because stereotyped beliefs about gender exist. For instance, the color pink may be used (e.g., Fitbit for women) or name (e.g., Mr. Clean). These marketing practices carry over to smart technology with cues such as names (e.g., Alexa, Cortana) or contours (e.g., angular, circular shape). Many advertisements target social category of consumers by signaling multiple modalities, including text (e.g., for women), symbol (e.g., pink ribbon), and image (e.g., a picture of a professional woman).

If the product cue (color, name) evokes a social category (gender) then it spontaneously retrieves associated social norms and expectations. Abele and 
Wojciszke (2013) note that a communal role (e.g., empathic, emotional, and dependent) and an agentic role (e.g., decisive, dominant, and aggressive) are femalegendered and male-gendered, respectively. Empirical studies report submissive and deferential behaviors (e.g., communality) of a low-status entity but a high-status entity shows assertive and dominant behaviors (e.g., agency) (Bem 1974; Luchs and Mooradian 2012). Similarly, in the lab experiments on person perceptions, a lowstatus entity was perceived with good intention; but, a high-status entity was perceived with good capability (Conway et al. 1996). This finding is consistent with social cognition theory that explains the association between social category as status marker and gendered role as its associated attribute (Fiske et al. 2002).

Other studies directly manipulated the product's cue to assess its effect on judgments. For instance, a pioneering lab experiment manipulated the computer's sound (female vs. male) to teach two different topics (Nass et al. 1997). The research found a male sound led to better perceptions of the computer as a teacher on the topic of computer and technology; a female sound, however, created a perception as a better teacher about love and relationship. Furthermore, a computer with a male-sound was evaluated as more informative than a computer with a female-sound on both malegendered (technology) and female-gendered (love and relationship) topics. This evidence supports gender stereotyping. Similarly, Tay and colleagues (2014) conducted lab experiments to examine individuals' evaluations of robots. They found that evaluations were higher when stereotypical beliefs of gender were confirmed; e.g. a care bot presented with introvertedpersonality's (e.g., gentle) voice. These 
stereotyped associations, in turn, impact consumer decision making including evaluations and adoption of smart technology devices.

While the empirical evidence on biased judgments is extensive tt lacks a theoretical foundation. Gendering, a mental model for favoring specific characteristics of, suited to, or biased toward one gender or the other (Wajcman 2010), can be a useful theoretical background to explain those findings. Through the lens of gendering, a product's association with the social category of female leads to specific stereotyped associations. Gendering can help to explain the stereotyped results. Examining gendering effects is integral to advancing and refining our understanding of consumer's smart product judgments.

\section{Social Cognition Theory and Alternative Perspectives on Consumer Judgments}

Product cues are information embedded in a product to signal properties of product for consumer inference (Richardson et al. 1994). These cues may be intrinsic (a.k.a. proximal) as well as extrinsic (a.k.a. distal) (Brunswick 1956; Richardson et al. 1994). On the one hand, intrinsic cues include physical properties of a product/service itself (e.g., taste, color, shape, sound, weight, texture). On the other hand, extrinsic cues are non-physical properties of a product (e.g., brand name/founder/user, price, and retail channel) (Krishna et al. 2017; Zeithaml 1988).

When a product's intrinsic or extrinsic cue is human-like (e.g. color, shape, name, creator), then the inference process is likely to be based on the social category because social technology is seen as alive (Mourey, Olson and Yoon 2017) and pseudo-interpersonal (Hoffman and Novak 2018). For instance, physical properties of 
a product such as color (e.g. pink) or shape (e.g. curved), is associated with the concept of woman (Puntoni et al. 2011; Ulrich et al. 2011). Similarly, drawing from literature on social category-based person perception (Eyssel and Kuchenbrandt 2012; Fiske et al. 2002), indicating a product creator as a female entrepreneur or a product user as a housewife explicitly may direct the inference of a woman.

Social cognition theory explains how individuals make sense of interpersonal relationships. In this view, a social category (e.g. age, gender, ethnic group, profession, religion, nationality) of relationship partner is a fundamental concept because the agent's social category helps infer its associated attribute from individuals' schema (Haslam and Whelan 2008). One of the social categories of great interest to marketing practitioners and marketing researchers alike is gender. Brand names such as Mr. Clean or Aunt Jemima are used to communicate product properties such as strength or appeal to certain target groups.

Existing literature on product cues (Micheli and Gemser 2016) suggested that human-like cues (e.g., product name, product creator) are more likely to be used to infer the technological companion's social category, activating the associated scripts with rules and expectations. Specifically, the use of social category (e.g., gender) can be a helpful cognitive marker to evaluate a technological companion, which differentiate them from other technological relationship partner (Haslam and Whelan 2008).

Alternative theoretical perspectives have driven specific research on the gender-technology relationship. The first is the information processing perspective, 
the second is the individual difference perspective, and the third is the associations between a consumer's gender and technological products.

The information processing perspective has been used to explain gendercongruent behavior. In one study, activation of a female identity via multiple modes made the gender identity salient. It led to gender-congruent behavior by reducing the motivation to fight (gender-incongruent) breast cancer (Puntoni, Sweldens, and Tavassoli 2011). Other researchers also suggested that salience of female identity negatively influenced a consumer's acceptance of gender identity-threatening messages (e.g., notification for association between binge drinking and breast cancer) (Klein and Harris 2009). The emphasis of information processing perspective is to determine the marketing effectiveness of using product cues to signal target customers. For example, research found that the match between perceived gender of an ambient scent and a store's gender-based products enhanced consumer judgments (Spangenberg et al. 2006).

In another stream of research, gender identity was treated as a consumer characteristic. Empirical studies showed that women demonstrated lower risk tolerance (He et al. 2008) and less innovative attitude (Akhter 2003) than men. Researchers examined why male consumers' adoption of eco-friendly products is lower than their female counterparts and attributed it to the existing stereotypical association between eco-friendliness and the female-gendered role (Brough et al. 2016). Incongruent with masculinity, this dampened motivations of male consumers' adoption of eco-friendly products. 
The last theoretical perspective has been used to explore the associations between a consumer's gender and technological products. For instance, Dholakia and Chiang (2003) focused on the shopper to assess whether stereotyped beliefs about shoppers and shopping affected product evaluations. The research found that a technological product's association with a female shopper affected its perception as superior in kindness and inferior in innovativeness. Similarly, Gefen and Straub (1997) surveyed email usage in North America, Asia, and Europe and found that female consumers are more likely to use email for socialization (e.g., intimacy, support, consensus, and rapport) than men (Gefen and Straub 1997). Venkatraman (2013) conducted qualitative interviews with female heads of household using ZMET techniques to examine whether a female consumer uses digital technology at home differently compared to a male consumer. The author found that a female consumer uses technology as an instrument to configure their domestic chores for interpersonal and social purposes. It differed from a male consumer focus on technology for fun and play.

The empirical studies employing the alternative perspectives are instructive, but they are not without limitations. The focus of information processing approach is to examine how individuals' gender schema directs information processing, which is different from gendering, a stereotype-activated mental model which favors or disfavors a judgment as a function of identified gendered cue. The individual difference approach is how a consumer's gender identity as a consumer characteristic determines judgments and behaviors., This differs from gendering that evaluates products which are gendered. The final approach used the consumer's gender to 
explain product usage rather than gendering of technology itself. The alternative perspectives differ from the gendering lens based on social cognition theory adopted in this dissertation.

Existing research approaches have not explicitly investigated any specific product cue and certainly not human-like characteristics of products. They have also not specifically focused on product cues that lead to a gender inference of the product itself. Instead, past marketing research has examined gender attached to a consumer rather than the gender attached to a product. Research perspectives grounded in information processing or individual differences focused on a transaction between a consumer and a technological product. While the multiple studies have generated strong evidence on the gender associations with technological products, they have not treated the products themselves as social agents or examined the underlying process by which gender associations lead to consumer judgments. Therefore, the growing context of smart technologies with human-like characteristics remains unexplored.

Social cognition theory is helpful to address this research gap. This theory offers a theoretical perspective that is able to address the research questions emanating out of the growing use of smart technologies. According to social cognition theory, when a product's intrinsic or extrinsic cue is human-like (e.g. color, shape, name, creator), then a social category is likely to be inferred and this inference influences the consumer's interactions with the smart product. Additionally, this theory provides that social categories used by consumers help retrieve associated attributes, which predict interaction patterns governed by social norms and expectations (Fiske 2000; Wegner and Bargh 1998). For example, Mr. Clean is seen as a white male, which likely 
activates stereotypical attributes of its social category such as manly, strong, and powerful. Social cognition theory is different from theories focusing on anthropomorphized or personalized brand (e.g., brand personality) (MacInnis and Folkes, 2017; Fournier and Alvarez 2012) because this view emphasizes a humanlike product cue (e.g., social category) to a smart technological agent rather than a generic branded object.

Introducing social cognition theory to consumer-technology relationships is theoretically and managerially relevant. Because social cognition theory suggests that social roles are inferred from social categories (Fiske 1993, 2000; Fiske and Haslam 1996), gendered roles will act as a mediator in gendering which then influences consumer judgments about the technology as a social agent.

There is evidence on social category inferences but the stimuli have been humans, not smart products. Bargh and collegues (1996) used lab experiments to expose participants to a social category (e.g., the elderly). They found that the exposure to the social category increased accessibility of its associated attribute (e.g., weak and slow) in an automatic fashion, which activated associated stereotypes affecting decision making. Similarly, other scholars on person perception have conducted studies that showed enhanced performance on a test when exposed to the social category of university professor (Dijksterhuis and van Knippenberg 1998).

Compared to literature on person perception, our focus is on smart products. Specifically, the research examines whether the smart technological product's humanlike cue leads to social category of gender and its associated attributes. Our goal is to 
provide a theoretical explanation of empirical results that indicate gender stereotypes exist and affect consumer judgments.

\section{Gendering Effects on Consumer Judgments}

The gendering lens allows predicting the direction and magnitude of judgments. Consumer judgments are defined as cognitive assessments (Cacioppo and Petty 1981). Since marketers are interested in consumer judgments affecting likely adoption of products, this dissertation uses the gendering lens and social cognitive theory to focus on consumer judgments. Four judgments have been assessed in this research - perceived quality, perceived creativity, consumer evaluation, and persuasion effectiveness.

\section{Perceived Quality}

Perceived quality, i.e. utility derived from the expected performance of technology, seems to be more related to the male-gendered role because of its focus on consistent and standard capacities (Sweeney and Soutar 2001). Empirical research showed that a male user of technology and its associated superior competence were commonly used as a functional appeal (e.g., perceived usefulness) (Gefen and Straub 1997; Meuter et al. 2003). Compared to the previous finding about a male user, empirical research found that a female user of technology and her associated superior kindness were commonly used as an emotional appeal (e.g., easiness of use). Similarly, past research on perceived quality suggests perceived quality diminishes in various domains including sustainable products (Luchs et al. 2010; Newman, Gordlin, and Dhar 2014), socially responsible brands (Aaker, Vohs, and Mogilner 2010) and 
healthy food (Raghunathan, Naylor, and Hoyer 2006) as an effect of good intention (female-gendered role).

Perceived Creativity

Perceived creativity is defined as "the production of novel and useful ideas" (Amabile et al., 1996, p. 1154) in market offerings, which has been conceptualized along two dimensions: novelty and appropriateness (Dahl, Chattopadhyay, and Gorn 1999). The concept of novelty is related to an outside-of-the-box mindset and being unconventional or unexpected. The concept of appropriateness is the degree of usefulness to accomplish a goal (Barron, 1955; Stein, 1953; see also Runco and Jaeger, 2012). Both novelty and appropriateness appear to emphasize agentic malegendered roles for divergent thinking over adaptive female-gendered roles for convergent thinking (Diedrich et al. 2015; Proudfoot, Kay, and Koval 2015; Adams 2015; Kilgour and Koslow 2009). Specifically, Lebuda and Karwowski (2013) reported in an empirical study that a scientific theory signed by a female author received a lower rating than one with an anonymous author in the domain of technology.

\section{Consumer evaluation}

Consumer evaluation is a general attitude towards a target object. It is measured by the strength and valence of consumer attitude (Yoo and Donthu 2001). The inclusion of consumer evaluation as a dependent variable helps to measure general attitudes towards products as a function of gendered cue. Country of origin (COO) research indicates consumer evaluation is influenced by two gendered 
dimensions of country perception: female-gendered for good intention (e.g., friendliness) and male-gendered for good capacity (e.g., economic development) (Chattalas, Kramer, and Takada 2008; Herz and Diamantopoulos, 2013; Maher and Carter 2011). For instance, France is associated highly with female-gendered roles, but Germany is associated with male-gendered roles (Halkias, Davvetas and Diamantopoulos 2016). As a consequence, French clothing is judged favorably because of stereotyped beliefs on femininity, while a German machine is judged favorably based on stereotyped beliefs on masculinity (Maher and Carter 2011; Halkias, Davvetas and Diamantopoulos 2016). Similar effects have been reported for other countries (e.g. U.S., Japan) and a variety of product domains (e.g. TV, automobiles) (Magnusson, Westjohn, and Zdravkovic 2011).

\section{Persuasion Effectiveness}

Persuasion effectiveness is indicated as a change in attitude advocated by a message. The detailed measurement includes valence of product's impression, liking of the product, thoughts about the effectiveness and confidence of the product, and likelihood to buy the product (Touré-Tillery and McGill 2015). Inclusion of persuasion effectiveness is relevant because a gendered cue embedded in a product itself may modify persuasion effectiveness like a gendered mascot or spokescharacter of the product message. Empirical evidence shows that the same message can increase or decrease persuasion effectiveness as a function of an audio cue (Searles et al. 2017). Specifically, in the domain of political marketing, a low-pitch voice is found to be more persuasive in the male-dominant domains (jobs/trades, taxes, and national 
defense), but a high-pitch voice is more persuasive in the female-relevant domains (childcare, education, and elderly care).

The drawing upon the theoretical foundation in this chapter, the next chapter attempts to provide a deeper understanding of when and how gendering occurs in consumer judgments of technology, and what mediates and moderates the effect of gendering on consumer judgments. The research focus is on smart technological products used in the domestic sphere. In addition, the proposed research investigates whether the automatic activation of a stereotype can be modified in terms of its effects on consumer judgments. Based on a review of the literature, arguments are built for conditions that influence:

1) when gendering occurs in the consumer evaluation of technology;

2) the outcomes associated with gendering;

3) the process that underlies the gendering effect;

4) mediating and moderating variables that affect the relationship between gendering and its effects; and

5) the effect of intervention on gendering.

\section{CHAPTER 3: RESEARCH FRAMEWORK AND HYPOTHESES}

\section{Research Framework}

This dissertation attempts to examine how smart technology's gendered cues affect consumers' responses. Given the focus on gendering of domestic smart 
technology, two models are used to shape the empirical investigations of the relationships between gendering and its effect on consumer judgments. The Stereotype Model is the base model used to explain when gendering occurs and to examine the process and outcomes of gendering. The Disruption Model is used to examine the effect of disrupting gender stereotypes.

\section{The Stereotype Model}

Gendering explains a mental model for favoring specific characteristics suited to or biased toward one gender or the other (Wajcman 2010). Existing insights from person perception to technology perception suggest a consumer engages in gendering by identifying a gendered cue and applying a gender stereotype. Stangor (1988) empirically examined how gender stereotype influences consumer judgments in two stages. In the first stage, a consumer encodes schema-consistent information to maintain the gender stereotype. In the second stage, this spontaneous use of gender schema increases the retrieval of attribute associated with gender stereotype (e.g., kindness for waitress).

Scholars in social science have examined empirically conditions of gendering in the realm of technology. Roff (2016) investigated Robotics Challenges supported by the Defense Advanced Research Projects Agency. The author suggested that human-like shape (e.g., torso, head, and limbs) and motion cues (e.g., gait and voice) made individuals assume roles of war robots. When a robot possessed a femalegendered characteristic, it was more likely to be seen as a non-combatant (innocent, victim, and powerless), whereas a robot that possessed a male-gendered characteristic 
was seen as a warrior. Scholars also found that a nurse robot presented with a femalegendered characteristic and a security robot presented with a male-gendered characteristic affected consumers' attitudes positively (Tay et al. 2014). It is likely that this gendering process occurs in an automatic fashion, activating stereotypes (Bargh et al. 1996) due to easy retrieval from stored memory of learned stereotypes (Gibson 2008; Kimmel and Aronson 2004).

Figure 2 describes the basic Stereotype Model that links a gendered cue to stereotyped judgments due to the underlying gendering process

Figure 2 Stereotype Model

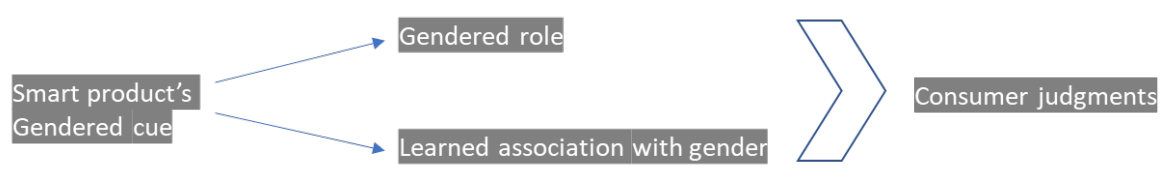

While marketers have widely used intrinsic and extrinsic cues to infuse gender into products, existing research has not examined whether the cues lead to underlying consumer processes involved in gendering. Imbuing technology with a gendered cue (intrinsic or extrinsic) is likely to increase accessibility of its associated attributes (e.g., congruent gendered role) according to the Stereotype Model. As a result, we expect:

H1 Presence of a specified gendered cue in a technology product is likely to make a congruent gendered role accessible.

This process of accessing a congruent gendered role occurs due to culturally learned associations between a social category and its gendered roles based on ease of 
processing (Bargh et al.1996; Banaji and Greenwald 1995; Berger and Fitzsimons 2008; Brebner et al. 2009). The process operates in an automatic fashion, activating stereotypes (Bargh et al. 1996), and reducing reaction time due to easy retrieval from stored memory of learned stereotypes (Gibson 2008; Kimmel and Aronson 2004). Once gender stereotype is activated, it is difficult to control evoked gender roles (Bargh 1989, 1990; Wegner and Bargh 1998). Response latency is more likely to represent strength of accessibility activated by retrieval cues (Feldman and Lynch 1988). Therefore, a specified gendered cue will increase salience of a specific gender concept, which reduces response latency. As a result, we expect:

H2 Presence of a specified gendered cue is likely to make retrieval of gender associations easier.

When a gendered cue leads to stereotyped perception of gendered roles, these stereotyped perceptions influence consumer judgments. A study on satisfaction ratings of physicians has shown that a female physician was more likely to obtain a lower rating than a male physician (Hekman et al. 2010). Other studies have provided evidence on stereotypical perceptions; for instance, judgments of employees. The empirical evidence indicates that the biased judgments due to gendering, defined as a mental model for favoring specific characteristics of, suited to, or biased toward one gender or the other (Wajcman 2010), tends to particularly affect the female gender negatively.The Stereotype Model suggests that gendered roles may act as a mediator of consumer judgments. This leads to the following hypothesis regarding gender stereotypes' effects on consumer judgments: 
H3 A female gendered cue is more likely to negatively influence consumer judgments than a male gendered cue.

Moderation is a factor interacting with a gendered cue, increasing or decreasing the gendering effects (MacKinnon and Luecken 2008). Individual-relating factors (e.g., personal innovativeness, objective/subjective knowledge on technology) and situational factors (e.g., high or low cognitive load in processing of product message, hedonic or utilitarian consumption motivation) have been examined as potential moderators (Jhang et al. 2012; Schepers and Wetzels 2007).

This dissertation attempts to examine the moderating role of technology newness because existing schema and learned associations are less likely to be applicable for a really new technology than incrementally new technology. For example, once interactions with technological social agents become familiar, new cues may hold less importance than for unfamiliar or novel social agents. It is likely consumers see the new technology as one-of-a-kind, which prevents leveraging prior knowledge or attitudes due to high uncertainty (Min, Kalwani, and Robinson 2006). Conversely, for incrementally new technology with low newness, consumers can utilize existing knowledge or attitudes because prior knowledge can help understand an incrementally new technology as a subcategory to the existing one. Dual Attitude Theory suggests that changing an existing attitude is more difficult than forming a new attitude (Anderson and Levy 2007; Gawronski 2013). This theory is likely to apply to technological products as well. 
Technology newness is defined as "the degree of discontinuity in product functionality and technological innovativeness as perceived by consumers" (Ma, Yang, and Mourali 2014). For really new technology, the effect of an externally provided gendered cue is greater than for an incrementally new technology because it will likely be used as a basis for inferring quality and creativity of the technology (Moreau et al. 2001; Rindova and Petkova 2007) and reducing uncertainty and ambiguity of technology newness (Festinger 1954; Greenwald et al. 2002; Hoeffler 2003; Whitfield and Jordan 2009). Conversely, when technology is perceived to be incrementally new, existing experience (including target user groups and functional specifications) will be used to infer quality and creativity of technology (Moreau et al. 2001; Rindova and Petkova 2007). Therefore,

H4a The effect of gendered cues on consumer judgments is more likely to be greater for really new technology than incrementally new technology.

Discontinuity is also associated with high levels of perceived risk and risk tolerance has been empirically reported as a male-gendered attribute (Pavlou 2003; Meyers-Levy and Loken 2015). In this regard, really new technology with high discontinuity can be seen as a more masculine domain than incrementally new technology with low discontinuity. When a female gendered cue is imbued in a really new technology, perceived incongruence between the female cue and really new technology is likely to be greater than the one between the female cue and incrementally new technology. The lack of congruence prevents ease of pairing the female cue with existing schemas, which tends to negatively affect consumer judgments of really new technology (Cornwell et al., 2006; d'Astous and Bitz, 1995; 
Johar and Pham, 1999; Rifon et al., 2004; Simmons and Becker-Olsen, 2006).

Therefore,

H4b A female gendered cue will influence consumer judgments more negatively for really new technology than for incrementally new technology.

Figure 3 Stereotype Model with Hypotheses

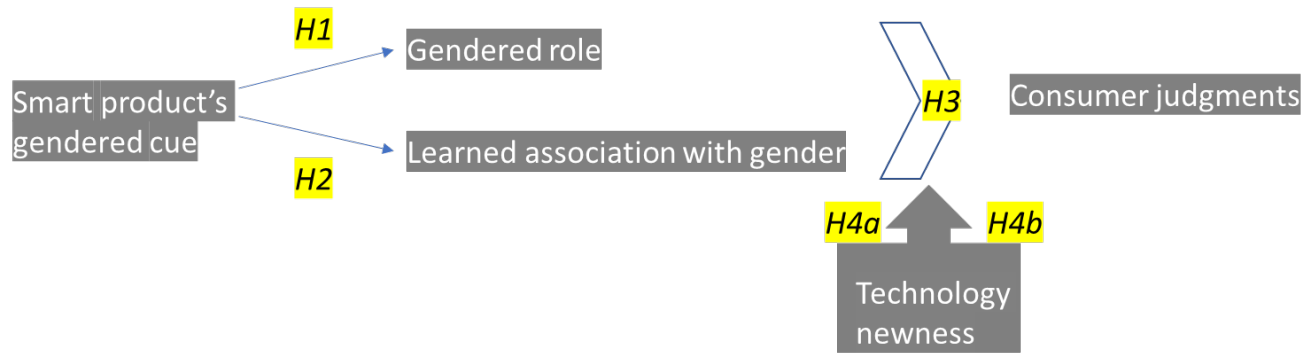

\section{The Disruption Model}

The gendering effects on consumer judgments occur when consumers access congruent gendered roles as a function of a gendered cue. While the Stereotype Model suggested the automatic retrieval of gender-congruent role, the empirical evidence seems to indicate that this retrieval process tends to lead to biased judgments disadvantageous to females. The Disruption Model is an attempt to interfere in the automatic process. Researchers report that consumers are less likely to infer attributes based on social category membership when the description of a category member is not consistent with the category label (Yamauchi and Markman, 2000). For instance, pan-cultural analysis of person perception about gendered roles indicate a cue against 
prescribed stereotypes (e.g., career woman, gay man) may modify the association between a category marker and its roles. For example, compared to the general category of woman, a career woman was perceived as low on female-gendered roles (warmth) but high on male-gendered roles (competence) (Fiske et al. 2002).. Similarly, compared to the general category of man, a gay man was perceived as low on male-gendered roles (competence) but high on female-gendered roles (warmth) (Fiske et al. 2002).

Research on information relevance and consumer judgments suggests that consumers are less likely to use a counter-stereotypical role for consumer judgments because of high ambiguity (Ha and Hoch 1989). A counter-stereotypical gendered cue isperceived as a violation of the essence of gender category. When a counterstereotypical role is presented, category-based inference is reduced because a counterstereotypical role does not belong to the category schema completely, reducing its reliance on consumer judgments (Gregan-Paxton, Hoeffler and Zhao 2005). To attenuate gendering effects, use of a counter-stereotypical cue can interfere its use as a diagnostic cue (Lynch 2006; Herr, Kardes, and Kim 1991; Miniard, Sirdeshmukh, and Innis 1992). A counter-stereotypical cue can disrupt the learned associations with gender and stereotype, reducing the likelihood of using the gendered cue as a diagnostic cue. Provision of counter-stereotypical information is likely to be more effective than just negating gender stereotypes (Gawronski et al. 2008). Therefore,

H5 The presence of a counter-stereotypical cue is likely to make gendered roles less relevant than the presence of a stereotypical cue. 
Research on categorization and consumer judgments suggests that typicality of category membership and nature of category modify strength of consumer judgments. Typicality is the degree to which the target is a good example, representative of the category (Loken 2006; Loken and Ward 1990). A counter-stereotypical gendered cue entails less typicality, which demonstrates a weaker membership of a natural category: gender. A counter-stereotypical role is seen as a violation of gender schema, which is associated with negative disconfirmation (Oliver and DeSarbo 1988; Oliver and Swan 1989; Tse and Wilton 1988). This explains why a counter-stereotypical cue will influence consumer judgments negatively.

H6 Presence of a counter-stereotypical cue will interfere with stereotypical gendering effects.

Figure 4 Disruption Model with Hypotheses

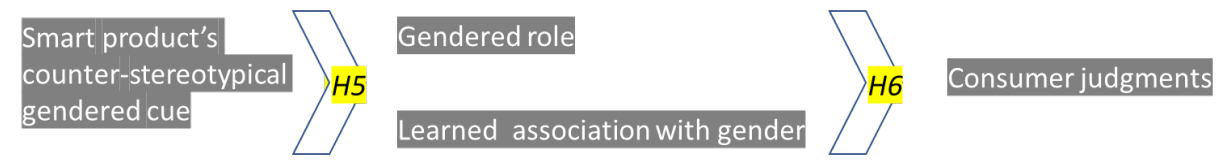

The next chapter empirically tests the hypotheses. The chapter describes the methodology and the results of two exploratory and five experimental studies that provides empirical evidence and insights regarding gendering of smart technologies. 


\section{CHAPTER 4: METHODOLOGY, ANALYSIS, AND FINDINGS}

\section{Overview of Exploratory Studies}

To enhance our understanding of how a consumer engages in gendering and its effects, this chapter describes the methodologies used to answer two fundamental questions: One is whether gendering occurs because of a gender cue and whether gendering affects consumer judgments. Both qualitative and experimental research designs are used to investigate the research questions.

The research questions are examined in the context of smart technology by using two qualitative exploratory studies and five lab experiments. This research context is relevant because smart technology is often presented with intrinsic or extrinsic human-like cues (e.g. color, shape, name, creator) and performs a task with human-like capacities that work independently (autonomy), operate based on its own decisions (authority), and be connected to work with other technological products (agency) (Hoffman and Novak 2019).

In the first exploratory study, free associations regarding smart technology at home have been explored to investigate whether gendering occurs in typology of smart technology. The second exploratory study attempts to examine pet names, singular names based on consumer-smart technology relationships, to gain insights on the judgments of gendering. Drawing upon findings from the two exploratory studies, five experiments are designed to investigate the process and effect of gendering, including moderating and disrupting the effects. The experimental findings help advance how gendering influences well-established consumer judgments. 


\section{Exploratory Studies}

\section{Exploratory Study 1 - Qualitative interview}

In exploratory study 1, Q-methodology was used to explore how consumers think of domestic technology and whether gendering occurs in their free associations. The Q methodology involves a card sorting task designed to classify dimensions of common ground and divergence (McKeown and Thomas 2013). This technique has been used in consumer research on a consumer's relationship with products (Kleine et al. 1995; Sirgy 1982).

The Q-methodology was used to uncover the underlying mental model that shape consumers' perceptions and reactions to technological products used in a domestic space. Given products listed in individual cards, consumers sort the products into groups. This technique helps to explore the within-group similarities and between-group differences between items in the pile sort. For example, Qmethodology can answer the following questions: How are items in the same classified group or in different groups? And what are the characteristics of the least representative exemplar and the most representative exemplar of each group? (McKeown and Thomas 2013). Our goal in this specific exploratory study is to discover whether gendering is one of the fundamental dimensions of organizing domestic technology in the card sort task.

\section{Overview of Study Design}

\section{Stimuli}


Smart technology at home performs domestic tasks, such as cooking and cleaning, with less and less human effort. For example, an automated cleaning device can get rid of dirt independently with their own intelligence (Hoffman and Novak 2019). In this research context, domestic smart technology is both more meaningful and familiar to consumers who must negotiate and navigate the meaning of technology at home because of a socio-historical tension between a realm of men (technology) and a realm of women (domestic space) (Wajcman 2010). Dholakia (2012) suggested how this tension was manifested in the domestic sphere: the spatial division at home specifically sees the outdoor as a man's domain, but indoor is seen as a woman's domain.

A diverse set of 20 technological products for indoor and outdoor in the domestic sphere was chosen as stimuli (Table 1). The selected items included different consumer technologies that are likely to be used at home for a variety of spaces (e.g., indoor, outdoor), domestic tasks (e.g., cooking, cleaning), and technological features (e.g., voice recognition, mobile app connectivity) (Dholakia 2012, Wajcman 1991; 2010). Each product was presented in color on $8.5 \times 11$-inch card described with a picture and text. The goal was to elicit free associations through the card sorting technique.

Table 1 Stimuli

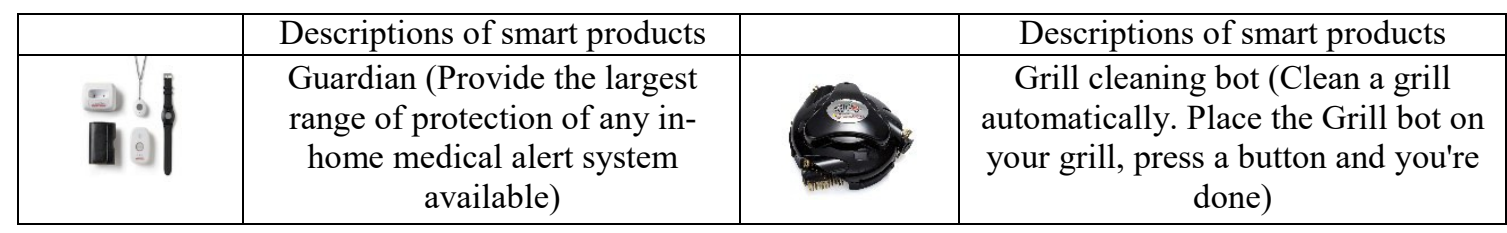




\begin{tabular}{|c|c|c|c|}
\hline-1 & $\begin{array}{l}\text { Dream Machine (Keep your } \\
\text { baby's comfort at your } \\
\text { fingertips) }\end{array}$ & & $\begin{array}{l}\text { Vacuum bot (Vacuum up, schedule } \\
\text { cleaning via the app, and charge } \\
\text { automatically) }\end{array}$ \\
\hline & $\begin{array}{l}\text { Lock (make the world's first } \\
\text { smart fingerprint padlock that } \\
\text { unlocks in } 0.8 \text { seconds) }\end{array}$ & & $\begin{array}{l}\text { Washer (Provide the ultimate } \\
\text { washing flexibility, with two } \\
\text { separately controlled washers in the } \\
\text { same unit) }\end{array}$ \\
\hline & $\begin{array}{c}\text { Sleep tracker (Provide recovery } \\
\text { and readiness analysis based on } \\
\text { whole-night heart-rate- } \\
\text { variability) }\end{array}$ & & $\begin{array}{l}\text { Cocktail maker (Allow anyone to } \\
\text { make world-class cocktails at home) }\end{array}$ \\
\hline & $\begin{array}{l}\text { Door Security (Let you see and } \\
\text { speak with visitors via your } \\
\text { smart device, whether you're } \\
\text { upstairs or across town) }\end{array}$ & & $\begin{array}{l}\text { Refrigerator (Provide voice } \\
\text { recognition and internal cameras for } \\
\text { remote viewing of stored food items } \\
\text { from your smartphone) }\end{array}$ \\
\hline & $\begin{array}{l}\text { Sleep Light (Provide you with } \\
\text { light and sound programs that } \\
\text { will adapt to your personal body } \\
\text { clock and positively impact your } \\
\text { sleeping conditions) }\end{array}$ & & $\begin{array}{l}\text { Cooking robot (Cooks with the skill } \\
\text { and flair of a chef) }\end{array}$ \\
\hline & $\begin{array}{l}\text { Thermostat (Control half your } \\
\text { energy bill - more than } \\
\text { appliances, more than } \\
\text { electronics) }\end{array}$ & & $\begin{array}{l}\text { Massage chair (Provide intense } \\
\text { massaging action to soothe sore } \\
\text { muscles and a remote control to } \\
\text { access its features) }\end{array}$ \\
\hline & $\begin{array}{c}\text { Toothbrush (Provides a } \\
\text { clinically proven superior } \\
\text { performance) }\end{array}$ & & $\begin{array}{c}\text { Styler (Use deeply penetrating } \\
\text { steam to minimize wrinkles in } \\
\text { clothing, and it reduces unpleasant } \\
\text { odors from fabrics for an improved } \\
\text { scent) }\end{array}$ \\
\hline & $\begin{array}{l}\text { Dishwasher (Clean dishes at } \\
\text { every angle and make pre- } \\
\text { rinsing unnecessary) }\end{array}$ & & $\begin{array}{l}\text { Moodo (Let you mix and match } \\
\text { your own signature home scent) }\end{array}$ \\
\hline & $\begin{array}{l}\text { Automower (Provide app } \\
\text { connectivity with GPS tracking } \\
\text { for automated performance) }\end{array}$ & & $\begin{array}{l}\text { Click and Grow (Provide zero-effort } \\
\text { gardening solutions perfect for } \\
\text { urban homes) }\end{array}$ \\
\hline
\end{tabular}

\section{Participant Sampling}

Twenty participants were recruited using snowballing technique for comprehensiveness and diversity, rather than representativeness or quantity. Social categories (e.g., age, gender, occupation, education) of participants served important roles to provide personalized frames of reference to interpret consumers' relationships with smart technological products (Thompson 1997). The use of snowballing 
technique was relevant to recruit participants associated with diverse social categories

to reach out non-student samples, which enhances quality of data with the wide range

of interpretative standpoints who interact with smart technological products in their

domestic spheres. The focal sample was $35 \%$ female and $65 \%$ male with an age range

of 21 and 60. For confidentiality, a pseudonym has been given to each participant.

(Please see Table 2 for demographics and other individual characteristics).

Table 2 Demographic Characteristics of Participants

\begin{tabular}{|c|c|c|c|c|c|c|c|}
\hline Name & Gender & Age & Occupation & Education & $\begin{array}{l}\text { Living } \\
\text { condition }\end{array}$ & $\begin{array}{l}\text { Relationship status } \\
\text { (\# of children) }\end{array}$ & Note \\
\hline Sarah & $\bar{F}$ & 26 & $\begin{array}{l}\text { Graduate } \\
\text { student }\end{array}$ & $\begin{array}{l}\text { Graduate } \\
\text { student }\end{array}$ & $\begin{array}{l}\text { With } \\
\text { boyfriend }\end{array}$ & Single & $\begin{array}{l}\text { Caucasian (Parents } \\
\text { are from Finland), } \\
\text { Major in Chemistry }\end{array}$ \\
\hline Charles & $\mathrm{M}$ & 31 & $\begin{array}{l}\text { Graduate } \\
\text { student }\end{array}$ & $\begin{array}{l}\text { Graduate } \\
\text { student }\end{array}$ & With wife & $\begin{array}{l}\text { Married } \\
\text { (No children) }\end{array}$ & $\begin{array}{l}\text { Born and raised in } \\
\text { South Korea. } \\
\text { Major in Education }\end{array}$ \\
\hline Brian & $\mathrm{M}$ & 24 & $\begin{array}{l}\text { Graduate } \\
\text { student }\end{array}$ & $\begin{array}{l}\text { Graduate } \\
\text { student }\end{array}$ & Alone & Single & $\begin{array}{l}\text { Caucasian, } \\
\text { Major in Chemistry }\end{array}$ \\
\hline Chris & $\mathrm{M}$ & 28 & $\begin{array}{l}\text { Graduate } \\
\text { student }\end{array}$ & $\begin{array}{l}\text { Graduate } \\
\text { student }\end{array}$ & Alone & Single & \begin{tabular}{lr} 
African & \multicolumn{2}{r}{ American } \\
(Parents are & from \\
Jamaica), & \\
Major & \\
Psychology & in
\end{tabular} \\
\hline Kevin & $\mathrm{M}$ & 31 & $\begin{array}{l}\text { Graduate } \\
\text { student }\end{array}$ & $\begin{array}{l}\text { Graduate } \\
\text { student }\end{array}$ & With wife & $\begin{array}{l}\text { Married } \\
\text { (No children) }\end{array}$ & $\begin{array}{l}\text { Born and raised in } \\
\text { Japan. } \\
\text { Major in Economics }\end{array}$ \\
\hline David & $\mathrm{M}$ & 27 & $\begin{array}{l}\text { Graduate } \\
\text { student }\end{array}$ & $\begin{array}{l}\text { Graduate } \\
\text { student }\end{array}$ & $\begin{array}{l}\text { With } \\
\text { roommate }\end{array}$ & Single & $\begin{array}{l}\text { Caucasian, } \\
\text { Major } \\
\text { Neuroscience }\end{array}$ \\
\hline Adam & $\mathrm{M}$ & 22 & $\begin{array}{l}\text { Floor clerk at } \\
\text { liquor store }\end{array}$ & $\begin{array}{l}\text { High school } \\
\text { graduate }\end{array}$ & $\begin{array}{l}\text { With } \\
\text { roommate }\end{array}$ & Single & Caucasian \\
\hline Abu & $\mathrm{M}$ & 27 & $\begin{array}{l}\text { Graduate } \\
\text { student }\end{array}$ & $\begin{array}{l}\text { Graduate } \\
\text { student }\end{array}$ & Alone & Single & $\begin{array}{l}\text { Born and raised in } \\
\text { Saudi Arabia. } \\
\text { Major in Pharmacy }\end{array}$ \\
\hline Tony & $\mathrm{M}$ & 21 & IT support & $\begin{array}{l}\text { High school } \\
\text { graduate }\end{array}$ & With parents & Single & Caucasian \\
\hline Peter & $\mathrm{M}$ & 38 & $\begin{array}{l}\text { Network } \\
\text { engineer }\end{array}$ & $\begin{array}{l}\text { High school } \\
\text { graduate }\end{array}$ & $\begin{array}{l}\text { With wife and } \\
\text { two children }\end{array}$ & $\begin{array}{l}\text { Married } \\
\text { ( } 2 \text { children })\end{array}$ & Caucasian \\
\hline Rob & $\mathrm{M}$ & 40 & $\begin{array}{l}\text { Registered } \\
\text { nurse }\end{array}$ & Bachelor's & $\begin{array}{l}\text { With } \\
\text { boyfriend } \\
\text { (Gay partner) }\end{array}$ & Single & $\begin{array}{l}\text { Caucasian, } \\
\text { non-heterosexual } \\
\text { orientation (gay) }\end{array}$ \\
\hline Donna & $\mathrm{F}$ & 22 & $\begin{array}{l}\text { Graduate } \\
\text { student }\end{array}$ & $\begin{array}{l}\text { Graduate } \\
\text { student }\end{array}$ & $\begin{array}{l}\text { With } \\
\text { roommates }\end{array}$ & Single & $\begin{array}{l}\text { African } \\
\text { (French-speaking } \\
\text { Cameroon), } \\
\text { Major in industrial } \\
\text { engineering }\end{array}$ \\
\hline Cat & $\mathrm{F}$ & 27 & $\begin{array}{ll}\text { High } & \text { school } \\
\text { teacher }\end{array}$ & Master's & Alone & Single & $\begin{array}{l}\text { Caucasian, } \\
\text { Major in biology }\end{array}$ \\
\hline Victoria & $\mathrm{F}$ & 25 & $\begin{array}{l}\text { Graduate } \\
\text { student }\end{array}$ & $\begin{array}{l}\text { Graduate } \\
\text { student }\end{array}$ & $\begin{array}{l}\text { With } \\
\text { boyfriend }\end{array}$ & Single & $\begin{array}{l}\text { Caucasian, } \\
\text { Major } \\
\text { psychology }\end{array}$ \\
\hline Clare & $\mathrm{F}$ & 27 & $\begin{array}{l}\text { Floor clerk at } \\
\text { Kohl's }\end{array}$ & $\begin{array}{l}\text { High school } \\
\text { graduate }\end{array}$ & $\begin{array}{ll}\begin{array}{l}\text { With } \\
\text { children }\end{array} & 3\end{array}$ & $\begin{array}{l}\text { Divorced } \\
\text { (3 children) }\end{array}$ & Caucasian \\
\hline
\end{tabular}




\begin{tabular}{|l|l|l|l|l|l|l|l|}
\hline Iris & F & 60 & Adjunct faculty & Master's & With husband & $\begin{array}{l}\text { Married } \\
\text { (3 children) }\end{array}$ & $\begin{array}{l}\text { Caucasian, } \\
\text { Registered nurse }\end{array}$ \\
\hline Joe & M & 44 & Professor & Ph.D. & $\begin{array}{l}\text { With wife and } \\
\text { children }\end{array}$ & $\begin{array}{l}\text { Married } \\
\text { (3 children) }\end{array}$ & Caucasian \\
\hline James & M & 23 & $\begin{array}{l}\text { Graduate } \\
\text { student }\end{array}$ & $\begin{array}{l}\text { Graduate } \\
\text { student }\end{array}$ & With parents & Single & $\begin{array}{l}\text { Caucasian, } \\
\text { Major in Statistics }\end{array}$ \\
\hline Fatima & F & 21 & $\begin{array}{l}\text { Undergraduate } \\
\text { student }\end{array}$ & $\begin{array}{l}\text { Undergraduate } \\
\text { student }\end{array}$ & With husband & Married & $\begin{array}{l}\text { Born and raised in } \\
\text { Saudi Arabia, } \\
\text { Major } \\
\text { Administrative } \\
\text { justice }\end{array}$ \\
\hline Nick & M & 21 & $\begin{array}{l}\text { Technician at } \\
\text { CVS }\end{array}$ & $\begin{array}{l}\text { High school } \\
\text { graduate }\end{array}$ & With parents & Single & Caucasian \\
\hline
\end{tabular}

Procedure

Following McKeown and Thomas (2013), the researcher conducted interviews with each participant individually. Participants were told that there were no right or wrong criteria for grouping items; the number of groups could be as many as the respondent wanted. Participants were instructed to "think out loud" while they sorted the cards, which helped better understand their processes and perspectives for grouping. The focus of this study was to examine whether gendering will emerge spontaneously as a dimension in sorting of the domestic technologies without any explicit elicitation.

After sorting cards into groups, participants were asked to explain their reasoning during the grouping process and to identify the least and most representative exemplar of each group. The Interview Protocol in Appendices provides more details (Appendix $1)$.

\section{Analysis and Results}

Multidimensional scaling is used to identify how a smart technological product can be classified based on their attributes. The statistical foundation of multidimensional scaling is an inversed factor analysis (Kim, Frisby and Davison 2004) to obtain a perceptual map and demonstrate the dimensions of classifying items 
and clusters among items. Data from a cart sort task is relevant to use multidimensional scaling for a perceptual map and clusters, which represents findings in a spatial manner. Since the perceptual map from the multidimensional scaling reveals emergent dimensions from similarity and dissimilarity among items and estimates the relative importance in consumers' mental model (Giguère 2006). Cluster analysis is very useful to recognize meaningful regions of the perceptual map by identifying maximum discrepancy between groups and minimum discrepancy within groups (Steyvers 2002). Consumer research on a consumer's relationship with products (Kleine et al. 1995; Sirgy 1982) has used the analytical techniques to gain indepth understanding of how consumers make sense of relationships with products.

\section{Multidimensional Scaling Analysis of Sorting Data}

Multidimensional scaling analysis was applied to examine the card sort task. This technique analyzes the relationships among items at the individual level (e.g., items $\times$ items proximity matrix for each participant) and compiles the individual-level measures of relationship to the aggregated matrix to identify latent dimensions and to define the patterns among items (Kim, Frisby and Davison 2004). A 20 x 20 binary matrix was constructed for each participant. For the measures of relationships, when two cards were sorted in the same pile (e.g., similarity in grouping), a 0 was assigned to the intersecting cell of the two cards. When two cards were sorted in a different pile (e.g., dissimilarity in grouping), a 1 was assigned to the intersecting cell of the two cards. The matrix was symmetrical. The numbers on the off diagonals represented the number of times the cards were not sorted in the same piles. The numbers on the diagonal were zeroes. Dissimilarity judgments were calculated by adding the 20 
matrices together. ALSCAL (Alternating Least Squares Scaling) in SPSS version 24 was used to analyze the aggregated dissimilarity matrix for multidimensional scaling.

To identify latent dimensions and to select the optimal dimensionality, badness fit index (i.e., Stress) and explained variance were assessed (Giguère 2006). Stress is defined as the difference between predicted Euclidean distance and target Euclidean distance (e.g., similar to least squares in regression modeling). $\mathrm{R}^{2}$, explained variance, is the indicator to fit to minimize (stress) $)^{2}$ rather than stress. The increased amount of $\mathrm{R}^{2}$ means more explained variance added by a new dimension (Giguère 2006). The scree plot is important to determine whether adding an extra dimension can reduce the badness-of-fit (Rounds and Tracey 1993). The number of dimensions is determined by a Stress value less than 0.05 (Prediger 1982). Table 3 illustrates fit indices in more details.

Table 3 Fit indices

\begin{tabular}{|c|c|c|c|c|c|c|}
\hline $\begin{array}{c}\text { Number of } \\
\text { dimensions }\end{array}$ & 1 & 2 & 3 & 4 & 5 & 6 \\
\hline Stress & .62 & .37 & .26 & .21 & .16 & .13 \\
\hline $\mathrm{R}^{2}$ & .10 & .24 & .33 & .40 & .49 & .60 \\
\hline
\end{tabular}

The elbow of the plot at the two-dimension (stress value $=.37$ ) gives better interpretation and clarity on data analysis. Two-dimensional configuration was selected for ease of interpretation because of the smaller decrease in stress between the one- and three-dimensional solutions (relative to the one- and two-dimensional solution) (Steyvers 2002). Figure 5 illustrates fit indices in more details. 
Figure 5 Scree plot

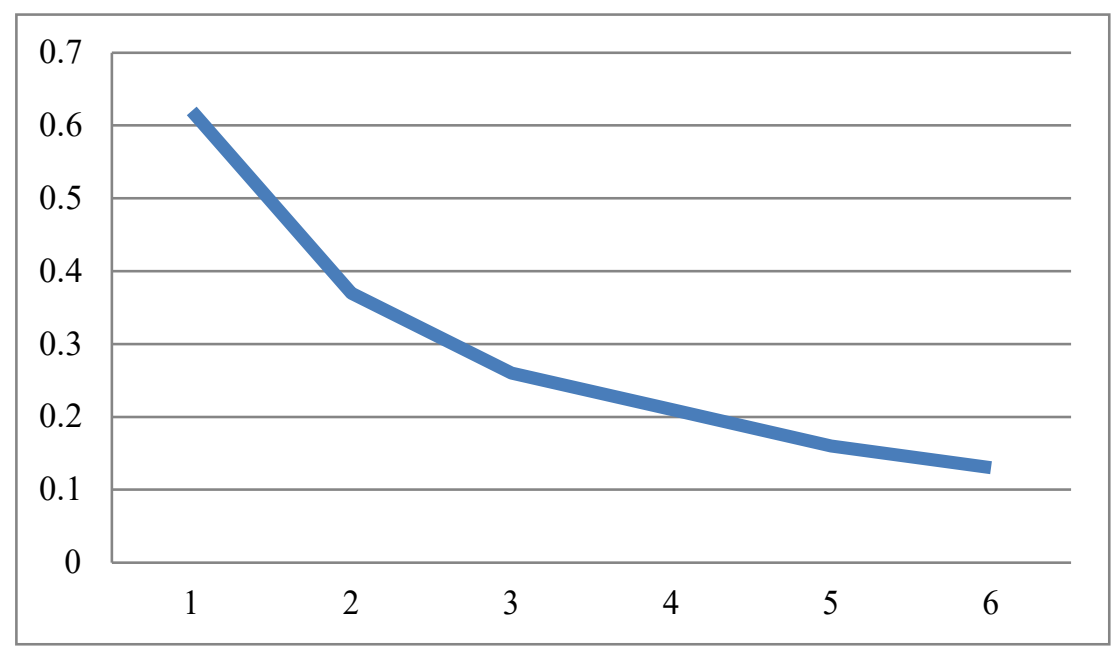

Two dimensions emerged from the multidimensional scaling (Figure 5). Table 3 illustrates the ratings of card deck on two dimensions. In multidimensional scaling, the dimensions were estimated by measures of relationship among aggregated matrix, which is theoretically the inverted ordinary factor analysis (Kim, Frisby and Davison 2004). Combined with insights from think aloud interviews, labeling dimensions is important because it gives theoretical insights. The two dimensions suggest participants distinguished between technological products based on gendered role of technology and the degree of task specificity (Please see Table 4).

Table 4 Two-dimensional Solution

\begin{tabular}{|l|l|l|l|}
\hline & Descriptions of ads & $\begin{array}{l}\text { Dimension 1: } \\
\text { Gendered role }\end{array}$ & $\begin{array}{l}\text { Dimension 2: } \\
\text { Task specificity }\end{array}$ \\
\hline & Cluster 1: Safety & -0.13 \\
\hline & $\begin{array}{l}\text { Guardian (Provide the largest range of protection } \\
\text { of any in-home medical alert system available) }\end{array}$ & -1.55 & -0.44 \\
\hline & $\begin{array}{l}\text { Dream Machine (Keep your baby's comfort at your } \\
\text { fingertips) }\end{array}$ & -1.40 & 0.86 \\
\hline
\end{tabular}




\begin{tabular}{|c|c|c|c|}
\hline & $\begin{array}{l}\text { Sleep tracker (Provide recovery and readiness } \\
\text { analysis based on whole-night heart-rate- } \\
\text { variability) }\end{array}$ & -1.23 & -0.67 \\
\hline & $\begin{array}{l}\text { Door Security (Let you see and speak with visitors } \\
\text { via your smart device, whether you're upstairs or } \\
\text { across town) }\end{array}$ & -1.21 & 1.03 \\
\hline & $\begin{array}{l}\text { Sleep Light (Provide you with light and sound } \\
\text { programs that will adapt to your personal body } \\
\text { clock and positively impact your sleeping } \\
\text { conditions) }\end{array}$ & -1.11 & 0.86 \\
\hline & $\begin{array}{l}\text { Thermostat (Control half your energy bill - more } \\
\text { than appliances, more than electronics) }\end{array}$ & -0.72 & 1.16 \\
\hline & $\begin{array}{l}\text { Toothbrush (Provides a clinically proven superior } \\
\text { performance) }\end{array}$ & -0.3 & 1.46 \\
\hline & \multicolumn{3}{|l|}{ Cluster 2: Cleaning } \\
\hline & $\begin{array}{l}\text { Dishwasher (Clean dishes at every angle and make } \\
\text { pre-rinsing unnecessary) }\end{array}$ & 1.43 & 0.43 \\
\hline & $\begin{array}{l}\text { Automower (Provide app connectivity with GPS } \\
\text { tracking for automated performance) }\end{array}$ & 1.04 & 0.91 \\
\hline & $\begin{array}{l}\text { Grill cleaning bot (Clean a grill automatically. } \\
\text { Place the Grill bot on your grill, press a button and } \\
\text { you're done) }\end{array}$ & 1.01 & 0.98 \\
\hline & $\begin{array}{l}\text { Vacuum bot (Vacuum up, schedule cleaning via } \\
\text { the app, and charge automatically) }\end{array}$ & 0.62 & 1.28 \\
\hline & $\begin{array}{l}\text { Washer (Provide the ultimate washing flexibility, } \\
\text { with two separately controlled washers in the same } \\
\text { unit) }\end{array}$ & 0.56 & 0.78 \\
\hline & \multicolumn{3}{|l|}{ Cluster 3: Cooking } \\
\hline & $\begin{array}{l}\text { Cocktail maker (Allow anyone to make world- } \\
\text { class cocktails at home) }\end{array}$ & 1.26 & -0.48 \\
\hline & $\begin{array}{l}\text { Refrigerator (Provide voice recognition and } \\
\text { internal cameras for remote viewing of stored food } \\
\text { items from your smartphone) }\end{array}$ & 1.14 & -0.18 \\
\hline \multirow[t]{2}{*}{ anis } & $\begin{array}{l}\text { Cooking robot (Cooks with the skill and flair of a } \\
\text { chef) }\end{array}$ & 1.21 & -0.59 \\
\hline & \multicolumn{3}{|l|}{ Cluster 4: Customization } \\
\hline & $\begin{array}{l}\text { Massage chair (Provide intense massaging action } \\
\text { to soothe sore muscles and a remote control to } \\
\text { access its features) }\end{array}$ & -0.20 & -1.50 \\
\hline
\end{tabular}




\begin{tabular}{|l|l|l|l|}
\hline & $\begin{array}{l}\text { Styler (Use deeply penetrating steam to minimize } \\
\text { wrinkles in clothing, and it reduces unpleasant } \\
\text { odors from fabrics for an improved scent) }\end{array}$ & 0.31 & -1.40 \\
\hline & $\begin{array}{l}\text { Moodo (Let you mix and match your own } \\
\text { signature home scent) }\end{array}$ & -0.15 & -1.39 \\
\hline & $\begin{array}{l}\text { Click and Grow (Provide zero-effort gardening } \\
\text { solutions perfect for urban homes) }\end{array}$ & 0.61 & -1.26 \\
\hline
\end{tabular}

The first dimension of the multidimensional scaling solution represents how the technological product depicts its role. The role, a patterned capacity, can be predicted by a product cue including gendered intrinsic (e.g., color) or extrinsic (e.g., name) cue. Specifically, gendered role is defined as "the culturally and socially constructed meanings that describe how women and men should behave in certain situations according to feminine and masculine roles learned throughout life." (Myers et al. 2003). Sorting suggests that participants grouped technological products by gendered roles. At the high end of this dimension, the technological product provides a "protection" role against threats. For example, Guardian, the umbrella brand name for multiple devices, supplies the largest range of protection of any in-home medical alert system available. This product description elicited the male-gendered role, protecting your family as "the man of the house." At the low end of this dimension, the technological product provides a "care" role for others. For example, Dishwasher proudly presents how it makes your care easier: Clean dishes at every angle and make pre-rinsing unnecessary. This product description elicited the female-gendered role, "angel in the house - proper, agreeable, and decorous (Rivkin and Ryan 2017, p. 820)," delivering skillful domestic labor.

The second dimension of the multidimensional scaling solution suggests the 
degree to which the technological product is specified in a constricted labor domain. Task specificity is to the degree to which a consumer can specify the exchange (e.g., rights and obligations) between a consumer and technology and predict the task of technological product (Lusch and Brown 1996). At the high end of this dimension, a technological product provides accomplishment of a well-defined task. For example, Toothbrush, a well-established domain of domestic technology, oscillates back and forth to clean your teeth and gums. At the low end of this dimension, a technological product builds collaborative relationships with coordinated interdependent efforts. For example, the massage chair works with a consumer to make them in control of the chair's features. This product description elicited little perception of task specificity, leading to openness for consumer-technology relationships.

These two dimensions revealed through multidimensional scaling suggest that gendered role of technology and the degree of task specificity are important to the typology of domestic technology. Cluster analysis was used to examine how technological products fall into sub regions and interpret the meanings of classification to extend our understanding of the dimensions.

\section{Cluster Analysis}

Cluster analysis uses a spatial representation based on Euclidean distances to recognize the dissimilarity (e.g., distance) between groups and similarity (e.g., closeness) within a group. Four clusters were identified by considering each item's weights on two dimensions and spatial relationships among items. Figure 6 illustrates the perceptual map. 
Figure 6 Two-Dimensional Multidimensional Scaling Perceptual Map

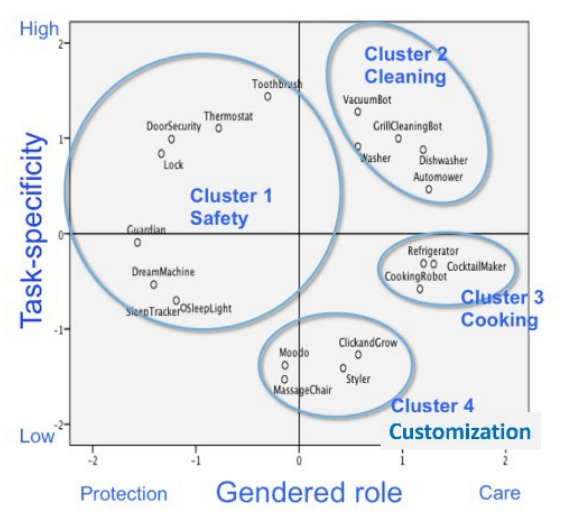

Cluster 1 is Safety. This cluster included 8 technological products: Guardian, Dream machine, Lock, Sleep tracker, Door security, Sleep light, Thermostat, and Toothbrush. In this cluster, all the items are located on one side of Dimension 1, which align with the male-gendered protection role (e.g, protection against threats). Participants' think-aloud responses enhance our understanding of male-gendered role and the concept of safety.

This lock looks masculine because it looks aggressive in dark color [Brian].

Brian voluntarily searched an intrinsic gendered cue (dark color) and inferred a malegendered role (aggressiveness). This indicated how a consumer uses a gender cue to predict the role of technology.

A man in the household sets up a door security and a woman can welcome a guest [Chris].

Chris showed a distinction between a male's domain and a woman's domain by conjuring a potential usage scenario. He grew up in Bronx, New York with his grandmother and mother who was a janitor for corporate buildings, and kept cultural 
heritages as an immigrant family from Central America. This use of extrinsic cue is ingrained with the cultural reference point (Thompson 1997), which can be varied across participants.

This sleep tracker is particularly designed for athletics and bikers. As athletics and bikers are often portrayed as males more than women, this sleep tracker is male-gendered [Donna].

Assuming athletics and bikers as males, Donna judged the sleep tracker as a malegendered technological product. Her insight may come from unconsciously culturally learned associations between gender and activity. To illustrate, FitBit, one of the wellknown fitness tracker, featured a man as a biker, but a woman as a night out shopper (Fitbit 2019).

I am interested in buying the door security because it seems easy to install and use with mobile app for video surveillance and remote monitoring [Joe].

Joe is a good example of personalized cultural reference points (Thompson 1997). He had a wife and three children under 10 years old and was concerned about data security issues of smart home devices. The only technological item he was interested in was the door security because he can protect his family wherever he is. This explains how a technological product supports us in a salient gendered role and gains more traction.

In this cluster, the concept of safety was related to male-gendered role by identifying either an intrinsic (Brian) or extrinsic product cue (Donna, Chris, and Joe). 
Perception of male-gendered role was associated with culturally and socially constructed meanings of how men and women should behave in the hetero-normative society.

Cluster 2 comprises of 5 technological products: Dishwasher, Automower, Grill cleaning bot, vacuum bot, and washer. The theme of Cluster 2 is cleaning, eliminating impurities. In this cluster, all the items are located in the top right corner, the intersection of female-gendered role (care) and high task specificity. Participants' responses from items can be helpful to enhance our understanding of female-gendered role and the concept of cleaning.

I saw a washer commercial that a mom taught how to wash to a dad. Washer is female-gendered because a mom often takes care of children's clothes associated with different school activities (e.g., dancing, sports) [Iris]

Iris recognized that washer possesses high task specificity (e.g., cleaning devices for all kinds of clothes) and is seen as female-gendered based on external cues (e.g., user image, commercial). As the eldest participant in the study, she recognized social pressures on a woman to be a caretaker, to take care of others. She reported that she had become a registered nurse, rather than a doctor, because that was recommended for women when she grew up in 70s. Similarly, she commented that even a washer commercial could normalize the different gendered roles regarding washing. Her insight was helpful to understand how gender roles can be socially and culturally shaped.

White and circle window of the washer looks feminine [Brian]. 
Brian voluntarily utilized intrinsic product cues, such as color and shape, to infer characteristics of technology. His sensitivity to product cues helps him to verbalize his impressions on aesthetics. He did not mention task-specificity directly, but feminine aesthetics may infer female-gendered role, which emphasizes adaptability, reducing perception of task specificity.

The vacuum bot reminds me of "Consuela", a Hispanic cleaning lady in TV Show Family Guy [Tony].

Tony was another example of showing how sociocultural associations shape gendering. In the TV show, the portrayal of cleaning lady as Consuela may give more realistic and humorous feelings by playing with gender and race-based stereotypes. However, the widespread use of stereotype normalizes stereotype-based division of labor without thinking of stereotype's socioeconomical ramifications.

Vacuum bot is female-gendered because it makes care taking jobs easier for a mom like her [Clare].

Clare was a single mom with three kids. She was a solo care taker and excited by automated devices for housework which would lessn her burden; However, as a sales clerk at Kohl's, her budget was limited in adopting mechanized aids. Automated cleaning devices were perceived as enhancing participants' sense of independence and autonomy rather than relying on human-based professional service (e.g., housekeeping, lawn service company).

The concept of cleaning in this cluster was related to female-gendered role 
with high task specificity. Mechanized cleaning has been relatively well established to fulfill people's expectations of the specific task (e.g., Roomba), and cleaning was female-gendered like a Consuela.

Cluster 3 comprises of 3 technological products: Cocktail maker, refrigerator, and cooking robot. The theme of Cluster 3 is cooking, making food preparation easier. In this cluster, all the items are located in the middle right corner, the intersection of female-gendered role (care) and medium-level of task specificity. Participants' responses from items can be helpful to enhance our understanding of female-gendered role and the concept of cooking.

When a face or a voice is added to arms-only cooking robot, it would be seen as a Martha Stewart and a Gordon Ramsay, which makes them either femalegendered technology or male-gendered technology [James].

James was original because he attempted to make a robot gendered to assess it. $\mathrm{He}$ reacted to the product description of comparing the robot to a master chef. For example, Martha Stewart and Gordon Ramsay are considered as master chefs. While Martha Stewart is an American female chef of home cooking, Gordon Ramsay is a British male chef of high-end restaurant cooking. His voluntary search for gender cues in a mechanical product was interesting because he appeared to be more comfortable with a gendered machine by imagining a hypothetical robot with a gendered face or voice.

Cocktail maker is gender-neutral because it can make a female-gendered drink (e.g., cosmopolitan) and a male gendered drink (e.g., whisky-based cocktail) 


\section{[Victoria].}

Unlike James, Victoria did not see a cooking machine as gender-ambiguous. Instead, she saw it as gender-neutral because it can be used for male and female users. For example, she wanted to know the type of liquor used in the product description because it is an important cue for social category membership. Men tend to love whisky-based strong drinks but women tend to like vodka-based colorful drinks, which signals different skills and qualities.

In this cluster, perception of cooking was perceived as either gender-neutral or gender-ambiguous although it was located in the female-gendered section. The intrinsic cue (e.g., human's arms-like machine) or extrinsic cue of product (e.g., user image) may activate a consumer's social cognition. Gendered cue may be important to determine the social cognition process.

Cluster 4 comprises of 4 technological products: Massage chair, Styler, Moodo, and Click and Grow. The theme of Cluster 4 is customization. Participants reported Moodo, Styler, Click and Grow, and Massage Chair provide versatile services for personalization to serve for a particular taste. For example, Moodo can be colored and shaped in a different way as a personal fragrance for men and women, Styler can be specialized in a specifically gendered outfit (e.g., suit skirt vs. pants), Click and Grow can offer a specialized treatment for herbs for men and women like gendered supplements, and massage chair can offer personalized touches for different body types of men and women. In this cluster, all the items are located in the bottom center corner for low task-specificity due to high adaptability and personalization. The 
cluster did not belong to either gendered role. Participants' responses from items can be helpful to enhance our understanding of female-gendered role and the concept of cooking.

It's fragrance. Is it a perfume or cologne? Is it for men or women? [Tony].

Moodo was fragrance for home, not a person; However, Tony voluntarily searched for a gendered cue to help him understand the technological product better. Like Victoria's cocktail maker, his reaction shows that gendering can be a powerful marketing technique to create gendered associations by displaying versatilities for diverse users.

The only time I have ever seen a styler is when I was in the army, which is a mandatory 2-year service for Korean males in 20s. The styler was used to eliminate dusts, sweats, and odor of military uniforms after physical trainings [Charles].

Uniforms signal specific occupations. Due to gendered division of occupations, a specific uniform may signal a gendered role (e.g., cop uniform for men; waitress uniform for women). For him, from his personal reference point, a styler was associated with a military setting, but different uniforms may signal diverse social categories.

Styler is female-gendered because a woman can make a fashion statement with it [Victoria].

Victoria's comment was useful to understand why the devices for clothes were 
perceived differently. It is interesting that a washer was seen as female-gendered, but gendered division of occupations did not make a styler clearly either gendered. In this cluster, devices for customization were perceived as low task specificity because it delivered performances adaptably.

\section{Discussion}

Q-methodology and multidimensional scaling, supplemented by free associations of domestic technology, identified gendering and task specificity as two dimensions for typology of domestic technology. Free associations helped identify how consumers search for intrinsic and extrinsic human-like cues, leading to assigning gender to smart technology at home. Particularly, voluntary search for product cue to infer gender was noticeable. For example, Nick was disappointed by the arms-only cooking robot without face and voice as the product cues, gender inference from product cues help predict the quality of cuisine as a function of gendered cooking technology. Tony wanted to find a gendered product cue to predict the type of scent for Moodo. Sarah called automower "Mr. Automower," but Tony called vacuum "Consuela" because it reminded him of a Hispanic cleaning lady in the TV Show FamilyGuy.

Perceptual mapping based on free associations was instructive, but the underlying dimensions and clusters were from the typology of items based on aggregated data. The next exploratory study examines a pet name represented by a consumer's own vernacular word to signal their singular relationship with domestic smart technology. 


\section{Exploratory Study 2 - Pet name exercise}

Exploratory study 2 examined consumers' own words for assigning a pet name to a product (a.k.a. pet name exercise). Specifically, if a consumer assigns a human-like pet name to a technological product, it can demonstrate how a consumer reflects on their relationship with the product. Scholars have suggested that a consumertechnology interaction includes anthropomorphizing technological products (Pieroni et al. 2015). Investigating pet names is instructive because pseudo-interpersonal relationship of consumer-technology determines a singular meaning of pet name (Kleine and Baker 2004; Lastovicka and Sirianni 2011).

Belk (1991) has suggested that a pet name is given to a companion animal to demonstrate transcendence of objective value, their non-substitutability of the companionships. Similarly, when technology becomes a partner, to manifest and assure their passion, intimacy, and commitment to the partner, a consumer puts a pet name rather than a generic brand name to a non-human entity (Lastovicka and Sirianni 2011). This technique helps to investigate whether gendering influences assignment of pet names to a technological product (Kleine and Baker 2004; Lastovicka and Sirianni 2011).

Consumer research scholars have examined pet names to understand consumer-brand relationships. In this research, the pet name exercise is used to address an outstanding research question of "how consumers might learn to interpret the behavior of smart objects using the language of their own experience to understand objects on their own terms as objects" (Hoffman and Novak 2017, p. 1194). To 
achieve this objective, this study will ask participants conduct two tasks: genderexplicit categorization task and gender-implicit pet name assignment task.

\section{Overview of Study Design}

\section{Stimuli}

Eight smart technological products (Door security, thermostat, grill cleaning robot, automower, vacuum, refrigerator, cooking robot, cocktail maker) were selected drawing upon findings from the previous study. Door security and thermostat were selected as representatives from Cluster 1 (Safety) to show high task-specificity and male-gendered role. Though two technological products belong to the same cluster, their relationships could differ from one another. Examining a consumer's vernacular word to assign a pet name will be helpful to understand the quality of relationship at a more advanced level. Grill cleaning robot, automower, and vacuum were selected as representatives of Cluster 2 (Cleaning) to show high task-specificity and femalegendered role in the previous study. All the three items were spatially represented as female-gendered role in the perceptual map, but participants saw a automower as male-gendered (e.g., Sarah's comment) and a vacuum as female-gendered (e.g., Tony's comment) respectively. Inclusion of three automated cleaning devices dedicated to different domains may help figure out how gendering principles apply to qualify a singular relationship with domestic technology in addition to basic functionality (e.g., cleaning). Refrigerator, cooking robot, and cocktail maker from Cluster 3 (Cooking) were selected because participants spontaneously searched for gendered cues for the devices (e.g., cooking-robot and cocktail maker) but none of the 
participants were interested in human-like cues in a device (e.g., refrigerator). Inclusion of three smart cooking devices may help what makes a consumer interested in gendered cues or not in the single domain. In this study, 48 undergraduate student participants were recruited to assign pet names to the selected set of smart domestic products.

\section{Procedure}

Participants were asked to perform two tasks with eight smart technological products. First, for gender-implicit pet name task, participants were asked to provide a pet name for the products with their own words based on their free associations. Second, for gender-explicit categorization task, participants chose one of three options: gender-neutral, male-gendered, or female-gendered. In the pet name task, without any gender-relating cues, participants engaged with the smart product. Conversely, in the gender-explicit categorization task, participants were asked to assign each product to a given specific gender category. This different task was designed to explore how gendering occurs at the individual level.

\section{Results}

First, the pet names in each participant's vernacular term were examined to identify the characteristics of names (Please see Table 5). Pet names in their words based on their free associations have been analyzed with respect to two questions: (1) Is the pet name non-living object or living entity and (2) Is it gendered? From the pet names assigned to the 8 smart products, we can infer participants are more likely to see vacuum as a non-living object, but least likely to see cooking robot as a non-living 
object. Among living pet names, automower (34.78\%) is seen as most gender ambiguous, but vacuum (6.25\%) is seen as least gender ambiguous. Automower is radically new technology that has not been introduced to home yet, but vacuum (e.g., Roomba) has been introduced successfully by targeting a specific gender in the advertising campaign. The concept of gender-ambiguous is important, which means it received both-gendered names (e.g., Hanson). In addition, spatial domain of technology appear to determine pet name assignment. For example, automower $(17.39 \%)$ and grill cleaning bot $(41.30 \%)$ are both used in outdoor, which made them received more pet names for male-gendered living entities. On the other hand, vacuum dominantly received non-living male-gendered pet names because it is used in indoor. This empirical finding is consistent with Dholakia (2012).

Table 5 Gender-implicit pet name task

\begin{tabular}{|l|l|l|l|l|l|l|l|l|l|}
\hline & & Fridge & Automower & Thermostat & $\begin{array}{l}\text { Cooking } \\
\text { robot }\end{array}$ & $\begin{array}{l}\text { Grill } \\
\text { cleaning } \\
\text { bot }\end{array}$ & $\begin{array}{l}\text { Door } \\
\text { security }\end{array}$ & $\begin{array}{l}\text { Cocktail } \\
\text { Maker }\end{array}$ & $\begin{array}{l}\text { Vacuum } \\
\text { pon- } \\
\text { living } \\
\text { pet name }\end{array}$ \\
\cline { 2 - 8 } & Female-gendered & $0.00 \%$ & $4.35 \%$ & $4.26 \%$ & $0.00 \%$ & $0.00 \%$ & $2.08 \%$ & $0.00 \%$ & $0.00 \%$ \\
\cline { 2 - 8 } & Sub total & $48.89 \%$ & $45.65 \%$ & $48.94 \%$ & $20.45 \%$ & $43.48 \%$ & $43.75 \%$ & $52.08 \%$ & $70.83 \%$ \\
\hline \multirow{2}{*}{$\begin{array}{l}\text { Living } \\
\text { pet name }\end{array}$} & Both & $11.11 \%$ & $34.78 \%$ & $25.53 \%$ & $31.82 \%$ & $15.22 \%$ & $20.83 \%$ & $10.42 \%$ & $6.25 \%$ \\
\cline { 2 - 9 } & Male-gendered & $22.22 \%$ & $17.39 \%$ & $14.89 \%$ & $34.09 \%$ & $41.30 \%$ & $25.00 \%$ & $29.17 \%$ & $8.33 \%$ \\
\cline { 2 - 9 } & Female-gendered & $17.78 \%$ & $2.17 \%$ & $10.64 \%$ & $13.64 \%$ & $0.00 \%$ & $10.42 \%$ & $8.33 \%$ & $14.58 \%$ \\
\cline { 2 - 8 } & Sub total & $51.11 \%$ & $54.34 \%$ & $51.06 \%$ & $79.55 \%$ & $56.52 \%$ & $56.25 \%$ & $47.92 \%$ & $29.16 \%$ \\
\hline & Total & $100.00 \%$ & $100.00 \%$ & $100.00 \%$ & $100.00 \%$ & $100.00 \%$ & $100.00 \%$ & $100.00 \%$ & $100.00 \%$ \\
\hline
\end{tabular}

Second, data from gender-explicit categorization task was examined with respect to categorization among three given options: gender-neutral, male-gendered, or female-gendered. The gender-neutral concept is important because it implies gender category is not applicable (e.g., non-assignability), which is different from genderambiguity. Table 5 shows that the gendered spatial division served important roles in 
the categorization task. For example, male-gendered items (e.g., automower, grill cleaning bot) are outdoor products, but female-gendered items (e.g., cocktail maker, vacuum) are indoor products. Fridge (68.75\%) and thermostat (70.83\%) were dominantly classified as gender-neutral category.

Table 6 Gender-explicit categorization task

\begin{tabular}{|l|l|l|l|l|l|l|l|l|}
\hline & Fridge & Automower & Thermostat & $\begin{array}{l}\text { Cooking } \\
\text { robot }\end{array}$ & $\begin{array}{l}\text { Grill } \\
\text { cleaning bot }\end{array}$ & $\begin{array}{l}\text { Door } \\
\text { security }\end{array}$ & $\begin{array}{l}\text { Cocktail } \\
\text { maker }\end{array}$ & Vacuum \\
\hline Gender-neutral & $68.75 \%$ & $10.42 \%$ & $70.83 \%$ & $47.92 \%$ & $8.33 \%$ & $64.58 \%$ & $41.67 \%$ & $37.50 \%$ \\
\hline Male-gendered & $16.67 \%$ & $87.50 \%$ & $12.50 \%$ & $22.92 \%$ & $89.58 \%$ & $6.25 \%$ & $12.50 \%$ & $8.33 \%$ \\
\hline Female-gendered & $14.58 \%$ & $2.08 \%$ & $16.67 \%$ & $29.17 \%$ & $2.08 \%$ & $29.17 \%$ & $45.83 \%$ & $54.17 \%$ \\
\hline Total & $100.00 \%$ & $100.00 \%$ & $100.00 \%$ & $100.00 \%$ & $100.00 \%$ & $100.00 \%$ & $100.00 \%$ & $100.00 \%$ \\
\hline
\end{tabular}

\section{Discussion}

Using gender-implicit categorization task and gender-explicit pet name task was complementary to explore consumer-smart technology relationships through the lens of gendering. Both tasks identified spatial division served important roles in gendering, which is consistent with Dholakia (2012). In addition, this study discovers two important concepts: gender-neutral and gender-ambiguous. For example, a smart refrigerator was perceived as a non-living object and gender-neutral (not gendered in neither female or male direction), but a cooking robot was perceived as a living entity and gender-ambiguous (not align with the specific concept of gender).

The exploratory studies focused on the first research question - whether a consumer assigns gender to a non-animated smart technological object at home. The findings confirmed that gender is an important dimension for classifying domestic technological products. The exploratory studies also revealed that domestic smart 
products can be viewed as living entities (Mourey et al. 2017). For instance, the vacuum and cocktail maker were perceived to be non-living entities $(70.8 \%$ and $52.1 \%$ respectively) while the cooking robot was perceived as the most living entity $(79.6 \%)$

The exploratory studies did not address the second research question - whether and how gendering affects consumer judgments. Drawing upon the results of the two exploratory studies, a series of lab experiments have been designed to specifically address the second research question, in addition to confirming results of the exploratory studies but in the controlled lab setting with gender-manipulated technological products.

\section{Overview of Lab Experiments}

To examine the process and effects of gendering, five lab experiments (Experiments $1 \mathrm{~A}$ and $\mathrm{B}, 2 \mathrm{~A}$ and $\mathrm{B}$, and 3) were designed to investigate consumer responses to gendered technological products. Table 7 summarizes stimuli and manipulation (Please see Appendix 2). Results from exploratory studies were used to select stimuli products include fridge (non-living, gender-neutral object), cooking robot (living, gender-ambiguous entity), and Automower (living, male-gendered entity), which helped discover generalizable empirical findings.

Table 7 Summary of Experiment Design

\begin{tabular}{|l|l|l|}
\hline & $\begin{array}{l}\text { Stimuli } \\
\text { products }\end{array}$ & Manipulation \\
\hline Experiment 1A & Fridge & Gendered name cue (Jill vs. Jack) \\
\hline Experiment 1B & Fridge & Gendered creator cue (Lab Tech Gals vs. No cue) \\
\hline
\end{tabular}




\begin{tabular}{|l|l|l|}
\hline Experiment 2A & Cooking robot & $\begin{array}{l}\text { Gendered name cue (Jill vs. Jack) x Technology newness } \\
\text { (Radically vs. incrementally new) }\end{array}$ \\
\hline Experiment 2B & Cooking robot & Technology newness (Radically vs. incrementally new) \\
\hline Experiment 3 & Automower & $\begin{array}{l}\text { Gendered name cue (Jill vs. Jack) x Gendered role } \\
\text { (Stereotypical vs. Counter-stereotypical) }\end{array}$ \\
\hline
\end{tabular}

This dissertation adopts implicit and explicit measures to examine the process of gendering, a mental model for favoring specific characteristics of, suited to, or biased toward one gender or the other (Wajcman 2010). An explicit measure is a selfreported assessment that captures a mental model as a deliberate process whereas an implicit measure is an alternative to retrieve an unconscious and automatic learned association. (Gawronski et al. 2007). The use of both explicit and implicit measures is useful in research on stereotyped perceptions because the association between a social category marker and its properties is a learned association without awareness, and the traditional self-reported measure alone would not reflect what individuals really think due to social desirability bias. Payne et al. (2005) suggested that gendering process with explicit and implicit measures affects behavioral outcomes. Lab experiments found that exposure to a specific social category (e.g., Black) affects implicit attitude, which increases accuracy of a stereotype-congruent concept (e.g., gun) but decreases accuracy of a stereotype-incongruent concept (e.g., tool). This shows how implicit and explicit process measures influence consumer judgments by encoding of schemaconsistent information and modifying the use of retrieved social-category specific roles.

The explicit measure of gendering was assessed with a rating 12 -item scale of gendered role compose of 12 items adapted from Bem (1974) and Luchs and 
Mooradian (2012). For implicit measure, accuracy of gender categorization (Lee and Labroo 2004; Schwartz 2004) and response time (Dempsey and Mitchell 2010; Fazio 1990; Sweldens et al. 2010) were assessed to quantify ease of learned association retrieval. Accuracy measure was assessed with participants' agreement (e.g., yes/no format) with an association between a specific gender category (e.g., woman) and the gendered cue of technological product (e.g., Jill). The amount of time to finish the agreement task was recorded by computer software as response time.

In addition to the explicit and implicit measures of the underlying gendering process, behavioral outcomes of the process in terms of four consumer judgment variables were also assessed. Specifically, perceived quality (i.e., utility) was assessed with a 6-item scale adopted from Sweeney and Souter (2001), perceived creativity (i.e., novelty and appropriateness) with a 6-item scale adopted from Dahl, Chattopadhyay, and Gorn (1999), consumer evaluation (i.e., valence and magnitude of attitude) with a 4-item scale adapted from Yoo and Donthu (2001), and persuasion effectiveness (i.e., perceived desirability) with a 5-item scale adapted from TouréTillery and McGill (2015) (See Appendix 3 for details).

\section{Experiment 1A}

\section{Pretest}

To ensure a strong induction of a gendered product cue, a smart technological product's name (Jill/Jack) was selected. A cooking robot was selected because it was gender-ambiguous in the previous exploratory study, which makes it ideal to test manipulation of name for gendering manipulation. A pretest was conducted to 
examine whether provision of extrinsic product cue makes a gender-ambiguous object gendered. Thirty-seven participants recruited from Amazon Mechanical Turk were assigned to one of two gendered names (Jill or Jack). Participants were randomly assigned to one of ads in two versions. The only difference of two ads was name manipulation. Perceived female-gendered role in Jill condition was higher than in Jack condition $\left(\mathrm{M}_{\mathrm{Jill}}=2.42, \mathrm{M}_{\mathrm{Jack}}=3.70, p<.05\right)$. Conversely, perceived male-gendered role in Jack condition was higher than in Jill condition $\left(\mathrm{M}_{\mathrm{Jill}}=3.55, \mathrm{M}_{\mathrm{Jack}}=4.92, p<.05\right)$. This pretest indicated that the cue manipulation was successful.

\section{Design and Procedure of Experiment 1A}

The study used a two-cell design by giving a product name (Jill vs. Jack). One hundred thirty-two participants were recruited from Amazon Mechanical Turk. The goal of Experiment 1A is whether a consumer engages in gendering in the presence of gendered name (Jill vs. Jack) to examine the process and effect of gendering.

Participants were randomly assigned to either a Jack or a Jill condition. A smart refrigerator was selected because it was perceived as a non-living and genderneutral object.. Participants were randomly assigned to one of messages in two versions. One was a smart refrigerator called Jack, and the other was the same refrigerator called Jill. The only difference between the two ads was the manipulated name. After reading a product message (Please see the Appendix 2), participants were asked to respond to the relevance of the individually displayed word (e.g., woman or man in a counterbalanced order) regarding the smart refrigerator, in a yes/no format. Participants' agreement on the association between a specific gender category and the 
technological product (yes or no) and its reaction time were measured to examine whether the ease of processing the gender association drives assigning a gender to a non-animated smart technological product (Lee and Labroo 2004; Schwartz 2004).

Participants then completed a survey that measured their responses to the product. Female-gendered role (Bem 1974; Luchs and Mooradian 2012), and consumer judgments including perceived quality, perceived creativity, consumer evaluation, and persuasion effectiveness were measured.

\section{Results}

The data for two-cell design was analyzed to examine hypotheses (H1, H2, and H3).

First, a manipulation check on the gendered cue was conducted by asking participant to recall the manipulated gendered cue and select among two names of products, the female-gendered name (Jill) and the male-gendered name (Jack). Participants ( $\mathrm{n}=129)$ who correctly recalled the gendered cue were used for further analysis. Second, multiitem dependent measures and their reliabilities were qualified for further analysis: perceived quality $(\alpha=.92)$, perceived creativity $(\alpha=.84)$, persuasion effectiveness $(\alpha$ $=.91)$, and consumer evaluation $(\alpha=.88)$. Table 8 illustrated all means of various measures evaluated in the study.

Table 8 Means of Experiment 1A

\begin{tabular}{|l|c|l|l|c|c|c|}
\hline & $\begin{array}{l}\text { Female- } \\
\text { gendered } \\
\text { role }\end{array}$ & $\begin{array}{l}\text { Male- } \\
\text { gendered } \\
\text { role }\end{array}$ & $\begin{array}{l}\text { Perceived } \\
\text { quality }\end{array}$ & $\begin{array}{l}\text { Perceived } \\
\text { creativity }\end{array}$ & $\begin{array}{l}\text { Persuasion } \\
\text { effectiveness }\end{array}$ & $\begin{array}{l}\text { Consumer } \\
\text { evaluation }\end{array}$ \\
\hline $\begin{array}{l}\text { Jill } \\
\text { condition }\end{array}$ & 3.44 & 4.10 & 5.14 & 5.39 & 5.13 & 5.59 \\
\hline $\begin{array}{l}\text { Jack } \\
\text { condition }\end{array}$ & 2.79 & 4.03 & 5.02 & 5.37 & 5.00 & 5.49 \\
\hline
\end{tabular}


Smart refrigerator's perceived gendered role

Analysis was conducted to examine whether a gendered product name cue increases perceived gendered role. Perceived female-gendered role was perceived higher in the Jill condition than in the Jack condition $\left(\mathrm{M}_{\mathrm{Jill}}=3.44>\mathrm{M}_{\mathrm{Jack}}=2.79, p<\right.$ $.05)$. For perceived male-gendered role, there was no statistically significant difference between two conditions $\left(\mathrm{M}_{\mathrm{Jill}}=4.10, \mathrm{M}_{\mathrm{Jack}}=4.03\right.$, N.S. $)$.

Accuracy and accessibility of gender category-smart refrigerator associations

Analysis was conducted to investigate the effect of gendering on ease of processing the gender category-technological product association drives gendering Measured data (e.g., yes or no format) on participants' agreement with an association between a specific gender category and the technological product was analyzed. For example, "yes" responses to the Jill-Woman and Jack-Man pairs indicate correct categorization, "no" responses to the Jill-Man and Jack-Woman pairs indicate incorrect categorization (Lee and Labroo 2004; Schwartz 2004). Analysis revealed that higher percentages of correct agreement and disagreement were observed in Jill condition than Jack condition, but this difference is statistically not significant $\left(\mathrm{X}(1)^{2}\right.$ $=2.79$ ). Figure 7 illustrates the findings. 
Figure 7 Accuracy of gender category-smart refrigerator associations

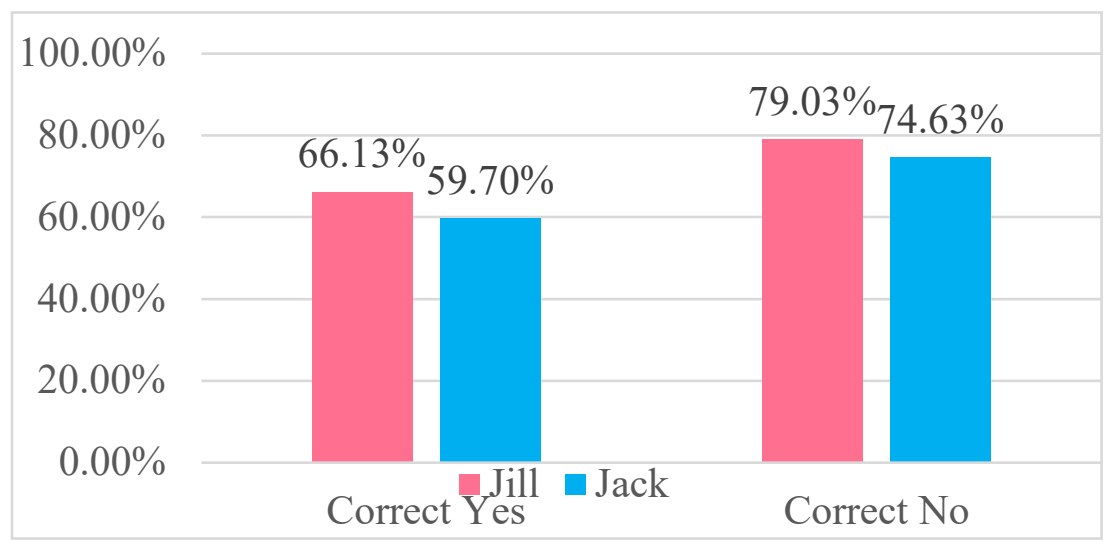

Reaction time is inversely related to the accessibility of a concept in a consumer's mind (Dempsey and Mitchell 2010; Fazio 1990; Sweldens et al. 2010). For both "yes" and "no" responses, reaction times of Jill condition were greater than Jack condition $(p<.05)$. For combined responses, the same pattern was reported ( $p$ $<.08)$. This indicates that a consumer experienced more troubles to process femalegendered technology than male-gendered technology (Please see Figure 8).

Figure 8 Accessibility of gender category-smart refrigerator associations

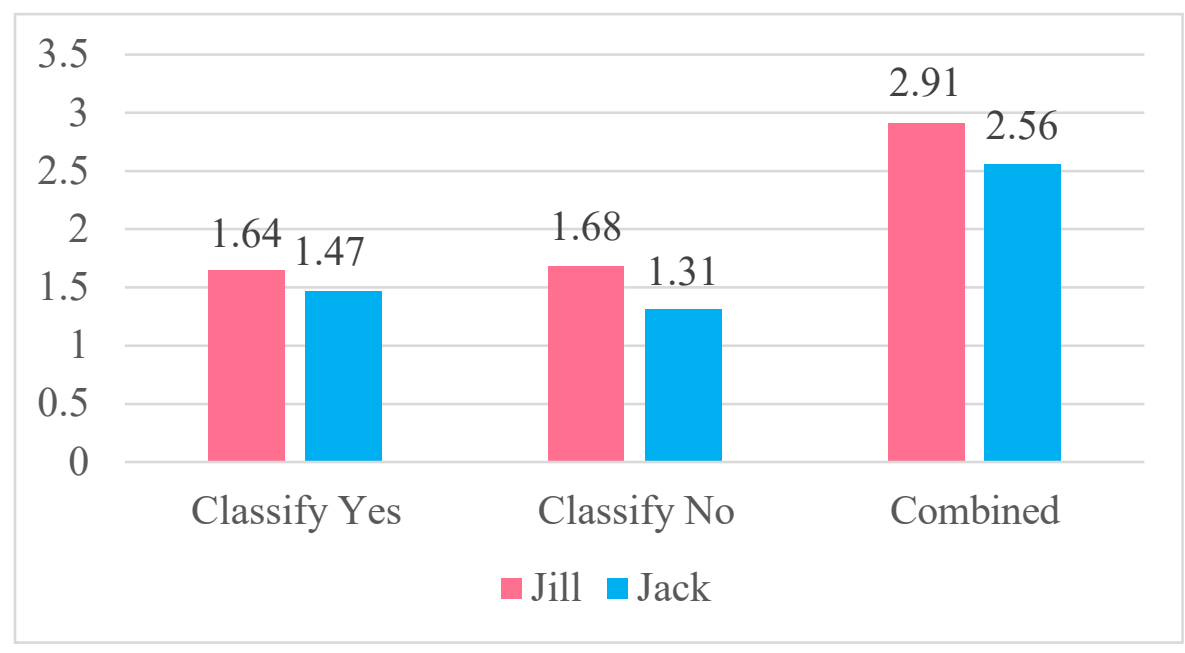




\section{Gendering effects on consumer judgments}

Analysis was conducted to investigate whether female-gendered cue negatively affects downstream consumer judgments. A mediation model (PROCESS model 4, Hayes 2013) with gendered name (assigned 0 for Jill and 1 for Jack) as the independent variable, perceived female-gendered role as the mediator, and perceived quality (DV 1), perceived creativity (DV 2), consumer evaluation (DV 3), and persuasion effectiveness (DV 4) as the dependent variable, respectively, yielded significant mediation via perceived female-gendered role.

In Panel A, the female-gendered name, Jill (vs. Jack), increased perceived female-gendered role (Path A: $\mathrm{B}=-.65$, S.E. $=.20, p<.05$ ), and perceived femalegendered role was positively associated with perceived quality $(\mathrm{B}=.23$, S.E. $=.06, p$ $<.001)$. The direct effect of gendered name on perceived quality was not statistically significant. In Panel B, the female-gendered name, Jill (vs. Jack), increased perceived female-gendered role (Path A: $\mathrm{B}=-.65$, S.E. $=.20, p<.05$ ), and perceived femalegendered role was positively associated with perceived creativity $(\mathrm{B}=.21, \mathrm{~S} . \mathrm{E} .=.05, p$ $<.001)$. The direct effect of gendered name on perceived creativity was not statistically significant. In Panel C, the female-gendered name, Jill (vs. Jack), increased perceived female-gendered role (Path A: $\mathrm{B}=-.65$, S.E. $=.20, p<.05$ ), but there was no statistically significant relationship between perceived female-gendered role and consumer evaluation. There was a statistically significant direct effect of gendered name on consumer evaluation $(\mathrm{B}=.65$, S.E. $=.29, p<.05)$. In Panel $\mathrm{D}$, the female-gendered name, Jill (vs. Jack), increased perceived female-gendered role (Path A: B=-.65, S.E. $=.20, p<.05$ ), and perceived female-gendered role was positively associated with 
perceived creativity $(\mathrm{B}=.28$, S.E. $=.07, p<.01)$. The direct effect of gendered name on perceived creativity was not statistically significant.

Overall, perceived female-gendered role was a mediator to the gendered name's indirect effect on perceived quality, perceived creativity, and persuasion effectiveness without direct effect. But, there was only gendered name's direct effect on consumer evaluation without indirect effect. This may be explained by the general nature of consumer evaluation (e.g., general attitude) unlike other specialized aspects of consumer judgments, such as quality, creativity, and persuasion. Figure 9 illustrates the effects in more detail.

Figure 9 Experiment 1A's mediation analysis

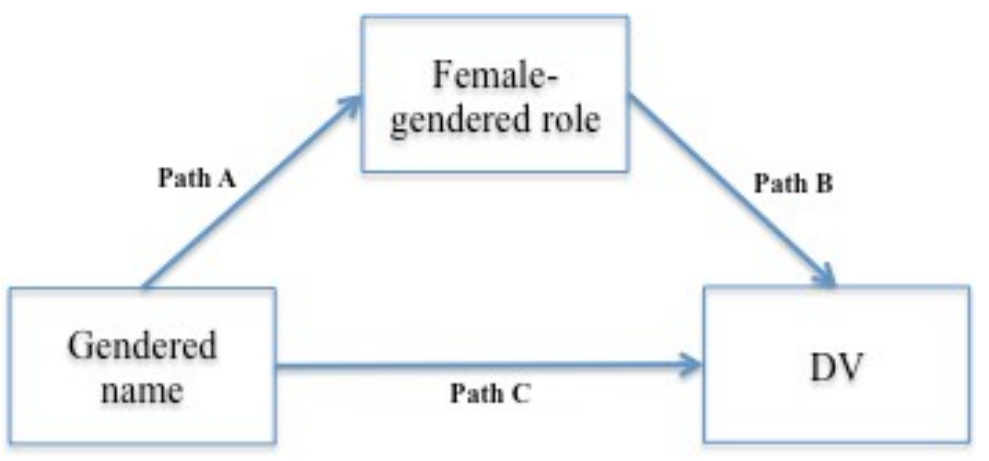

\begin{tabular}{|c|c|c|c|}
\hline \multirow[t]{2}{*}{ Dependent variable (DV) } & \multicolumn{2}{|c|}{ Mediation effect } & \multirow{2}{*}{$\begin{array}{c}\text { Direct effect } \\
\text { Name }=>\text { DV } \\
\text { (Path C) }\end{array}$} \\
\hline & $\begin{array}{c}\text { Name }=>\text { Female-gendered role } \\
\text { (Path A) }\end{array}$ & $\begin{array}{l}\text { Female-gendered role }=>\text { DV } \\
\text { (Path B) }\end{array}$ & \\
\hline Perceived quality (DV1) & $\mathrm{B}=-.65$, S.E. $=.29 *$ & $\mathrm{~B}=.23$, S.E. $=.06^{* * *}$ & $\mathrm{~B}=.02$, S.E. $=.19$, N.S. \\
\hline Perceived creativity (DV 2) & $\mathrm{B}=-.65$, S.E. $=.29 *$ & $\mathrm{~B}=.21, \mathrm{~S} . \mathrm{E} .=.05 * * *$ & $\mathrm{~B}=.11, \mathrm{~S} . \mathrm{E} .=.17, \mathrm{~N} . \mathrm{S}$ \\
\hline Consumer evaluation (DV 3) & $\mathrm{B}=-.65$, S.E. $=.29^{*}$ & $\mathrm{~B}=.07$, S.E. $=.05$, N.S. & $\mathrm{B}=.65, \mathrm{~S} . \mathrm{E} .=.29^{*}$ \\
\hline Persuasion effectiveness (DV 4) & $\mathrm{B}=-.65$, S.E. $=.29^{*}$ & $\mathrm{~B}=.28$, S.E. $=.07 * *$ & $\mathrm{~B}=.05, \mathrm{~S} . \mathrm{E} .=.25$, N.S. \\
\hline \multicolumn{4}{|c|}{ Note: Asterisk marks $(* * *, * *$, and $*)$ indicate $p$ values $(p<.001, p<.01$, and $p<.05)$} \\
\hline
\end{tabular}




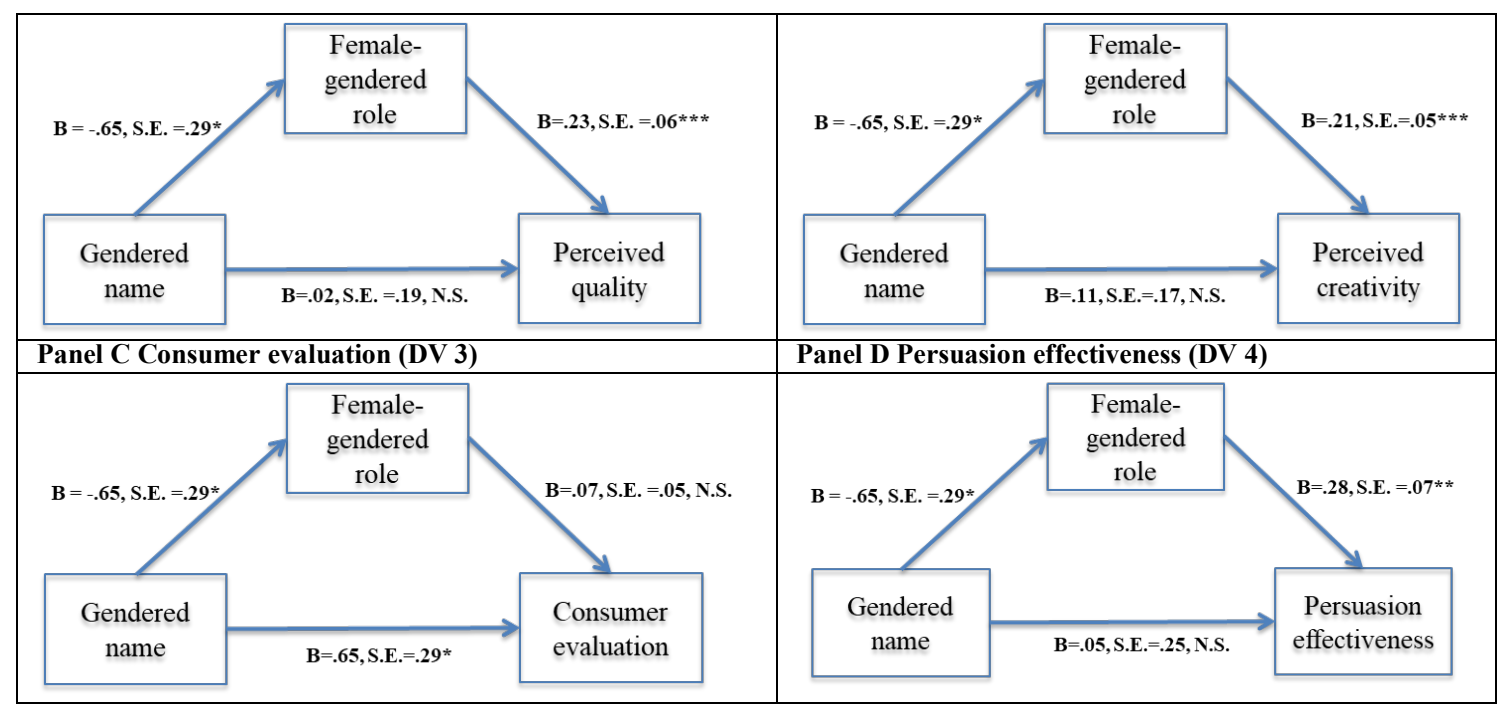

Post-hoc Analysis

Because of technology's male gendered association from military and industrial heritage, it was difficult to manipulate perceived male-gendered role in the lab experiment and tease out the effect of female-gendered role on consumer judgments. Post-hoc analysis was conducted to address the challenges by using a linear regression model with perceived female-gendered role as independent variable, perceived quality as dependent variable, and other controlled variables. Perceived female-gendered role was negatively correlated with perceived quality in the regression analysis controlled for involvement, ownership, respondent gender, respondent age, and familiarity (coefficient $=.27 * *$ ). This evidence shows male-bias in technology.

\section{Discussion}

The results suggest that a gendered name increases a congruent gendered role and ease of processing the gender category-technological product association. The 
effects of gendered cue on consumer judgments mediated by perceived femalegendered role were statistically significant. These results provide support for application of social cognition theory to consumer-technology relationship. Experiment 1A's findings are instructive, but a different mode of operationalization and replication can be beneficial to generalize the findings, which leads to Experiment 1B.

\section{Experiment 1B}

Experiment 1B was run to replicate Experiment 1A's finding with a different operationalization. Technology product's creators name has been selected for inducting of gendered product cue because prior literature and pet name exercise have shown male-as-creator bias in technology. Pretest was conducted to lay foundations for this study.

\section{Pretest}

Like in pretest of Experiment 1A, a gender ambiguous object (e.g., cooking machine) was used for the pretest of Experiment 1B. Thirty eight participants from Amazon Mechanical Turk were assigned to either gendered creator (Lab Tech Gals vs. Lab Tech Guys). Perceived female-gendered role in Jill condition was higher than Jack condition $\left(\mathrm{M}_{\mathrm{Gals}}=2.59, \mathrm{M}_{\mathrm{Guys}}=3.68, p=.06\right)$. Perceived male-gendered role in Jack condition was higher than Jill condition $\left(\mathrm{M}_{\mathrm{Gals}}=3.75, \mathrm{M}_{\mathrm{Guys}}=4.65, p=.08\right)$. Therefore, gendered creator as product cue marginally changed the perception of gendered role in the pretest. 


\section{Main Study: Design and Procedure}

This study used two-cell design (Lab Tech Gals vs. No cue). No cue condition was introduced to test male-as-creator bias compared to the Lab Tech Gals condition. One hundred thirty-four participants were recruited from Amazon Mechanical Turk. The goal of Experiment 1B is to extend and replicate Study 1's finding. While Study 1 used gendered name (Jill vs. Jack) to explore the process and effect of gendering, Experiment 1B used a different operationalization. Instead of gendered name cue, gendered creator cue (Lab Tech Gals) was used against no cue condition,

Participants were randomly assigned to either a Lab Tech Gals condition or a no cue condition. As Experiment 1A, smart refrigerator was used as a non-living and gender-neutral object. After reading a product message, response latency, femalegendered role, male-gendered role, perceived quality, persuasion effectiveness, perceived creativity, and consumer evaluation, along with ancillary measures were assessed.

\section{Results}

The data for two-cell design was analyzed to examine hypotheses $(\mathrm{H} 1, \mathrm{H} 2$, and $\mathrm{H} 3)$. First, a manipulation check on the gendered cue was conducted by asking participant to recall the manipulated gendered cue and select among two descriptions of the product: presence of gendered cue (e.g., Lab Tech Gals) or absence of gendered cue. Participants $(\mathrm{n}=114)$ who correctly recalled manipulation were used for further

analysis. Second, multi-item dependent measures and their reliabilities were qualified for further analysis: perceived quality $(\alpha=.93)$, perceived creativity $(\alpha=.87)$, 
persuasion effectiveness $(\alpha=.91)$, and consumer evaluation $(\alpha=.90)$. Table 9 illustrated all means measured in the study.

Table 9 Means of Experiment 1B

\begin{tabular}{|l|c|l|c|c|c|c|}
\hline & $\begin{array}{l}\text { Female- } \\
\text { gendered } \\
\text { role }\end{array}$ & $\begin{array}{l}\text { Male- } \\
\text { gendered } \\
\text { role }\end{array}$ & $\begin{array}{l}\text { Perceived } \\
\text { quality }\end{array}$ & $\begin{array}{l}\text { Perceived } \\
\text { creativity }\end{array}$ & $\begin{array}{l}\text { Persuasion } \\
\text { effectiveness }\end{array}$ & $\begin{array}{l}\text { Consumer } \\
\text { evaluation }\end{array}$ \\
\hline $\begin{array}{l}\text { Lab Tech Gals } \\
\text { condition }\end{array}$ & 2.93 & 4.15 & 4.97 & 5.23 & 4.85 & 5.50 \\
\hline No cue condition & 3.08 & 3.88 & 4.85 & 5.05 & 4.81 & 5.29 \\
\hline
\end{tabular}

Smart refrigerator's perceived gendered role

Analysis was conducted to examine whether a gendered product name cue increases perceived gendered role. For perceived male-gendered role, like Experiment 1A, there was no statistically significant difference between two conditions (N.S.). Unlike Experiment 1A, for female-gendered role, there was no statistically significant difference between two conditions as well (N.S). Figure 10 illustrates the finding.

Figure 10 Perceived Gendered Roles in Jill and No Cue Condition

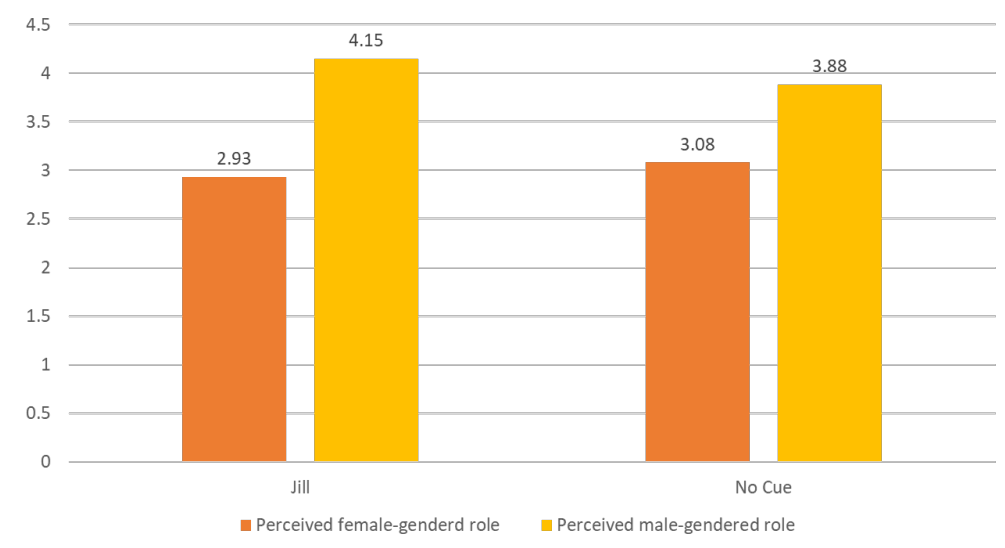

Ease of processing gender category-smart refrigerator associations 
Analysis was conducted to investigate the effect of gendering on ease of processing the gender category-technological product association drives gendering Measured data (e.g., yes or no format) on participants' agreement with an association between a specific gender category and the technological product was analyzed (Lee and Labroo 2004; Schwartz 2004). For agreement response, the concept of woman was seen as associated with Lab Tech Gals condition (22.00\%), but dissociated with no cue condition $(46.87 \%)(p<.001)$. The concept of man was seen as associated with no cue condition (12.5\%) but dissociated with Lab Tech Gals condition $(80.00 \%)(p<.001)$. Analysis revealed that Jill was associated with the concept of woman (22\%) and dissociated with the concept of man (80\%), which indicates that female-gendered technology was related to the concept of man in a negation format rather than the concept of woman in a confirmation format. Reaction time analysis revealed that there was no difference between categorization for the concept of woman (N.S.) and man (N.S.).

\section{Gendering effects on consumer judgments}

Analysis was conducted to investigate whether female-gendered cue will negatively affect downstream consumer judgments. Analysis revealed that there were no statistically significant differences in consumer judgments between Lab Tech Gals condition and No Cue condition in either mediated or direct manner.

\section{Ad-hoc Analysis}

As Experiment 1A, gendering manipulation and its effects on consumer judgments were not statistically strong and needs a simple linear regression model for further 
investigation. Regression analyses were conducted to test the effects of perceived gendered roles on consumer judgments. Perceived male-gendered role has significant, positive relationships with perceived quality, perceived creativity, and consumer evaluation $(\mathrm{p}<.001)$.

\section{Discussion}

Although Experiment 1B was designed to extend and replicate the finding of Experiment 1A, Experiment 1B only replicated findings regarding hypothesis 2 but failed to replicate the findings regarding hypotheses 1 and 3 . These results show that the agreement on the association between a specific gender category and the technological product (yes or no) was highly grounded in consumers' mind. The analysis revealed that the no cue condition was seen as being dissociated with the concept of woman but being associated with concept of man. This finding shows that consumers deem technology without a gendered cue as being associated with a male rather than a female. The empirical results are important to support socio-historical study on male-dominated technology advancement coming from military and industrial heritages (Wajcman 1991). However, there were no statistically significant differences in gendered role and consumer judgments across two conditions, which may show there is a potential moderator to understand the process and effect of gendering. The next studies will examine the moderators to change the gendering effects

\section{Experiment 2A}

The findings from previous studies informed the process and effects of 
gendering. One of the key finding is when technology is gendered, technology falls into a subject of gender stereotype. To advance our knowledge on gendering, it is important to examine what conditions may moderate the gendering effects. Prior literature (Chiang and Dholakia 2003). The researchers have suggested that association with male consumers was seen as more innovative than one with female consumers. This raises a research-worth question regarding technology newness and gendering effects. In this study, the selection of cooking machine was made to enhance generalization of findings because a cooking machine entails a different dimension from a smart refrigerator. In exploratory studies, a cooking machine was seen as a living entity and gender-ambiguous (not align with the concept of gender), but a smart refrigerator was seen as a non-living object and gender-neutral (gendered in either female or male direction). For example, in exploratory studies, cooking machine was selected as gender-ambiguous technology because it received both female (e.g., Martha) and male (e.g., Gordon) gendered namesA pretest was conducted to test technology newness prior to Experiment 2A.

\section{Pretest}

The pretest was designed to examine whether a technology can be manipulated to affect perception as radically new or incrementally new technology. Cooking machine was used as a gender-ambiguous technological product. The number of recipes, consumer-technology interaction mode, availability of course meal were manipulated (multiple dishes, voice-based interaction, and full-course meal for radically new technology, 10 recipes, button-based interaction, and no course meal for incrementally new technology). Participants perceived radically new technology was 
more novel than incrementally new technology $\left(M_{\text {radically new technology }}=6.42, M_{\text {incrementally }}\right.$ new technology $=5.11, p=.009$ ). This finding helps to set up subsequent studies.

\section{Main Study: Design and Procedure}

The goal of Experiment $2 \mathrm{~A}$ is to explore whether technology newness moderates gendering effects. Experiment 2A used a 2 (Gendered name cue: Jill vs. Jack) x 2 (Technology newness: Radically new vs. incrementally new) betweensubjects design. One hundred twenty-six participants were recruited from Amazon Mechanical Turk were randomly assigned to one of the four cells. Gendered names were used as manipulation of gendering. Pilot tested cooking machines in varied technology newness level were used for this study. As in previous studies, participants were asked to respond to respond to the relevance of the individually displayed word (e.g., woman or man in a counterbalanced order) regarding the smart refrigerator, in a yes/no format and assess measures including gendered roles, consumer judgments, and ancillary variables.

\section{Results}

The data for a $2 \times 2$ between-subjects design was analyzed to examine hypotheses. First, a manipulation check on technology newness was successful ( $M_{\text {Radically New }}$

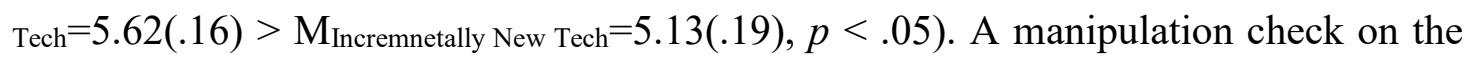
gendered cue was conducted by asking participant to recall the manipulated gendered cue and select among two names of products, the female-gendered name (Jill) and the male-gendered name (Jack). Participants ( $\mathrm{n}=105)$ who correctly recalled the gendered cue were used for further analysis. Second, multi-item dependent measures and their 
reliabilities were qualified for further analysis: Perceived quality $(\alpha=.88)$, perceived creativity $(\alpha=.80)$, persuasion effectiveness $(\alpha=.90)$, and consumer evaluation $(\alpha=$ $.81)$. Table 10 illustrated all means of measures used in the study.

Table 10 Means of Experiment 2A

\begin{tabular}{|l|c|c|c|c|c|c|}
\hline & $\begin{array}{l}\text { Female- } \\
\text { gendered } \\
\text { role }\end{array}$ & $\begin{array}{l}\text { Male- } \\
\text { gendered } \\
\text { role }\end{array}$ & $\begin{array}{l}\text { Perceived } \\
\text { quality }\end{array}$ & $\begin{array}{l}\text { Perceived } \\
\text { creativity }\end{array}$ & $\begin{array}{l}\text { Persuasion } \\
\text { effectiveness }\end{array}$ & $\begin{array}{l}\text { Consumer } \\
\text { evaluation }\end{array}$ \\
\hline $\begin{array}{l}\text { Jill x radically new } \\
\text { technology condition }\end{array}$ & 3.73 & 4.23 & 4.86 & 5.33 & 4.78 & 5.09 \\
\hline $\begin{array}{l}\text { Jill x incrementally } \\
\text { new condition }\end{array}$ & 3.69 & 3.98 & 5.01 & 5.06 & 4.74 & 5.15 \\
\hline $\begin{array}{l}\text { Jack x radically new } \\
\text { technology condition }\end{array}$ & 2.92 & 4.05 & 4.72 & 5.39 & 4.58 & 4.87 \\
\hline $\begin{array}{l}\text { Jack x incrementally } \\
\text { new condition }\end{array}$ & 3.00 & 3.70 & 4.47 & 5.12 & 4.70 & 4.90 \\
\hline
\end{tabular}

\section{Cooking robot's perceived gendered role}

Analysis was conducted to examine whether a gendered product name cue increases perceived gendered role. Jill condition $\left(\mathrm{M}_{\mathrm{Jill}}=3.71\right)$ increased perceived femalegendered role than Jack condition $\left(\mathrm{M}_{\mathrm{Jack}}=2.96\right)$. For perceived male-gendered role, analysis revealed that there were no statistically significant differences across conditions. Analysis also found that the technology newness did not influence perceived male-gendered role nor perceived female-gendered role.

\section{Ease of processing gender category-cooking robot associations}

Analysis was conducted to investigate the effect of gendering on ease of processing the gender category-technological product association drives gendering Measured data (e.g., yes or no format) on participants' agreement with an association between a specific gender category and the technological product was analyzed. For 
example, "yes" responses to the Jill-Woman and Jack-Man pairs indicate correct categorization, "no" responses to the Jill-Man and Jack-Woman pairs indicate incorrect categorization (Lee and Labroo 2004; Schwartz 2004). Analysis revealed that higher percentages of correct agreement and disagreement were observed in Jill condition than Jack condition, but this difference is statistically significant $\left(\mathrm{X}(1)^{2}=\right.$ 8.56). Figure 11 illustrates the findings.

Figure 11 Accuracy of gender category-cooking robot associations

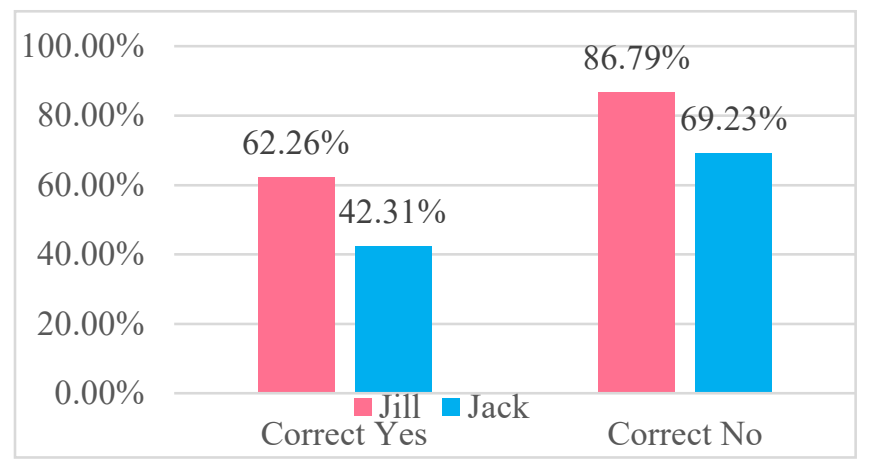

Reaction time is inversely related to the accessibility of a concept in a consumer's mind (Dempsey and Mitchell 2010; Fazio 1990; Sweldens et al. 2010). For both "yes" and "no" responses, reaction times of Jill condition were greater than Jack condition as in Experiment 1A, but the difference was not statistically significant. Figure 12 illustrates the findings. 
Figure 12 Accessibility of gender category-cooking robot associations

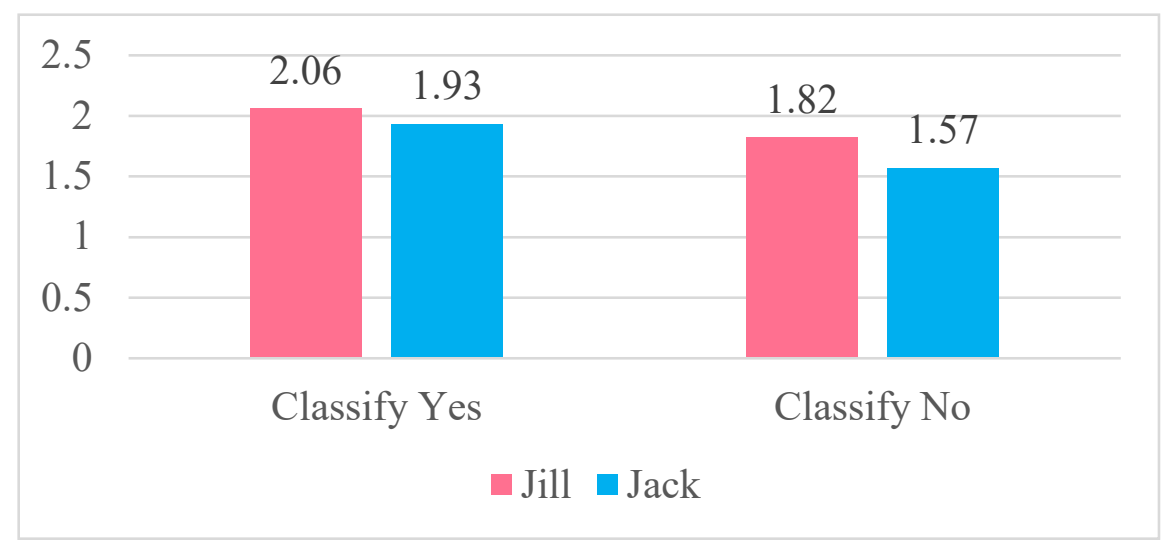

Gendering effects on consumer judgments

Analysis was conducted to investigate whether female-gendered cue will negatively affect downstream consumer judgments. In Jill condition, perceived quality in incrementally new technology $(\mathrm{M}=5.00)$ was higher than radically new technology $(\mathrm{M}=4.86)$. Conversely, in Jack condition, perceived quality was lower in incrementally new technology $(M=4.47)$ than radically new technology $(M=4.72)(p=.09)$. Other downstream consumer judgment variables did not show statistically significant differences between two conditions. Therefore, $\mathrm{H} 3$ was partially supported.

\section{Moderating role of technology newness}

Analysis was conducted to investigate whether gendered cues for really new technology will create a stronger effect on downstream consumer judgments than for incrementally new technology. The moderated mediation analysis (Model 14, Hayes 2013) has been used because this study is to examine the moderating effect of technology newness after inferred gendered role. Specifically, the analysis was conducted with gendered name (assigned 0 for Jill and 1 for Jack) as the independent 
variable, perceived female-gendered role as the mediator, technology newness as the moderator, and perceived quality (DV 1), perceived creativity (DV 2), consumer evaluation (DV 3), and persuasion effectiveness (DV 4) as the dependent variable, respectively; this analysis yielded significant mediation via perceived female-gendered role.

In Panel A, the female-gendered name, Jill (vs. Jack), increased perceived female-gendered role (Path A: B=-.75, S.E. $=.29, p<.01$ ), and the effect of perceived female-gendered role on perceived quality was moderated by technology newness. In radically new technology condition, perceived female-gendered role was negatively associated with perceived quality $(\mathrm{B}=-.28$, S.E. $=.12, p<.05)$, and, in incrementally new technology condition, perceived female-gendered role was negatively associated with perceived quality $(\mathrm{B}=-.17$, S.E. $=.09, p<.05)$. There was no direct effect of gendered name on perceived quality. In Panel B, the female-gendered name, Jill (vs. Jack), increased perceived female-gendered role (Path A: $\mathrm{B}=-.75$, S.E. $=.29, p<.01$ ), and the effect of perceived female-gendered role on perceived creativity was moderated by technology newness. In radically new technology condition, perceived female-gendered role was negatively associated with perceived creativity $(B=-.16$, S.E. $=.10, p<.05$ ), but in incrementally new technology condition, there was no statistically significant relationship between perceived female-gendered role and perceived creativity. There was no direct effect of gendered name on perceived creativity. In Panel C, the female-gendered name, Jill (vs. Jack), increased perceived female-gendered role (Path A: B=-.75, S.E. $=.29, p<.01$ ), and the effect of perceived female-gendered role on consumer evaluation was moderated by technology newness. 
In radically new technology condition, perceived female-gendered role was negatively associated with consumer evaluation ( $\mathrm{B}=-.20$, S.E. $=.20, p<.05)$, but in incrementally new technology condition, there was no statistically significant relationship between perceived female-gendered role and consumer evaluation. There was no direct effect of gendered name on consumer evaluation. In Panel D, the female-gendered name, Jill (vs. Jack), increased perceived female-gendered role (Path A: B=-.75, S.E. $=.29, p$ $<.01$ ), and the effect of perceived female-gendered role on persuasion effectiveness was moderated by technology newness. In radically new technology condition, perceived female-gendered role was negatively associated with persuasion effectiveness $(\mathrm{B}=-.35$, S.E. $=.16, p<.05)$, and, in incrementally new technology condition, perceived female-gendered role was negatively associated with persuasion effectiveness $(\mathrm{B}=-.20$, S.E. $=.14, p<.05)$. There was no direct effect of gendered name on persuasion effectiveness.

Overall, when perceived female-gendered role serves a mediating role, direct effects from the independent variable to dependent variables were eliminated. Perceived female-gendered role mediated the effect of gendered name on perceived quality and persuasion effectiveness, in both radically and incrementally new technology conditions. However, perceived female-gendered role mediated the effect of gendered name on perceived quality and consumer evaluation in the radically new condition but not in the incrementally new condition. Figure 13 illustrates the effects in more details. 


\section{Figure 13 Experiment 2A's moderated mediation analysis}

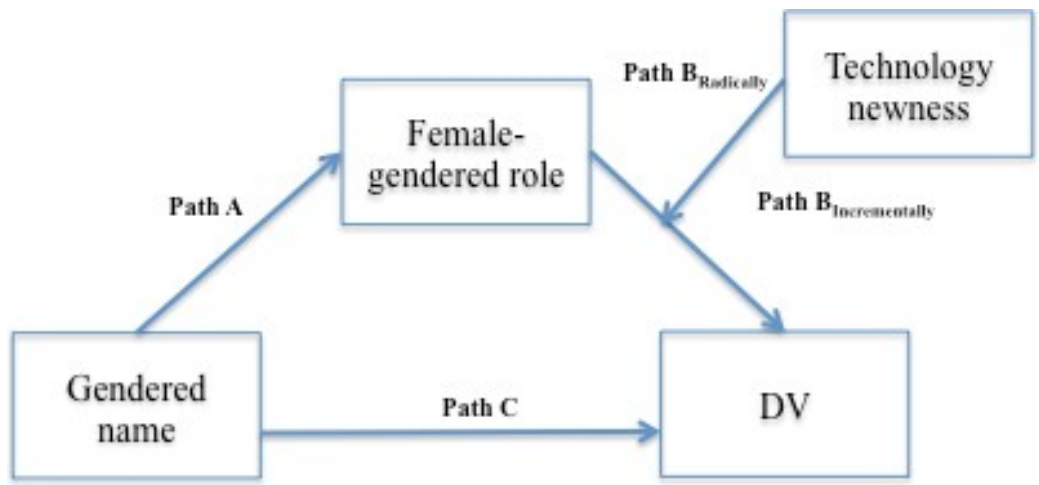

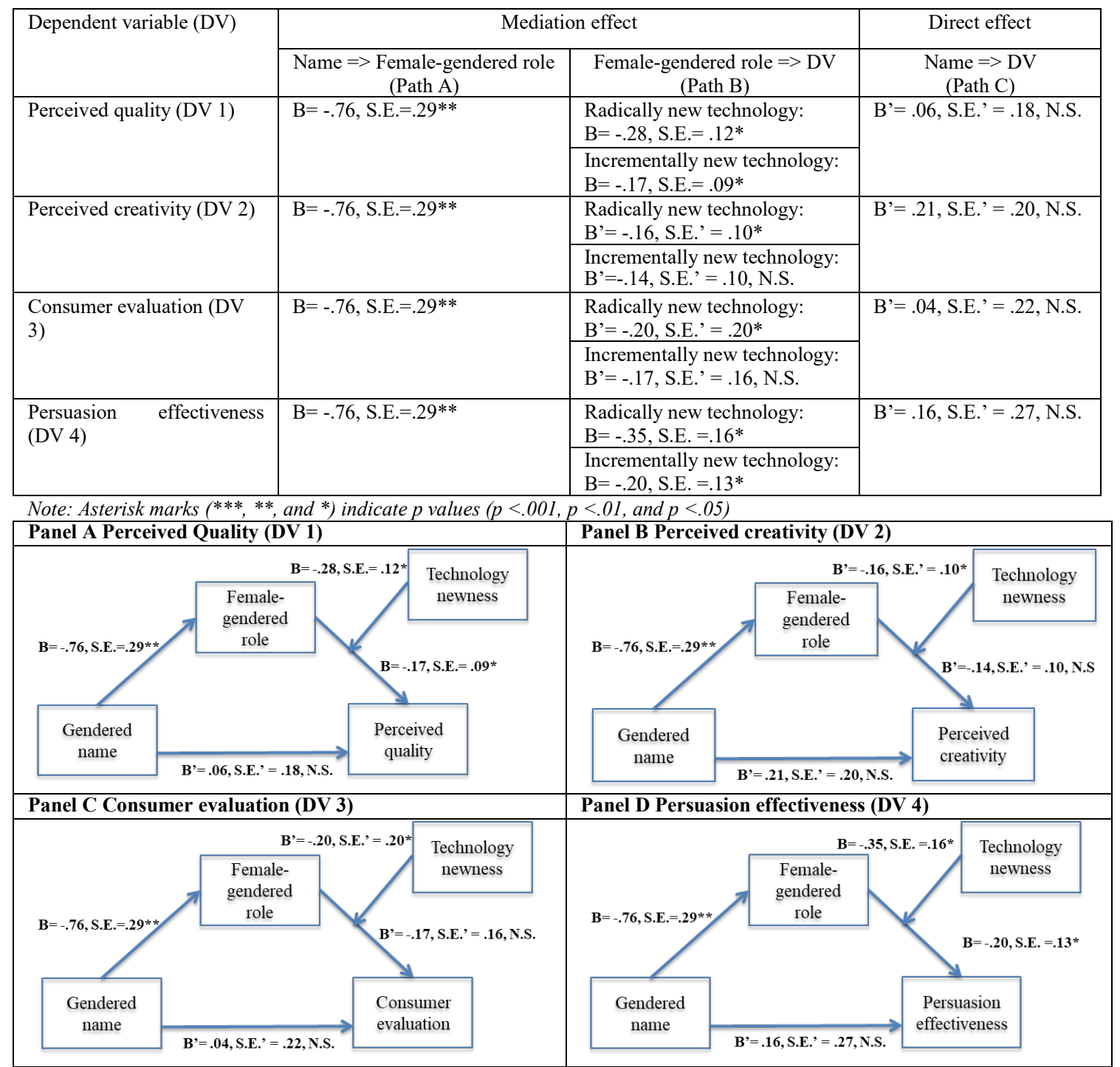


Ad-hoc Analysis

As Experiment 1A, male-gendered role manipulation was not successful due to male-bias in technology. To address this challenge, a regression analyses with malegendered role as independent variable were conducted to test the effects of perceived gendered roles on consumer judgments in the presence of moderating effect of technology newness. Perceived male-gendered role has significant, positive relationships with all downstream variables $(\mathrm{p}<.05)$. Technology newness may interact with unspecified variables.

\section{Discussion}

The results suggest that a gendered name increases a congruent gendered role and ease of processing the gender association. The effects of gendered cue on consumer judgments mediated by perceived female-gendered role were statistically significant. These results replicated Experiment 1A's finding that a female-gendered cue negatively affect consumer judgments mediated by female-gendered role. This is important because application of social cognition theory to consumer-technology relationship is generalizable to technological products in a broad range of spectrum from a gender-neutral non-living object to a gender-ambiguous living entity. Experiment 2A's findings are instructive, but it was not clearly explain the asymmetric effect of technology newness on the mediation model via female-gendered role. The next study will address this research question of focusing female-gendered cue with a different mode of operationalizing a gendered cue. 


\section{Experiment 2B}

\section{Main Study: Design and Procedure}

Although Experiment 2A found that technology newness did not affect either of perceived gendered role, this finding is conflicting from prior literature (Wajcman 1991; 2010) and needs to be examined empirically with a different operationalization. The goal of Experiment 2B was to extend Experiment 2A's finding by externally providing a female-gendered cue with a different gendered name (Ginny). The only difference between Experiment 2A and Experiment 2B is the type of gendered cue (i.e., male and female product cue for Experiment 2A, and only female product cue for Experiment 2B). A 2-cell (Radically vs. incrementally new technology) design was used with fifty-five participants recruited from Amazon Mechanical Turk. This design helps to test whether female gendered cue for really new technology will create a stronger effect on downstream consumer judgments than for incrementally new technology.Participants were randomly assigned to either one of the two cells. Pilot tested cooking machines in varied technology newness level were used as in Experiment 2A.

\section{Results}

The data for two-cell design was analyzed to examine hypotheses. First, participants $(n=55)$ passed manipulation checks on technology newness $\left(M_{\text {RadicallyNewTechnology }}=5.64\right.$, $\left.\mathrm{M}_{\text {IncrmentallyNewTechnology }}=4.85, p<.05\right)$ and recall of the product name successfully. 
Second, multi-item dependent measures and their reliabilities were qualified for further analysis: Perceived quality ( $\alpha=.91)$, perceived creativity $(\alpha=.81)$, persuasion effectiveness $(\alpha=.92)$, and consumer evaluation $(\alpha=.80)$ were measured (See the Appendices for details). Table 11 illustrated all means of measured used in the study.

Table 11 Means of Experiment 2B

\begin{tabular}{|l|c|c|c|c|c|c|}
\hline & $\begin{array}{l}\text { Female- } \\
\text { gendered role }\end{array}$ & $\begin{array}{l}\text { Male- } \\
\text { gendered role }\end{array}$ & $\begin{array}{l}\text { Perceived } \\
\text { quality }\end{array}$ & $\begin{array}{l}\text { Perceived } \\
\text { creativity }\end{array}$ & $\begin{array}{l}\text { Persuasion } \\
\text { effectiveness }\end{array}$ & $\begin{array}{c}\text { Consumer } \\
\text { evaluation }\end{array}$ \\
\hline $\begin{array}{l}\text { Radically new } \\
\text { technology } \\
\text { condition }\end{array}$ & 3.55 & 4.27 & 4.87 & 5.53 & 4.94 & 5.06 \\
\hline $\begin{array}{l}\text { Incrementally } \\
\text { new } \\
\begin{array}{l}\text { technology } \\
\text { condition }\end{array}\end{array}$ & 2.84 & 3.44 & 4.68 & 5.07 & 4.58 & 4.92 \\
\hline
\end{tabular}

\section{Cooking robot's perceived gendered role}

Analysis was conducted to examine whether a gendered product name cue increases perceived gendered role. Although a female product name cue was provided to both conditions of technology newness, male-gendered role, rather than female-gendered role was perceived. Male-gendered role was perceived higher in the radically new technology than incrementally new technology $\quad\left(M_{\text {RadicallyNewTechnology }}=4.26\right.$, $\mathrm{M}_{\text {IncrmentallyNewTechnology }}=3.44, p<.05$ ). This finding can be explained by a consumer's lay belief regarding technology as male-gendered role, despite the given femalegendered name cue.

\section{Gendering effects on consumer judgments}

Analysis was conducted to investigate whether female-gendered cue will negatively affect downstream consumer judgments. Perceived creativity was higher in radically 
new technology than incrementally new technology $\left(M_{\text {RadicallyNewTechnology }}=5.53\right.$, $\left.\mathrm{M}_{\text {IncrmentallyNewTechnology }}=5.07, p=.09\right)$. There were no statistically significant differences in other consumer judgment variables. Therefore, hypothesis 3 was partially supported.

\section{Moderating role of technology newness}

Analysis was conducted to investigate whether female-gendered cue for really new technology will create a stronger effect on downstream consumer judgments than for incrementally new technology. A mediation model (PROCESS model 4, Hayes 2013) with technology newness (assigned 0 for radically new technology and 1 for incrementally new technology) as the independent variable, perceived male-gendered role as the mediator, and perceived quality (DV 1), perceived creativity (DV 2), consumer evaluation (DV 3), and persuasion effectiveness (DV 4) as the dependent variable, respectively, yielded significant mediation via perceived male-gendered role.

In Panel A, radically (vs. incrementally) new technology increased perceived malegendered role (Path $\mathrm{A}: \mathrm{B}=-.82$, S.E. $=.37, p<.05$ ), and perceived male-gendered role was negatively associated with perceived quality $(\mathrm{B}=-.22$, S.E. $=.10, p<.05)$. The direct effect of technology newness on perceived quality was not statistically significant. In Panel B, radically (vs. incrementally) new technology increased perceived male-gendered role (Path $\mathrm{A}: \mathrm{B}=-.82, \mathrm{~S} . \mathrm{E} .=.37, p<.05$ ), and perceived malegendered role was negatively associated with perceived creativity $(B=-.22$, S.E. $=.10$, $p<.05)$. The direct effect of technology newness on perceived crativity was not statistically significant. In Panel C, radically (vs. incrementally) new technology 
increased perceived male-gendered role (Path A: $\mathrm{B}=-.82$, S.E. $=.37, p<.05$ ), and perceived male-gendered role was negatively associated with consumer evaluation $(\mathrm{B}=-.29$, S.E. $=.11, p<.01)$. The direct effect of technology newness on consumer evaluation was not statistically significant. In Panel D, radically (vs. incrementally) new technology increased perceived male-gendered role (Path $\mathrm{A}: \mathrm{B}=-.82$, S.E. $=.37, p$ $<.05$ ), and perceived male-gendered role was negatively associated with persuasion effectiveness $(\mathrm{B}=-.51, \mathrm{~S} . \mathrm{E} .=.31, p<.001)$. The direct effect of technology newness on persuasion effectiveness was not statistically significant.

Overall, when perceived male-gendered role serves a mediating role, direct effects from the independent variable to dependent variables were eliminated. Figure 14 illustrates the effects in more detail.

Figure 14 Experiment 2B's mediation analysis

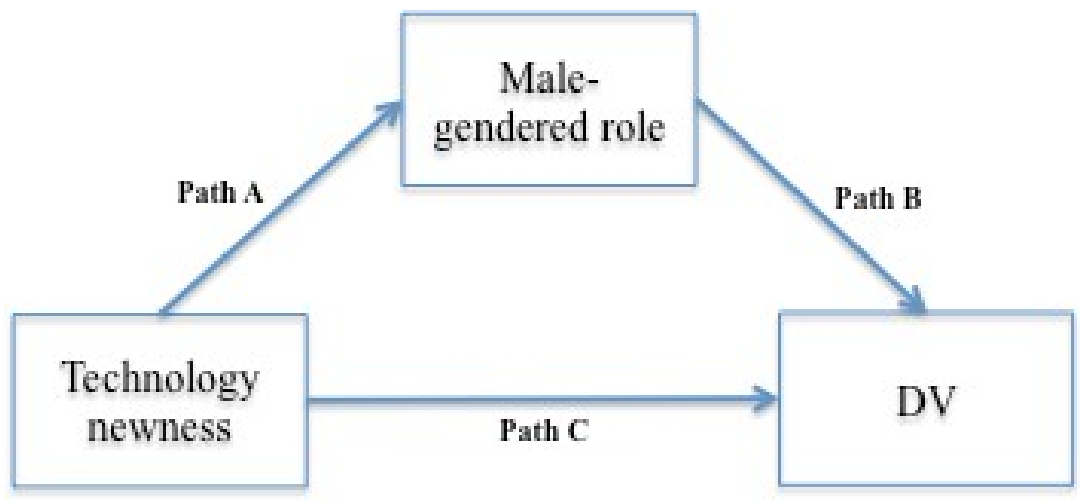

\begin{tabular}{|c|c|c|c|}
\hline \multirow[t]{2}{*}{ Dependent variable (DV) } & \multicolumn{2}{|c|}{ Mediation effect } & Direct effect \\
\hline & $\begin{array}{c}\text { Technology newness }=> \\
\text { Male-gendered role } \\
\text { (Path A) }\end{array}$ & $\begin{array}{c}\text { Male-gendered role }=>\text { DV } \\
\text { (Path B) }\end{array}$ & $\begin{array}{c}\text { Technology newness }=>\text { DV } \\
\text { (Path C) }\end{array}$ \\
\hline Perceived quality (DV 1) & $\mathrm{B}=-.82$, S.E. $=.37 *$ & $\mathrm{~B}=-.22$, S.E. $=.10^{*}$ & $\mathrm{~B}=.29$, S.E. $=.10$, N.S. \\
\hline Perceived creativity (DV 2) & $\mathrm{B}=-.82$, S.E. $=.37^{*}$ & $\mathrm{~B}=-.22$, S.E. $=.10^{*}$ & $\mathrm{~B}=-.28$, S.E. $=.27$, N.S. \\
\hline $\begin{array}{l}\text { Consumer evaluation (DV } \\
\text { 3) }\end{array}$ & $\mathrm{B}=-.82$, S.E. $=.37^{*}$ & $\mathrm{~B}=-.29$, S.E. $=.11 * *$ & $\mathrm{~B}=.10$, S.E. $=.30$, N.S. \\
\hline $\begin{array}{l}\text { Persuasion effectiveness } \\
\text { (DV 4) }\end{array}$ & $\mathrm{B}=-.82$, S.E. $=.37^{*}$ & $\mathrm{~B}=-.51, \mathrm{~S} . \mathrm{E} .=.13^{* * *}$ & $\mathrm{~B}=.06$, S.E. $=.37$, N.S. \\
\hline \multicolumn{4}{|c|}{ Note: Asterisk marks $(* * *, * *$, and $*)$ indicate $p$ values $(p<.001, p<.01$, and $p<.05)$} \\
\hline
\end{tabular}




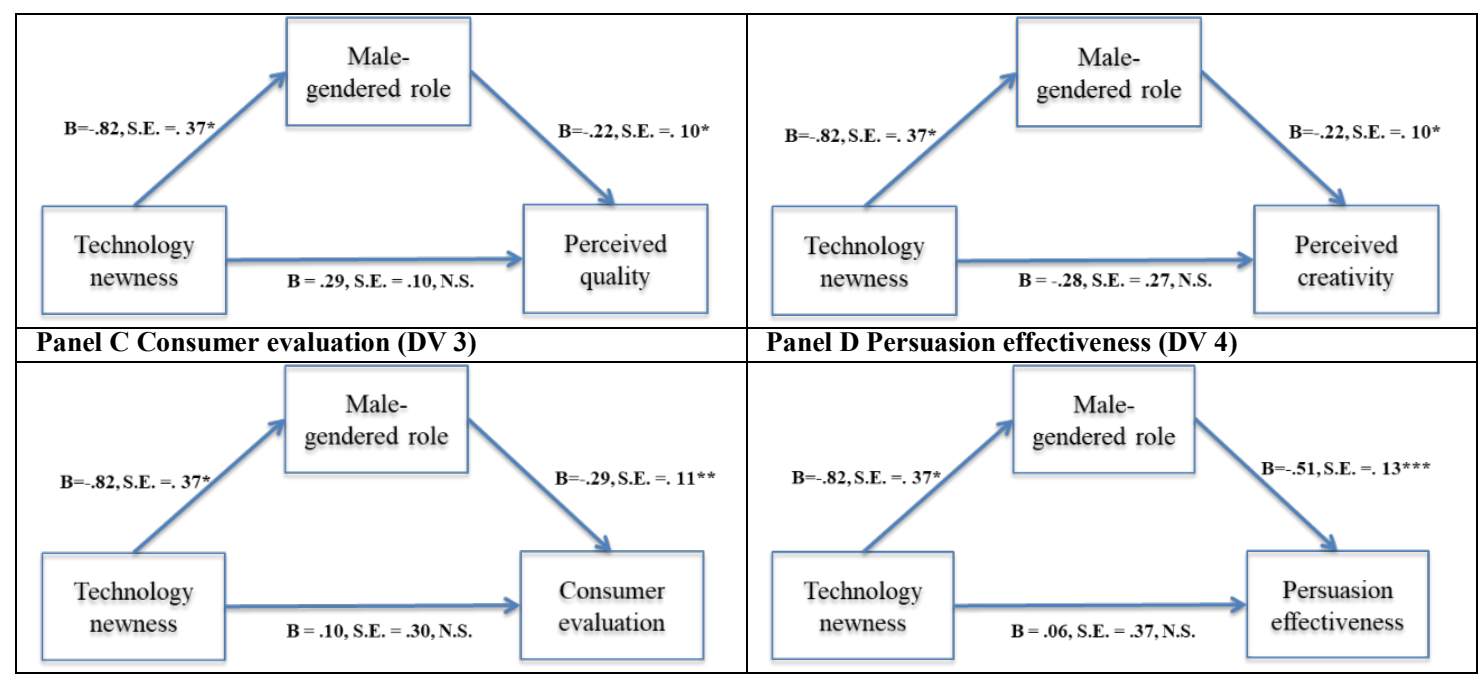

Ad-hoc Analysis

In addition to hypothesized mediating effect of male-gendered role, regression analyses were conducted to test the direct effects of perceived gendered roles on consumer judgments. Table 12 demonstrates that perceived male-gendered role is a statistically significant predictor for consumer judgments.

Table 12 Effects of perceived male-gendered role on consumer judgments

\begin{tabular}{|l|l|}
\hline DV & Coefficient \\
\hline Perceived creativity & $0.40^{* * *}$ \\
\hline Perceived Quality & $0.30^{*}$ \\
\hline Persuasion Effectiveness & $0.47^{* * *}$ \\
\hline Consumer Evaluation & $0.37^{* *}$ \\
\hline
\end{tabular}

\section{Discussion}

This study was designed to help test whether female gendered cue for really new technology will create a stronger effect on downstream consumer judgments than for incrementally new technology. The only difference between Experiment 2A and Experiment 2B was the type of gendered cue (i.e., male and female product cue for 
Experiment 2A, and only female product cue for Experiment 2B). This study found that male-gendered role, rather than female-gendered role was perceived, showing a consumer's lay belief of technology as male-gendered role, despite of given femalegendered name cue. Therefore, Experiment $2 \mathrm{~A}$ and $2 \mathrm{~B}$ provide evidence on the importance of gendered role on consumer judgments. The next study will address this research question by modifying stereo-typicality of gendered role to disrupt gendering effects.

\section{Experiment 3}

The goal of Experiment 3 is to disrupt gendering effects. Previous studies found that a gendered name affect consumer judgments mediated by perceived gendered roles. In this study, a counter-stereotypical role to combat the gendering process is used to examine the difference in perceived gendered roles and consumer judgments in contrast to a stereotypical gendered role.

\section{Main Study: Design and Procedure}

A 2 (Gendered cue: Jill vs. Jack) x 2 (Stereo-typicality of gendered role: Stereotypical vs. counter stereotypical) between-subjects design was used with one hundred thirty-three participants recruited from Amazon Mechanical Turk to test whether provision of counter-stereotypical gendered role attenuates gendering effects.

Participants were randomly assigned to one of the four cells. Gendered names were used as manipulation of gendering. A mowing machine was selected because it was seen as most gender-ambiguous like a cooking machine in the gender-implicit pet 
name task, and least female-gendered in the gender-explicit categorization task. In addition, a mowing machine is not as popular at home like a cooking machine. Therefore, selection of mowing machine gave an opportunity to generalize the empirical findings. Gendered name (Jill vs. Jack) was used as in previous studies. Stereo-typicality of gendered role was manipulated by statements to describe the performance of the mowing machine: either Love and Care or Power and Dependency. After reading the product message, as in previous studies, participants were asked to respond to the relevance of the individually displayed word (e.g., woman or man in a counterbalanced order) regarding the lawnmower, in a yes/no format and assess measures including gendered roles, consumer judgments, and ancillary variables.

\section{Results}

The data for two-cell design was analyzed to examine hypotheses (H2, H5 and H6). First, a manipulation check on the gendered cue was conducted by asking participant to recall the manipulated gendered cue and select among two names of products, the female name (Jill) and the male name (Jack). A manipulation check for typicality of gendered role was conducted by asking participant to recall the description of gendered role: either Love and Care or Power and Dependency. Participants $(\mathrm{n}=103)$ who correctly answer manipulation checks were used for further analysis. Second, multi-item dependent measures and their reliabilities were qualified for further analysis: Perceived quality $(\alpha=.89)$, perceived creativity $(\alpha=.87)$, persuasion effectiveness $(\alpha=.89)$, and consumer evaluation $(\alpha=.80)$. Table 13 illustrates all means of measures used in the study. 
Table 13 Means of Experiment 3

\begin{tabular}{|l|c|c|c|c|c|c|}
\hline & $\begin{array}{l}\text { Female- } \\
\text { gendered role }\end{array}$ & $\begin{array}{l}\text { Male- } \\
\text { gendered role }\end{array}$ & $\begin{array}{l}\text { Perceived } \\
\text { quality }\end{array}$ & $\begin{array}{l}\text { Perceived } \\
\text { creativity }\end{array}$ & $\begin{array}{l}\text { Persuasion } \\
\text { effectiveness }\end{array}$ & $\begin{array}{l}\text { Consumer } \\
\text { evaluation }\end{array}$ \\
\hline $\begin{array}{l}\text { Jill x stereotypical gendered } \\
\text { role }\end{array}$ & 3.42 & 4.19 & 4.70 & 5.44 & 4.63 & 5.25 \\
\hline $\begin{array}{l}\text { Jill x counter-stereotypical } \\
\text { gendered role }\end{array}$ & 3.15 & 3.77 & 4.99 & 5.36 & 4.98 & 5.18 \\
\hline $\begin{array}{l}\text { Jack x stereotypical gendered } \\
\text { role }\end{array}$ & 2.99 & 4.04 & 5.29 & 5.69 & 5.22 & 5.62 \\
\hline $\begin{array}{l}\text { Jack x counter-stereotypical } \\
\text { gendered role }\end{array}$ & 2.80 & 4.15 & 4.92 & 5.18 & 4.59 & 5.06 \\
\hline
\end{tabular}

Ease of processing gender category-automower associations

Analysis was conducted to investigate the effect of gendering on ease of processing the gender category-technological product association drives gendering Measured data (e.g., yes or no format) on participants' agreement with an association between a specific gender category and the technological product was analyzed. For example, "yes" responses to the Jill-Woman and Jack-Man pairs indicate correct categorization, "no" responses to the Jill-Man and Jack-Woman pairs indicate incorrect categorization (Lee and Labroo 2004; Schwartz 2004). Analysis revealed that counter-stereotypical cue may affect gendering, although the difference is not statistically significant. Figure 15 illustrates the findings.

Figure 15 Accuracy of gender category-automower associations

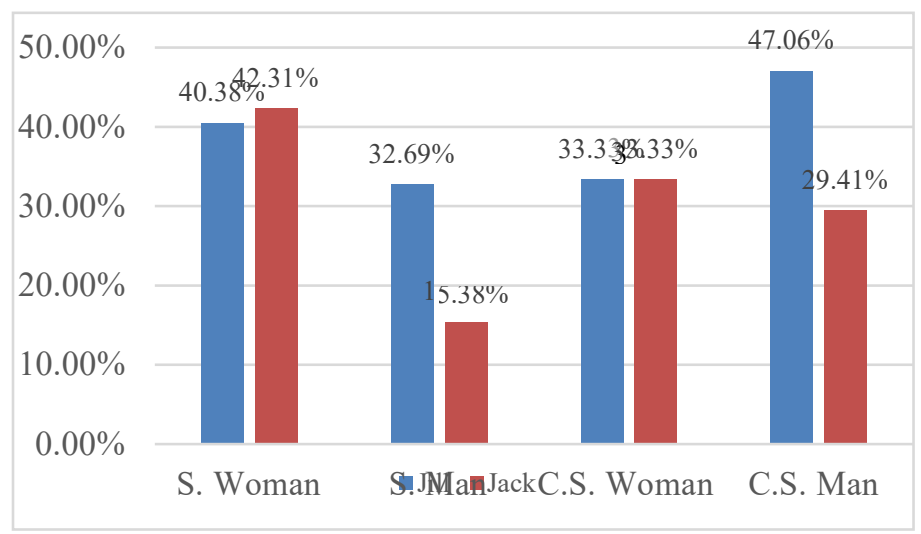


Reaction time is inversely related to the accessibility of a concept in a consumer's mind (Dempsey and Mitchell 2010; Fazio 1990; Sweldens et al. 2010). For correct responses in Jill and Jack conditions, stereotypical cue was processed faster than counter-stereotypical cue $(p<.05)$. Conversely, for incorrect responses in Jill and Jack conditions, this pattern disappeared (N.S.). Figure 16 illustrates the findings.

Figure 16 Accessibility of gender category-automower associations

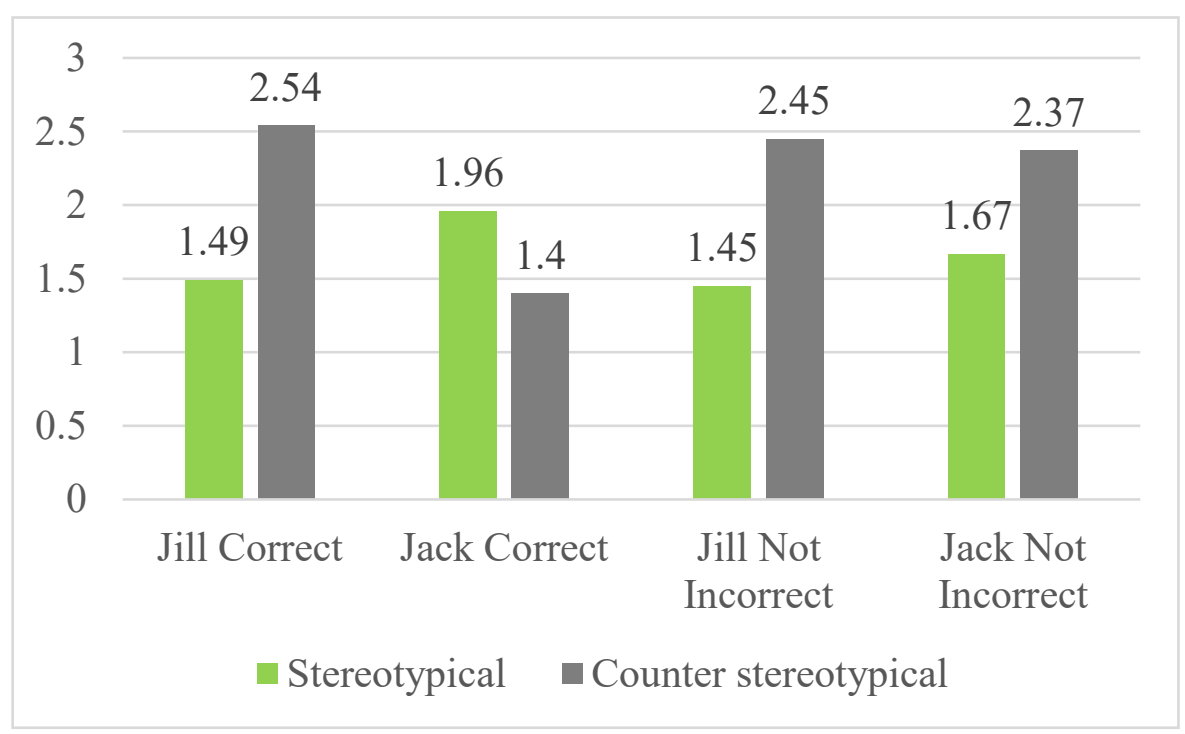

Gendering effects on consumer judgments

Analysis was conducted to investigate whether female-gendered cue will negatively affect downstream consumer judgments. For persuasion effectiveness, counterstereotypical Jill $(\mathrm{M}=4.98)$ was higher than stereotypical Jill $(\mathrm{M}=4.63)$, but stereotypical Jack was higher $(\mathrm{M}=5.61)$ than stereotypical Jack $(\mathrm{M}=5.15)(p<.06)$. For perceived quality, counter-stereotypical Jill $(M=4.99)$ was higher than stereotypical Jill $(\mathrm{M}=4.68)$, but stereotypical Jack $(\mathrm{M}=5.29)$ was higher than stereotypical Jack 
$(\mathrm{M}=4.92)(p<.10)$. There were no statistically significant differences in perceived creativity and consumer evaluation. Therefore, hypothesis 3 was partially supported.

Moderating effects of counter-stereotypical cue on perceived gendered roles

Analysis was conducted to examine whether provision of gender stereotypical cue and counter-stereotypical cue changes perceived gendered role. Analysis revealed that counter-stereotypical cue may affect gendering, but the difference was not statistically significant. Figure 17 illustrates this finding.

Figure 17 Perceived Gendered Role

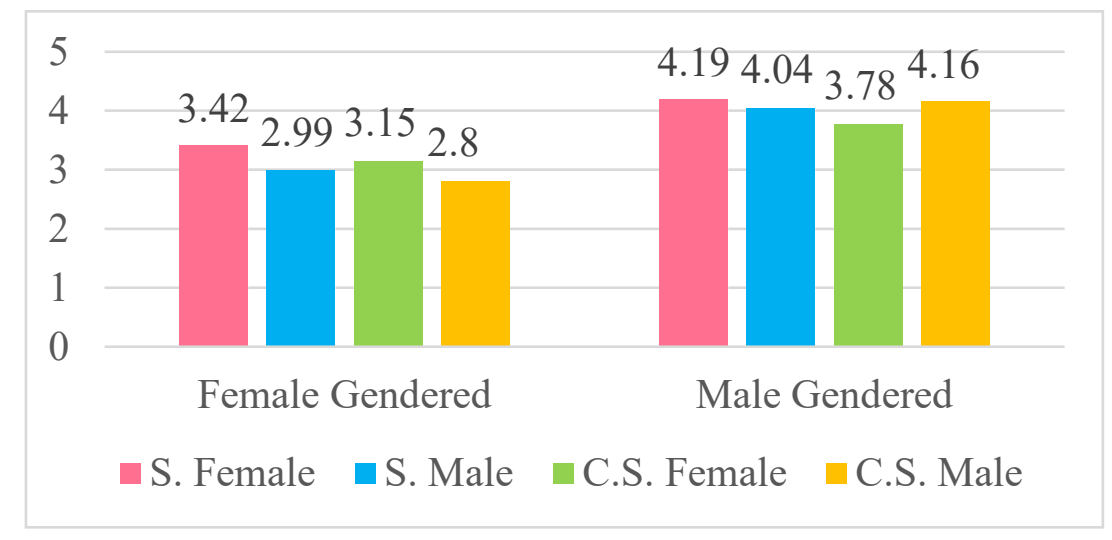

Moderating effects of counter-stereotypical cue on consumer judgments

Moderating effects of counter-stereotypical cue are statistically significant for perceived quality and persuasive effectiveness. Analysis on perceived quality as dependent variable revealed that counter-stereotypical cues may hurt perceptions of quality unless male gendering is strong. Figure 18 illustrates this finding. 
Figure 18 Effect of counter-stereotypical cue on perceived quality

\begin{tabular}{|l|l|l|l|}
\hline Panel 1 Mediated moderation model & Panel 2 Means of perceived quality \\
\hline & & \\
\hline
\end{tabular}

Analysis on persuasive effectiveness as dependent variable revealed that male gendering overcomes potential dampening effects of counter-stereotypical cues on persuasion effectiveness. Figure 19 illustrates this finding.

Figure 19 Effect of counter-stereotypical cue on persuasive effectiveness

\begin{tabular}{|l|l|l|}
\hline Panel 1 Mediated moderation model & Panel 2 Means of persuasive effectiveness \\
\hline & & \\
\hline
\end{tabular}

Post-hoc Analysis

In addition to hypothesized moderated mediation effects, regression analyses on consumer judgments were conducted with three independent variables (perceived male-gendered role, perceived female-gendered role, and stereo-typicality) and covariates controlled for involvement, product familiarity, and respondent gender. 
This tested direct effects of gendering and stereo-typicality of cues. The results revealed that perceived gendered roles are predictors for consumer judgments, which indicates the stickiness of male-bias in technology. Table 14 illustrates the findings.

Table 14 Direct effects of gendering and stereo-typicality of cues

\begin{tabular}{|l|l|l|l|l|l|}
\hline DV & R2 & $\begin{array}{l}\text { Perceived } \\
\text { male- } \\
\text { gendered } \\
\text { role }\end{array}$ & $\begin{array}{l}\text { Perceived } \\
\text { female- } \\
\text { gendered } \\
\text { role }\end{array}$ & $\begin{array}{l}\text { Stereo- } \\
\text { typicality }\end{array}$ & $\begin{array}{l}\text { Sig. } \\
\text { Covariates }\end{array}$ \\
\hline Perceived creativity & 0.21 & $.26^{*}$ & -0.05 & -0.16 & Involvement** \\
\hline Perceived Quality & 0.35 & $.37^{* *}$ & 0.06 & -0.00 & Involvement** \\
\hline Persuasion Effectiveness & 0.35 & $.44^{* * *}$ & -0.16 & -0.07 & Involvement** \\
\hline Consumer Evaluation & 0.28 & $.31^{* *}$ & -0.01 & -0.16 & $\begin{array}{l}\text { Involvement** } \\
\text { Gender* }\end{array}$ \\
\hline
\end{tabular}

\section{Discussion}

Experiment 3 used a counter-stereotypical role to combat the gendering process and examine the difference in perceived gendered roles and consumer judgments in contrast to a stereotypical gendered role. The study found that presence of a counter-stereotypical cue made gendered roles less relevant than presence of a stereotypical cue. In addition, this study provided evidence that presence of a counterstereotypical role will attenuate gendering effects by reducing the mediating effect of female and male gendered roles. These empirical insights can be helpful for marketing managers, consumers, and policy makers. The next chapter will discuss it in more details. 


\section{CHAPTER 5: DISCUSSION AND CONCLUSION}

\section{Summary of Research}

Exploratory studies revealed that assignment of gender to a product occurs in everyday domestic life. First, examining participants' free associations allowed identifying how consumers interactions with smart technological products can translate into perceived gendered roles. Capacities of technological products were perceived as gendered (e.g., female-gendered "care" role and male-gendered "care" role). In addition to intrinsic product cues (e.g., color, shape), extrinsic product cues (e.g., user) seem to serve significant roles in gendering. This finding was robust quantitatively and qualitatively because the results were from a diverse set of participants and domestic technological products. Second, the pet name exercise was meaningful to highlight the singular relationship between consumer and technology. Interestingly, a machine with dynamic movement (e.g., auto lawnmower) and a machine with human-resembling body (e.g., cooking robot) received genderambiguous names rather than gender-specific name and were perceived as living entity over non-living object. These empirical insights may be refined and extended by using lab experiments on the strategical marketing effectiveness of gendering.

In addition to two exploratory studies (free associations and pet names), the five lab experiments were conducted to assess female-gendered role, male-gendered role, and downstream consumer judgments including perceived quality, perceived creativity, persuasion effectiveness, and consumer evaluation. Also, they examined the

process and effect of gendering by identifying mediating and moderating variables and 
intervening its process and effect. The five lab experiments empirically tested the Stereotype Model (H1, H2, H3, H4a, and H4b) and the Disruption Model (H5 and H6). The Stereotype Model addresses when gendering occurs and to examine the process and examines outcomes of gendering. The Disruption Model (H5 and H6) relates to the effect of disrupting gender stereotypes by externally providing an ambiguous counter-stereotypical role.

Table 15 summarizes results of the five lab experiments. The five lab experiments were designed to test $\mathrm{H} 1, \mathrm{H} 2, \mathrm{H} 3, \mathrm{H} 4 \mathrm{a}, \mathrm{H} 4 \mathrm{~b}, \mathrm{H} 5$, and $\mathrm{H} 6 . \mathrm{H} 1$ and $\mathrm{H} 2$ attempted to examine the intersection between consumer culture theory and attitude theory. Particularly, questions of whether consumers perceive domestic technology consistent with theories on male-biased technology due to socio-cultural industrialization culture. $\mathrm{H} 3$ attempted to explore the intersection of gendered role theory and consumers' product judgments. We received support for a perceived gendered role to act as a product cue to signal quality. $\mathrm{H} 4 \mathrm{a}$ and $\mathrm{H} 4 \mathrm{~b}$ attempted to investigate the moderating factor of gendering effect by introducing theories regarding perceived technology newness and dual attitude theory of technology adoption. H5 and $\mathrm{H} 6$ attempted to disrupt gendering effect by introducing a counter-stereotypical role based on literature on social marketing and stereotypes. Many hypotheses were partially supported or not supported because it was very difficult technology femalegendered because of male-dominant socio-historical associations with technology. Also, in post-hoc analyses, perceived male-gendered role was positively related with consumer judgments, which gives another empirical evidence of male-dominance in technology. Throughout the studies, agreement on gender categorization and response 
time measure attempted to measure implicit biases, but coherence of results seem to be improved by using more precise software (e.g., implicit association test software) rather than currently used Timer feature of Qualtrics.

Table 15 Summaries of Study Results

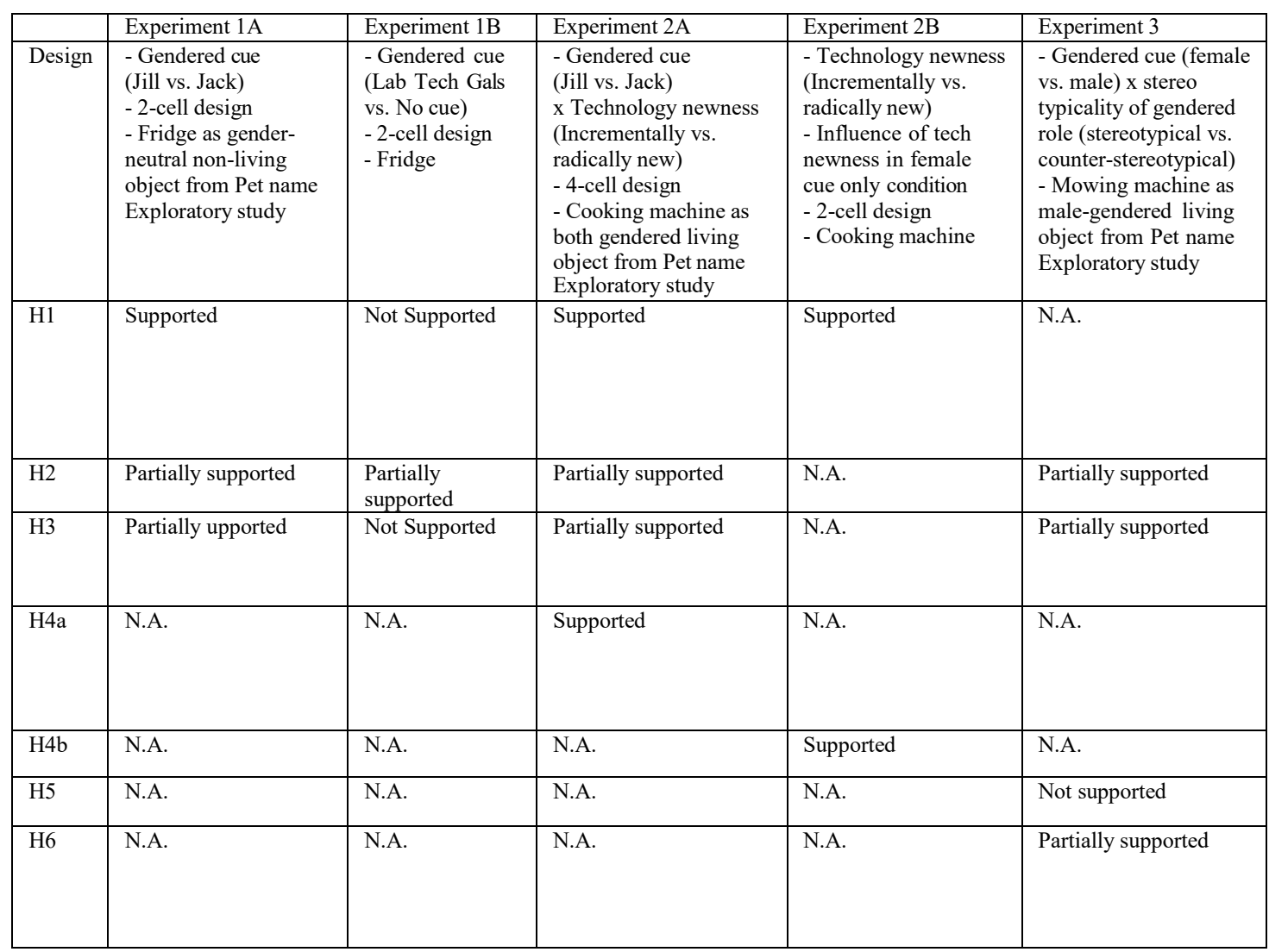

Overall, this paper has contributed to advance the underlying process and effects of gendering and develop an empirically grounded intervention for gendering process and effects. Specifically, this paper discovered that inferred gendered role is the mediator of gendering effects on consumer judgments and technology newness and ambiguity of gendered cue are moderators of gendering effects. Identifying a mediator and a moderator is helpful both theoretically and managerially (MacKinnon and Luecken 2008). First, a mediator is an intermediate variable in the causal sequence 
from the independent variable to the dependent variable. This is useful for implementing an intervention strategy to break the causal link. Second, a moderator allows us to understand other factors, which might interact with the independent variable, increasing or decreasing the effect of independent variable on the dependent variable (MacKinnon and Luecken 2008).

\section{Limitations and Future Research}

This paper attempted to increase generalizability of findings by using qualitative and quantitative methods and various technologies at home, it is not without limitation. The context of this research was a networked smart home, living space (Venkatesh et al. 2003). Like interpersonal relationships, smart domestic technology allows connecting machines to machines, humans to humans, or machines to humans across gendered realms of societies (e.g., interior of home for women and exterior of home for men). It is a research-worthy question of how smart technology shapes connections between other gendered technological products and consumers.

From a macro consumer culture standpoint, future research may recruit participants grounded in diverse cultural and linguistic practices to examine gendering effects. For example, cross-cultural studies may enhance gendering phenomena because Scandinavian countries' gendering effects would differ from U.S. according to OECD's Time Use Study. From a linguistic angle, unlike gender-neutral English or Korean, some language entails gendered nouns to refer household technology (e.g., "aspirateur" - masculine noun in French, which means vacuum in English, "tondeuse"

- feminine noun in French, which means mower in English). Mother tongue 
intervention effects on gendering effects are worthy of being empirically examined to understand gendering as language-grounded culture in addition to cultural practice.

From a micro consumer culture perspective, future research can benefit from infusing a more realistic view to marketplace. For example, the marketplace entails competition between brands associated with gendered cue. For example, a brand called "Shark" came into the market to fight against "Roomba". The follower brand Shark entails masculinity because the name highlights aggressiveness and competency of action, but the pioneer brand Roomba signals felinity because it seems to associated with gentleness and softness of samba dance. Future research may empirically investigate the effect of complementary gendered cue as brand name on consumer judgments in a competitive market. In addition, drawing upon insights from the prior research on Nielsen's 100 best-selling brands in consumer fast-moving consumer goods (Triantos et al. 2016) and brands' humanlike characteristics, future research may examine whether product category (e.g., with/without motion), usage situation (e.g., hedonic/utilitarian, public/private), modality of gendered cue (e.g., visual/verbal/audio cue), and target audience (e.g., for elderly, kids) may moderate gendering effects.

\section{Implications}

Overall, this paper has accomplished the goal to increase our limited understanding of gendering and its effect on consumer judgments. This is important for both theoretical and practical reasons. This research found that gendering can be cultural phenomena in everyday life (e.g., pet name exercise, qualitative interview, 
multi-dimensional scaling), and assigning gendered name to a technological companion can make technology gendered, which makes inferred gendered role by applying social category membership-based attribution and social cognition. This paper empirically examined the effect of gendering effects on downstream consumer judgments, which may help our understanding of the role of lay belief in perceived quality literature (e.g., sustainability liability, unhealthy is tasty belief). Gendered role as a mediator to consumers' perceived quality is insightful because it opens the door to understand how consumers mechanized and automated technology to help human roles in a private space, in addition to the public place. In addition, empirical examination of technology newness to moderate gendering effect helps advance our understanding of diffusion of innovation. Lastly, this research found that provision of counter-stereotypical role could be a way to attenuate gendering effects. Practically, a strategic preference on not using female-gendered technology for radically new technology can be a tactic, but an externally provided counter-stereotypical gendered cue is to address economic ramification of gendering effects especially when perceived female-gendered role is negatively correlated with consumer judgments. This paper attempted to address societal challenges by providing a counterstereotypical cue to attenuate gendering effects. This empirical insights help address unintended consequences of traditional marketing techniques and unconsciously culturally learned biases for more impactful policy making and intervention.

Theoretically, this research attempts to identify the underlying mechanism of gender bias and its unconscious and automatic elicitation. It also attempts through an intervention strategy (female name such as Jill or female scientists such as Lab Tech 
Gals) to disrupt biased judgments. These empirical insights will be very helpful not only for managers to determine the use and consequences of marketing technology products with gendered cues, but also for social marketing practitioners interested in societal well-being and countering stereotypical ideas.

For marketer, the use of gendered cue is a matter of strategic decision making to influence consumer choices. If a congruent gendered role is inferred from a gendered cue, marketers infuse various modalities of gendered cue highlight different features of technology to signal innovativeness. For example, the use of female gendered cue may attenuate perceived infringement of privacy due to inferred compassion, kindness, and gentleness, but the use of male gendered cue may emphasize the long-lasting robustness of technology against frequent breakdowns due to inferred strength, aggressiveness, and self-reliance.

For policy makers, insights from this paper can address the ongoing challenge on how to empower women's participation and advancement in technology marketing (Global Entrepreneurship Monitor's Women's Entrepreneurship 2016/2017 Report). Researchers have examined disrupt lay beliefs and nudge behavior changes for social good and designed specific strategies to counter stereotypes to influence consumers for greater societal well-being (Thaler and Sunstein 1999). To illustrate, in the context of food, health consciousness was introduced to address the lay belief of "unhealthy is tasty" (Mai and Hoffmann 2015). For sustainable and ethical products, explicit information (durability attribute, quality pledge, and credible media endorsement) has been provided to address sustainability liability (Aaker et al. 2010; Newman et al.2014). Therefore, policy makers may create the environment where gendering 
effects may be reduced by providing a counter-stereotypical gendered cue from various modalities to influence consumers and venture investors to empowering of women innovators and entrepreneurs. 


\section{APPENDICES}

Appendix 1 Interview Protocol

Appendix 2 Sample product messages used in lab experiments

Appendix 3 Scales 


\section{Appendix 1 Interview Protocol}

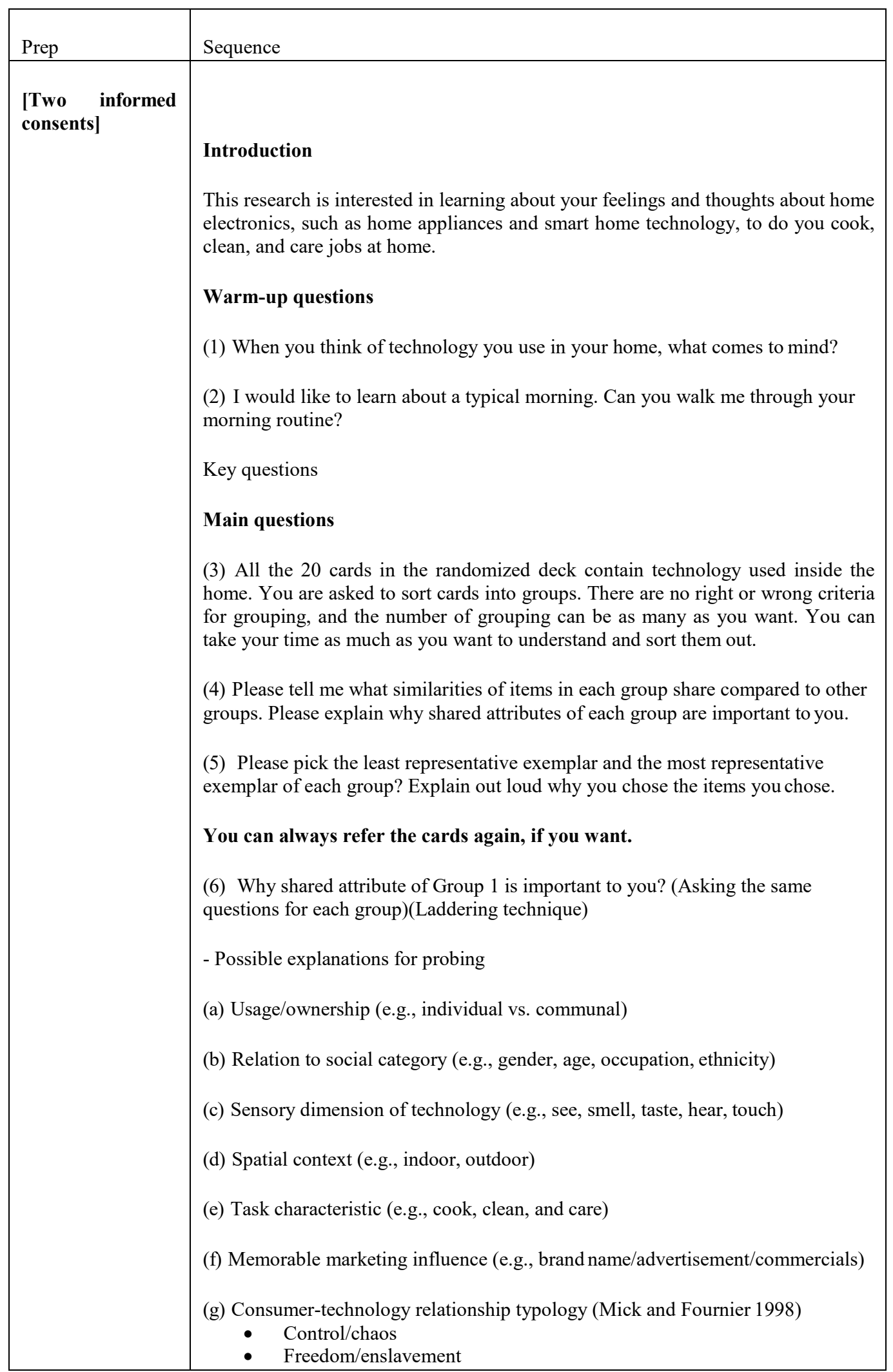




\begin{tabular}{|c|c|}
\hline $\begin{array}{l}\text { [Group } \\
\text { questionnaire] } \\
\text { [Self } \\
\text { questionnaire] }\end{array}$ & $\begin{array}{l}- \text { New/obsolete } \\
-\quad \text { Eompetence/incompetence } \\
-\quad \text { Fulfill/create needs } \\
-\quad \text { Assimilation/isolation } \\
\text { - Engaging/disengaging } \\
\text { (7) Please rate your evaluation for the least representative exemplar and the most } \\
\text { representative exemplar of each group. } \\
\text { (8) Please rate the following scales about yourself. } \\
\text { Closing } \\
\text { (9) Researcher's questions regarding group and self questionnaire } \\
\text { (10) Informants' comments }\end{array}$ \\
\hline
\end{tabular}


Appendix 2 Sample product messages used in lab experiments

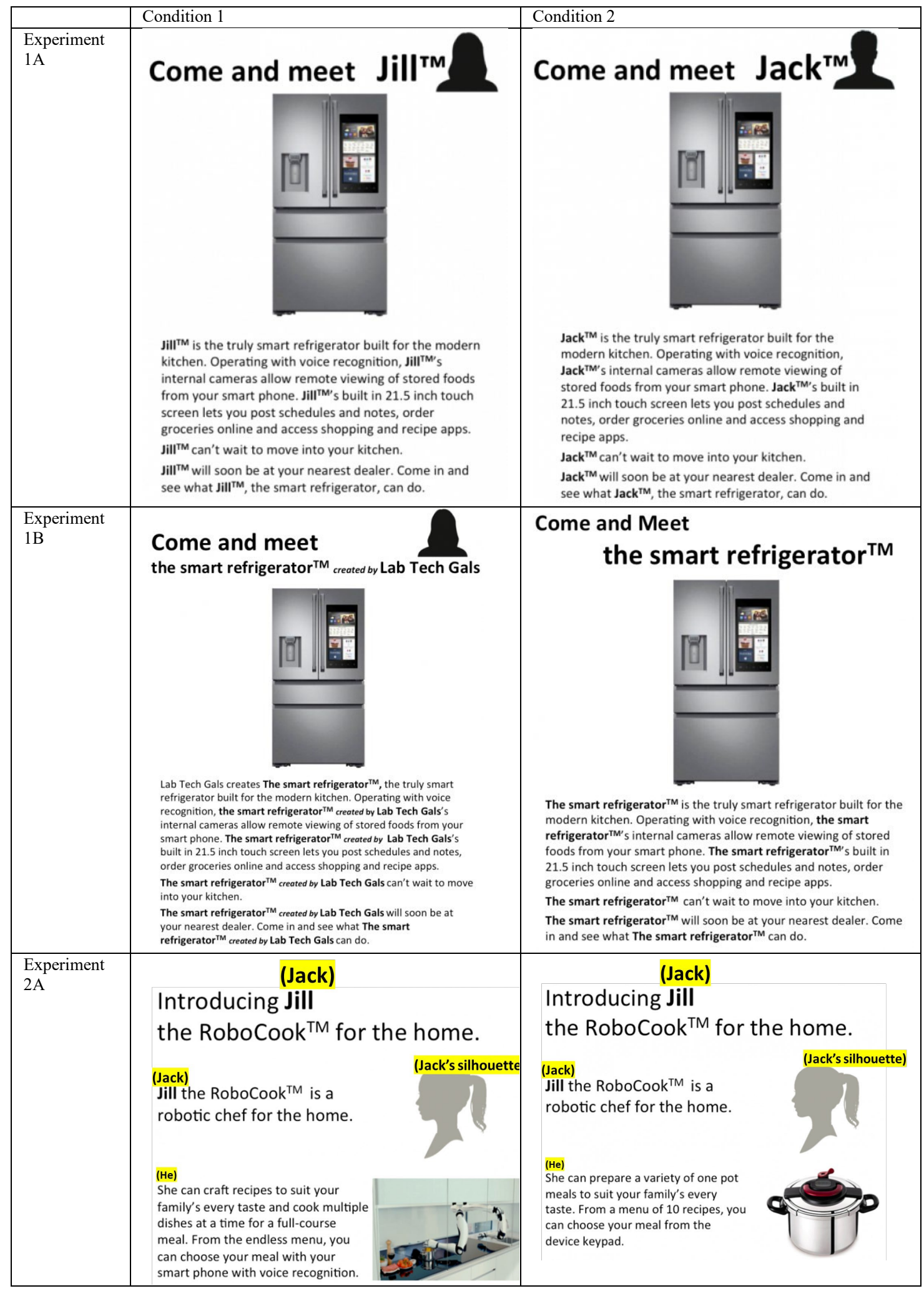




\begin{tabular}{|c|c|c|}
\hline Experiment 3 & $\begin{array}{l}\text { Introducing Jill } \\
\text { the RoboMower } \\
\text { Jill the RoboMower for the home. } \\
\text { the LOVE AND CARE to cut grass BEAUTIFULLY. } \\
\text { She is a robotic lawnmower. } \\
\text { She can cut grass and avoid } \\
\text { obstacles. } \\
\text { She has app connectivity with } \\
\text { GPS tracking, so she can be } \\
\text { remotely stopped or started if } \\
\text { needed. }\end{array}$ & 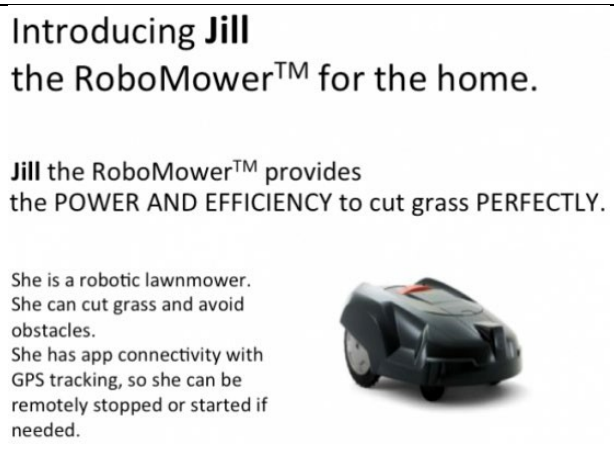 \\
\hline
\end{tabular}




\section{Appendix 3 Scales}

\begin{tabular}{|c|c|}
\hline & Items (7-point Likert scale) \\
\hline $\begin{array}{l}\text { Perceived quality } \\
\text { (Sweeney and Souter 2001) }\end{array}$ & $\begin{array}{l}\text { It has consistent quality } \\
\text { It is well made } \\
\text { It has an acceptable standard of quality } \\
\text { It has poor workmanship }(\mathrm{R}) \\
\text { It would not last a long time }(\mathrm{R}) \\
\text { It would perform consistently }\end{array}$ \\
\hline $\begin{array}{l}\text { Persuasion effectiveness } \\
\text { (Touré-Tillery and McGill 2015) }\end{array}$ & $\begin{array}{l}\text { Impressions of the product: Very bad (1) - Very good (7) } \\
\text { Liking of the product: Dislike extremely (1) - like extremely (7) } \\
\text { Thoughts about the effectiveness of the product: Very ineffective (1) - very effective (7) } \\
\text { Degree of confidence that it would work: Very doubtful (1) - Very confident (7) } \\
\text { Likelihood to buy the product: Very unlikely (1) - Very likely (7) }\end{array}$ \\
\hline $\begin{array}{l}\text { Perceived creativity } \\
\text { (Dahl, Chattopadhyay, and Gorn 1999) }\end{array}$ & $\begin{array}{l}\text { Ordinary (1) - Unique (7) } \\
\text { Commonplace (1) - Original (7) } \\
\text { Routine (1) - Fresh (7) } \\
\text { Useless (1) - Useful (7) } \\
\text { Ineffective (1) - Effective (7) } \\
\text { Worthless (1) - Worthwhile (7) }\end{array}$ \\
\hline $\begin{array}{l}\text { Consumer Evaluation } \\
\text { (Yoo and Donthu 2001) }\end{array}$ & $\begin{array}{l}\text { Very bad (1) - very good (7) } \\
\text { Very unattractive (1) - very attractive (7) } \\
\text { Very undesirable (1) - very desirable (7) } \\
\text { Very unlikable (1) - very likable (7) }\end{array}$ \\
\hline $\begin{array}{l}\text { Female-gendered role } \\
\text { (Bem 1974; Luchs and Mooradian } \\
\text { 2012) }\end{array}$ & $\begin{array}{l}\text { It is warm. } \\
\text { It is feminine. } \\
\text { It is gentle. } \\
\text { It is affectionate. } \\
\text { It is compassionate. } \\
\text { It is tender. }\end{array}$ \\
\hline $\begin{array}{l}\text { Male-gendered role } \\
\text { (Bem 1974; Luchs and Mooradian } \\
\text { 2012) }\end{array}$ & $\begin{array}{l}\text { It is dominant. } \\
\text { It is masculine. } \\
\text { It is individualistic. } \\
\text { It is ambitious. } \\
\text { It is analytical. } \\
\text { It is self-reliant. }\end{array}$ \\
\hline $\begin{array}{l}\text { Product involvement } \\
\text { (Zaichkowsky 1994) }\end{array}$ & $\begin{array}{l}\text { It is interesting to me. } \\
\text { It is valuable to me. } \\
\text { It is important to me. } \\
\text { It means a lot to me. } \\
\text { It matters to me. }\end{array}$ \\
\hline $\begin{array}{l}\text { Familiarity } \\
\text { (Kent and Allen 1994) }\end{array}$ & $\begin{array}{l}\text { I am experience with it. } \\
\text { I am knowledgeable with it. } \\
\text { I am familiar with it. } \\
\text { It is dense. }\end{array}$ \\
\hline $\begin{array}{l}\text { Complexity } \\
\text { (Geissler et al. 2006) }\end{array}$ & $\begin{array}{l}\text { It is complex. } \\
\text { It is interactive. } \\
\text { It has much variety. }\end{array}$ \\
\hline $\begin{array}{l}\text { Fluency } \\
\text { (Berger and Fitzsimons 2008) }\end{array}$ & $\begin{array}{l}\text { It is eye-catching. } \\
\text { It is easy to process. } \\
\text { It is very attractive. }\end{array}$ \\
\hline
\end{tabular}




\section{BIBLIOGRAPHY}

Aaker, J., Vohs, K. D., and Mogilner, C. (2010). Nonprofits are seen as warm and forprofits as competent: Firm stereotypes matter. Journal of Consumer Research, 37(2), 224-237.

Abele, A. E., and Wojciszke, B. (2013). The Big Two in social judgment and behavior. Social Psychology, 44(2), 61-62.

Adams, K. (2015), Even women think men are more creative, Harvard Business Review, December, 30-31.

Akhter, S. H. (2003). Digital divide and purchase intention: Why demographic psychology matters. Journal of Economic Psychology, 24(3), 321-327.

Alba, J. W., and Hutchinson, J. W. (1987). Dimensions of consumer expertise. Journal of Consumer Research, 13(4), 411-454.

Banaji, M. R., and Greenwald, A. G. (1995). Implicit gender stereotyping in judgments of fame. Journal of personality and social psychology, 68(2), 181198.

Bargh, J. A., Chen, M., and Burrows, L. (1996). Automaticity of social behavior: Direct effects of trait construct and stereotype activation on action. Journal of personality and social psychology, 71(2), 230-244. 
Bargh, J.A. (1989). Conditional automaticity: Varieties of automatic influence on social perception and cognition. In J. Uleman and J. Bargh (Eds.), Unintended thought (pp. 3-51). New York: Guilford Press.

Bargh, J.A. (1990). Auto-motives: Preconscious determinants of thought and behaviour. Multiple affects from multiple stages. In E.T. Higgins and R.M. Sorrentino (Eds.), Handbook of motivation and cognition: Foundations of social behavior (Vol. 2, pp. 93-130). New York: Guilford Press.

Barron, F. (1955). The disposition towards originality. Journal of Abnormal and Social Psychology, 51, 478-485.

Belk, R. W. (1991). The ineluctable mysteries of possessions. Journal of Social Behavior and Personality, 6(6), 17-55.

Bem, S. L. (1974). The measurement of psychological androgyny. Journal of Consulting and Clinical Psychology, 42(2), 155-162.

Berger, J., and Fitzsimons, G. (2008). Dogs on the street, pumas on your feet: How cues in the environment influence product evaluation and choice. Journal of Marketing Research, 45(1), 1-14.

Blair, I. V., and Banaji, M. R. (1996). Automatic and controlled processes in stereotype priming. Journal of personality and social psychology, 70(6), 11421163.

Bourdieu, P. (1998). State nobility. Cambridge: Polity Press. 
Brebner, J. L., Martin, D., and Macrae, C. N. (2009). Dude looks like a lady: Exploring the malleability of person categorization. European Journal of Social Psychology, 39(6), 1109-1119.

Brough, A. R., Wilkie, J. E., Ma, J., Isaac, M. S., and Gal, D. (2016). Is eco-friendly unmanly? The green-feminine stereotype and its effect on sustainable consumption. Journal of Consumer Research, 43(4), 567-582.

Brunswick, E. (1956), Perception and the Representative Design of Psychological Experiments. Berkeley: University of California Press.

Cantú, S. M., Simpson, J. A., Griskevicius, V., Weisberg, Y. J., Durante, K. M., and Beal, D. J. (2014). Fertile and selectively flirty: Women's behavior toward men changes across the ovulatory cycle. Psychological Science, 25(2), 431438.

Cacioppo, J. T., and Petty, R. E. (1981). Social psychological procedures for cognitive response assessment: The thought-listing technique. Cognitive Assessment, 309-342.

Conway, M., Pizzamiglio, M. T., and Mount, L. (1996). Status, communality, and agency: implications for stereotypes of gender and other groups. Journal of Personality and Social Psychology, 71(1), 25-38.

Cornwell, T.B., Humphreys, M.S., Maguire, A.M., Weeks, C.S. and Tellegen, C.L. (2006), Sponsorship-linked marketing: the role of articulation in memory, Journal of Consumer Research, 33(3), 312-321 
Cuddy, A. J., Fiske, S. T., and Glick, P. (2004). When professionals become mothers, warmth doesn't cut the ice. Journal of Social Issues, 60(4), 701-718.

Cuddy, A. J., Fiske, S. T., Kwan, V. S., Glick, P., Demoulin, S., Leyens, J. P., Bond, M. H., Croizet, J. C., Ellemers, N., Sleebos, E. andHtun, T. T. (2009). Stereotype content model across cultures: Towards universal similarities and some differences. British Journal of Social Psychology, 48(1), 1-33.

Dahl, D. W., Chattopadhyay, A., and Gorn, G. J. (1999). The use of visual mental imagery in new product design. Journal of Marketing Research, 36(1), 18-28.

d'Astous, A., and Bitz, P. (1995). Consumer evaluations of sponsorship programmes. European Journal of Marketing, 29(12), 6-22.

Davis, R., Lang, B., and San Diego, J. (2014). How gender affects the relationship between hedonic shopping motivation and purchase intentions? Journal of Consumer Behaviour, 13(1), 18-30.

De Grazia, V., and Furlough, E. (1996). The sex of things: Gender and Consumption. Berkeley. California Press.

Dempsey, M. A., and Mitchell, A. A. (2010). The influence of implicit attitudes on choice when consumers are confronted with conflicting attribute information. Journal of Consumer Research, 37(4), 614-625.

Dholakia, R. R. (2012). Technology and consumption: Understanding consumer choices and behaviors. New York: Springer Science and Business Media. 
Dholakia, R. R., and Chiang, K. P. (2003). Shoppers in cyberspace: are they from Venus or Mars and does it matter?. Journal of Consumer Psychology, 13(1-2), $171-176$.

Diedrich, J., Benedek, M., Jauk, E., and Neubauer, A. C. (2015). Are creative ideas novel and useful?. Psychology of Aesthetics, Creativity, and the Arts, 9(1), 35.

Dijksterhuis, A., and Van Knippenberg, A. (1998). The relation between perception and behavior, or how to win a game of trivial pursuit. Journal of personality and social psychology, 74(4), 865.

Dirks, M. A., Treat, T. A., and Weersing, V. R. (2007). Integrating theoretical, measurement, and intervention models of youth social competence. Clinical psychology review, 27(3), 327-347.

Doucé, L., Janssens, W., Leroi-Werelds, S., and Streukens, S. (2016). What to diffuse in a gender-specific store? The effect of male and female perfumes on customer value and behaviour. Journal of Consumer Behaviour, 15(3), 271280.

Eagly, A. H., and Wood, W. (2013). The nature-nurture debates: 25 years of challenges in understanding the psychology of gender. Perspectives on Psychological Science, 8(3), 340-357.

Epley, N., Waytz, A., and Cacioppo, J. T. (2007). On seeing human: a three-factor theory of anthropomorphism. Psychological review, 114(4), 864-886. 
Eyssel, F., and Kuchenbrandt, D. (2012). Social categorization of social robots: Anthropomorphism as a function of robot group membership. British Journal of Social Psychology, 51(4), 724-731.

Fazio, R. H. (1990), “A Practical Guide to the Use of Response Latency in Social Psychological Research," in Research Methods in Personality and Social Psychology, ed. Clyde Hendrick and Margaret Clark, Thousand Oaks, CA, 7497.

Feldman, J. M., and Lynch, J. G. (1988). Self-generated validity and other effects of measurement on belief, attitude, intention, and behavior. Journal of Applied Psychology, 73(3), 421-435.

Festinger, L. (1954). A theory of social comparison processes. Human Relations, 7(2), 117-140.

Fournier, S. (1998). Consumers and their brands: Developing relationship theory in consumer research. Journal of consumer research, 24(4), 343-373.

Fiske, S. T. (1993). Social cognition and social perception. Annual review of psychology, 44(1), 155-194.

Fiske, S. T. (2000). Stereotyping, prejudice, and discrimination at the seam between the centuries: Evolution, culture, mind, and brain. European Journal of Social Psychology, 30(3), 299-322. 
Fiske, S. T., Cuddy, A. J., Glick, P., and Xu, J. (2002). A model of (often mixed) stereotype content: competence and warmth respectively follow from perceived status and competition. Journal of Personality and Social Psychology, 82(6), 878-902.

Fiske, A. P., and Haslam, N. (1996). Social cognition is thinking about relationships. Current Directions in Psychological Science, 5(5), 143-148.

Fitbit, Available at: https://www.fitbit.com/home, retrieved on March, 2019

Fitzsimons, G.J., Hutchinson, J.W., Williams, P., Alba, J.W., Chartrand, T.L., Huber, J., Kardes, F.R., Menon, G., Raghubir, P., Russo, J.E. and Shiv, B. (2002). Non-conscious influences on consumer choice. Marketing Letters, 13(3), pp.269-279.

Gawronski, B., and Bodenhausen, G. V. (2014). Implicit and explicit evaluation: A brief review of the associative-propositional evaluation model. Social and Personality Psychology Compass, 8(8), 448-462.

Gefen, D., and Straub, D. W. (1997). Gender differences in the perception and use of e-mail: An extension to the technology acceptance model. MIS Quarterly, 21(4), 389-400.

Geissler, G. L., Zinkhan, G. M., and Watson, R. T. (2006). The influence of home page complexity on consumer attention, attitudes, and purchase intent. Journal of Advertising, 35(2), 69-80. 
Gibson, B. (2008). Can evaluative conditioning change attitudes toward mature brands? New evidence from the Implicit Association Test. Journal of Consumer Research, 35(1), 178-188.

Gill, R., and Grint, K. (1995). The gender-technology relation: Contemporary theory and research: An introduction. London: Taylor and Francis.

Global Entrepreneurship Monitor's Women’s Entrepreneurship 2016/2017 Report. https://www.babson.edu/Academics/centers/blank-center/globalresearch/gem/Documents/GEM\%202016-2017\%20Womens\%20Report.pdf

Gregan-Paxton, J., Hoeffler, S., and Zhao, M. (2005). When categorization is ambiguous: Factors that facilitate the use of a multiple category inference strategy. Journal of Consumer Psychology, 15(2), 127-140.

Greenwald, A. G., Banaji, M. R., Rudman, L. A., Farnham, S. D., Nosek, B. A., and Mellott, D. S. (2002). A unified theory of implicit attitudes, stereotypes, selfesteem, and self-concept. Psychological Review, 109(1), 3-25.

Giguère, G. (2006). Collecting and analyzing data in multidimensional scaling experiments: A guide for psychologists using SPSS. Tutorials in Quantitative Methods for Psychology, 2(1), 27-38.

Halkias, G., Davvetas, V., and Diamantopoulos, A. (2016). The interplay between country stereotypes and perceived brand globalness/localness as drivers of brand preference. Journal of Business Research, 69(9), 3621-3628. 
Haslam, N., and Whelan, J. (2008). Human natures: Psychological essentialism in thinking about differences between people. Social and Personality Psychology Compass, 2(3), 1297-1312.

Hayes, A. F. (2013). Introduction to mediation, moderation, and conditional process analysis: A regression-based approach. Guilford Publications.

He, X., Inman, J. J., and Mittal, V. (2008). Gender jeopardy in financial risk taking. Journal of Marketing Research, 45(4), 414-424.

Hekman, D. R., Aquino, K., Owens, B. P., Mitchell, T. R., Schilpzand, P., and Leavitt, K. (2010). An examination of whether and how racial and gender biases influence customer satisfaction. Academy of Management Journal, 53(2), 238264.

Herr, P. M., Kardes, F. R., and Kim, J. (1991). Effects of word-of-mouth and productattribute information on persuasion: An accessibility-diagnosticity perspective. Journal of consumer research, 17(4), 454-462.

Hirschman, E. C. (1980). Innovativeness, novelty seeking, and consumer creativity. Journal of consumer research, 7(3), 283-295.

Hoeffler, S. (2003). Measuring preferences for really new products. Journal of Marketing Research, 40(4), 406-420. 
Hoffman, D. L., and Novak, T. P. (2018). Consumer and object experience in the internet of things: An assemblage theory approach. Journal of Consumer Research, 44(6), 1178-120

Hyde, J. S. (2005). The gender similarities hypothesis. American Psychologist, 60(6), 581-592.

Im, S., and Workman Jr, J. P. (2004). Market orientation, creativity, and new product performance in high-technology firms. Journal of Marketing, 68(2), 114-132.

Jhang, J.H., S.J. Grant, and M.C. Campbell. 2012. Get it? Got it. Good! Enhancing new product acceptance by facilitating resolution of extreme incongruity. Journal of Marketing Research, 29 (2), 247-259.

Johar, G. V., and Pham, M. T. (1999). Relatedness, prominence, and constructive sponsor identification. Journal of Marketing Research, 36(3), 299-312.

Kent, R. J., and Allen, C. T. (1994). Competitive interference effects in consumer memory for advertising: the role of brand familiarity. Journal of Marketing, $58(3), 97-105$.

Kleine, S. S., and Baker, S. M. (2004). An integrative review of material possession attachment. Academy of marketing science review, 1(1), 1-39.

Kleine, S. S., Kleine III, R. E., and Allen, C. T. (1995). How is a possession "me” or "not me"? Characterizing types and an antecedent of material possession attachment. Journal of Consumer Research, 22(3), 327-343. 
Kilgour, M., and Koslow, S. (2009). Why and how do creative thinking techniques work?: Trading off originality and appropriateness to make more creative advertising. Journal of the Academy of Marketing Science, 37(3), 298-309.

Kim, S. K., Frisby, C. L., and Davison, M. L. (2004). Estimating cognitive profiles using profile analysis via multidimensional scaling (PAMS). Multivariate Behavioral Research, 39(4), 595-624.

Kimmel M. S., and Aronson, A. (Eds.). (2004). The Gendered Society reader. Oxford: Oxford University Press.

Koch, A. J., D'Mello, S. D., and Sackett, P. R. (2015). A meta-analysis of gender stereotypes and bias in experimental simulations of employment decision making. Journal of Applied Psychology, 100(1), 128-161.

Krishna, A., Cian, L., and Aydınoğlu, N. Z. (2017). Sensory Aspects of Package Design. Journal of Retailing, 93(1), 43-54.

Lastovicka, J. L., and Sirianni, N. J. (2011). Truly, madly, deeply: Consumers in the throes of material possession love. Journal of Consumer Research, 38(2), 323342.

Lebuda, I., and Karwowski, M. (2013). Tell me your name and I'll tell you how creative your work is: Author's name and gender as factors influencing assessment of products' creativity in four different domains. Creativity Research Journal, 25(1), 137-142. 
Lee, A. Y., and Labroo, A. A. (2004). The effect of conceptual and perceptual fluency on brand evaluation. Journal of Marketing Research, 41(2), 151-165.

Lerman, N., Oldenziel, R., and Mohun, A. P. (2003). Gender and technology: A reader. Baltimore: Johns Hopkins University Press.

Loken, B. (2006). Consumer psychology: categorization, inferences, affect, and persuasion. Annual Review of Psychology, 57, 453-485.

Loken, B., and Ward, J. (1990). Alternative approaches to understanding the determinants of typicality. Journal of Consumer Research, 17(2), 111-126.

Liberman, Z., Woodward, A. L., and Kinzler, K. D. (2017). The Origins of Social Categorization. Trends in Cognitive Sciences. 21. 556-568.

Luchs, M. G., and Mooradian, T. A. (2012). Sex, personality, and sustainable consumer behaviour: Elucidating the gender effect. Journal of Consumer Policy, 35(1), 127-144.

Lusch, R., and Brown, J. R. (1996). Interdependency, contracting, and relational behavior in marketing channels. Journal of Marketing, 60(4), 19-38.

Lynch Jr, J. G. (2006). Accessibility-diagnosticity and the multiple pathway anchoring and adjustment model. Journal of Consumer Research, 33(1), 25-27.

MacInnis, D. J., and Folkes, V. S. (2017). Humanizing brands: When brands seem to be like me, part of me, and in a relationship with me. Journal of Consumer Psychology, 27(3), 355-374. 
MacKinnon, D. P., and Luecken, L. J. (2008). How and for whom? Mediation and moderation in health psychology. Health Psychology, 27(2, Suppl), S99-S100

Magnusson, P., Westjohn, S. A., and Zdravkovic, S. (2011). "What? I thought Samsung was Japanese": accurate or not, perceived country of origin matters. International Marketing Review, 28(5), 454-472.

Maher, A. A., and Carter, L. L. (2011). The affective and cognitive components of country image: Perceptions of American products in Kuwait. International Marketing Review, 28(6), 559-580.

Mai, R., and Hoffmann, S. (2015). How to combat the unhealthy= tasty intuition: The influencing role of health consciousness. Journal of Public Policy and Marketing, 34(1), 63-83.

Mayer, K. B., and Buckley, W. F. (1969). Class and society. Random House.

McKeown, B., and Thomas, D. B. (2013). Q methodology, Sage publications.

Meuter, M. L., Bitner, M. J., Ostrom, A. L., and Brown, S. W. (2005). Choosing among alternative service delivery modes: An investigation of customer trial of self-service technologies. Journal of Marketing, 69(2), 61-83.

Meyers-Levy, J., and Loken, B. (2015). Revisiting gender differences: What we know and what lies ahead. Journal of Consumer Psychology, 25(1), 129-149. 
Micheli, P., and Gemser, G. (2016). Signaling strategies for innovative design: a study on design tradition and expert attention. Journal of Product Innovation Management, 33(5), 613-627.

Mick, D. G., and Fournier, S. (1998). Paradoxes of technology: Consumer cognizance, emotions, and coping strategies. Journal of Consumer research, 25(2), 123143.

Min, S., Kalwani, M. U., and Robinson, W. T. (2006). Market pioneer and early follower survival risks: A contingency analysis of really new versus incrementally new product-markets. Journal of Marketing, 70(1), 15-33.

Miniard, P. W., Sirdeshmukh, D., and Innis, D. E. (1992). Peripheral persuasion and brand choice. Journal of Consumer Research, 19(2), 226-239.

Moreau, C. P., Lehmann, D. R., and Markman, A. B. (2001). Entrenched knowledge structures and consumer response to new products. Journal of Marketing Research, 38(1), 14-29.

Mourey, J. A., Olson, J. G., and Yoon, C. (2017). Products as pals: Engaging with anthropomorphic products mitigates the effects of social exclusion. Journal of Consumer Research, 44(2), 414-431.

Mugge, R., and Dahl, D. W. (2013). Seeking the ideal level of design newness: Consumer response to radical and incremental product design. Journal of Product Innovation Management, 30(S1), 34-47. 
Myers, C. D., Riley III, J. L., and Robinson, M. E. (2003). Psychosocial contributions to sex-correlated differences in pain. The Clinical journal of pain, 19(4), 225232.

Nass, C., and Steuer, J. (1993). Voices, boxes, and sources of messages. Human Communication Research, 19(4), 504-527.

Nass, C., Moon, Y., and Green, N. (1997). Are machines gender neutral? Gender stereotypic responses to computers with voices. Journal of applied social psychology, 27(10), 864-876.

Newman, G. E., Gorlin, M., and Dhar, R. (2014). When going green backfires: How firm intentions shape the evaluation of socially beneficial product enhancements. Journal of Consumer Research, 41(3), 823-839.

New York Times (2018), Most Americans See Artificial Intelligence as a Threat to Jobs (Just Not Theirs), https:/www.nytimes.com/2018/03/06/us/artificialintelligence-jobs.html? module=inline (retrieved on Feb 3).

Novak, T. P., and Hoffman, D. L. (2019). Relationship journeys in the internet of things: a new framework for understanding interactions between consumers and smart objects. Journal of the Academy of Marketing Science, 47(2), 216237.

OECD (2018), Time Use, https://stats.oecd.org/Index.aspx?datasetcode=TIME_USE (retrieved on Feb 3, 2019) 
Oliver, R. L., and DeSarbo, W. S. (1988). Response determinants in satisfaction judgments. Journal of consumer research, 14(4), 495-507.

Oliver, R. L., and Swan, J. E. (1989). Equity and disconfirmation perceptions as influences on merchant and product satisfaction. Journal of consumer research, 16(3), 372-383.

Payne, B. K., Jacoby, L. L., and Lambert, A. J. (2005). Attitudes as accessibility bias: Dissociating automatic and controlled components. In R. A. Hassin, J. S. Uleman, and J. A. Bargh, (Eds.), The New Unconscious. New York: Oxford University Press.

Prediger, D. J. (1982). Dimensions underlying Holland's hexagon: Missing link between interests and occupations?. Journal of Vocational Behavior, 21(3), 259-287.

Proudfoot, D., Kay, A. C., and Koval, C. Z. (2015). A gender bias in the attribution of creativity: archival and experimental evidence for the perceived association between masculinity and creative thinking. Psychological Science, 26(11), $1751-1761$

Puntoni, S., Sweldens, S., and Tavassoli, N. T. (2011). Gender identity salience and perceived vulnerability to breast cancer. Journal of Marketing Research, 48(3), 413-424. 
Radford, S. K., and Bloch, P. H. (2011). Linking innovation to design: Consumer responses to visual product newness. Journal of Product Innovation Management, 28(s1), 208-220.

Rao, A. S., Georgeff, M. P., and Sonenberg, E. A. (1992). Social plans: A preliminary report. Decentralized AI, 3, 57-76.

Richardson, P. S., Dick, A. S., and Jain, A. K. (1994). Extrinsic and intrinsic cue effects on perceptions of store brand quality. Journal of Marketing, 58(5), 2836.

Rifon, N. J., Choi, S. M., Trimble, C. S., and Li, H. (2004). Congruence effects in sponsorship: The mediating role of sponsor credibility and consumer attributions of sponsor motive. Journal of Advertising, 33(1), 30-42.

Rindova, V. P., and Petkova, A. P. (2007). When is a new thing a good thing? Technological change, product form design, and perceptions of value for product innovations. Organization Science, 18(2), 217-232.

Rijsdijk, S. A., Hultink, E. J., and Diamantopoulos, A. (2007). Product intelligence: its conceptualization, measurement and impact on consumer satisfaction. Journal of the Academy of Marketing Science, 35(3), 340-356.

Rivkin, J., and Ryan, M. (Eds.). (2017). Literary theory: An anthology. John Wiley and Sons.

Rogers, E. M. (2003). Diffusion of innovations (5th ed.). New York: Free Press. 
Rogers, E. M., and Shoemaker, F. F. (1971). Communication of Innovations; A CrossCultural Approach. New York: Free Press

Rozin, P., Hormes, J. M., Faith, M. S., and Wansink, B. (2012). Is meat male? A quantitative multimethod framework to establish metaphoric relationships. Journal of Consumer Research, 39(3), 629-643.

Runco, M. A., and Jaeger, G. J. (2012). The standard definition of creativity. Creativity Research Journal, 24(1), 92-96.

Saad, G., and Vongas, J. G. (2009). The effect of conspicuous consumption on men's testosterone levels. Organizational Behavior and Human Decision Processes, $110(2), 80-92$.

Searles, K., Fowler, E. F., Ridout, T. N., Strach, P., and Zuber, K. (2017). The Effects of Men's and Women's Voices in Political Advertising. Journal of Political Marketing(0), 1-29.

Schepers, J., and Wetzels, M. (2007). A meta-analysis of the technology acceptance model: Investigating subjective norm and moderation effects. Information and Management, 44(1), 90-103.

Schwarz, N. (2011). Feelings-as-information theory. Handbook of theories of social psychology, 1, 289-308.

Simmons, C. J., and Becker-Olsen, K. L. (2006). Achieving marketing objectives through social sponsorships. Journal of Marketing, 70(4), 154-169. 
Slate (2018). Why It Matters That Alexa and Google Assistant Finally Have Male Voices. https://slate.com/technology/2018/05/alexa-google-finally-are-gettingmale-virtual-assistants-its-about-time.html?wpsrc=sh_all_dt_tw_ru

Spangenberg, E. R., Sprott, D. E., Grohmann, B., and Tracy, D. L. (2006). Gendercongruent ambient scent influences on approach and avoidance behaviors in a retail store. Journal of Business Research, 59(12), 1281-1287.

Stangor, C. (1988). Stereotype accessibility and information processing. Personality and Social Psychology Bulletin, 14(4), 694-708.

Stein, M. I. (1953). Creativity and culture. Journal of Psychology, 36, 31-322.

Stewart, A. J., and McDermott, C. (2004). Gender in psychology. Annu. Rev. Psychol., 55, 519-544.

Steyvers, M. 2002. Multidimensional Scaling. In: Encyclopedia of Cognitive Science. Macmillan Reference Ltd.

Sweeney, J. C., and Soutar, G. N. (2001). Consumer perceived value: The development of a multiple item scale. Journal of Retailing, 77(2), 203-220.

Sweldens, S., Van Osselaer, S. M., and Janiszewski, C. (2010). Evaluative conditioning procedures and the resilience of conditioned brand attitudes. Journal of Consumer Research, 37(3), 473-489.

Thaler, R. H., and Sunstein, C. R. (1999). Nudge: Improving decisions about health, wealth, and happiness. New Haven: Yales University Press. 
Thompson, C. J. (1997). Interpreting consumers: A hermeneutical framework for deriving marketing insights from the texts of consumers' consumption stories. Journal of Marketing Research, 34(4), 438-455.

Triantos, A., Plakoyiannaki, E., Outra, E., and Petridis, N. (2016). Anthropomorphic packaging: is there life on "Mars"?. European Journal of Marketing, 50(1/2), $260-275$.

Tse, D. K., and Wilton, P. C. (1988). Models of consumer satisfaction formation: An extension. Journal of marketing research, 25(2), 204-212.

Ulrich, I., Tissier-Desbordes, E., and Dubois, P. L. (2010). Brand gender and its dimensions. In A. Bradshaw, C. Hackley, and P. Maclaran (Eds.), European Advances in Consumer Research (Vol. 9). London: Association for Consumer Research.

Venkatraman, M. (2013). Consuming digital technologies and making home. Journal of Business Research, 66(12), 2626-2633.

Wajcman, J. (1991). Feminism confronts technology. University Park: Pennsylvania State University Press.

Wajcman, J. (2010). Feminist theories of technology. Cambridge journal of economics, 34(1), 143-152.

Wegener, D. T., and Petty, R. E. (1998). The naive scientist revisited: Naive theories and social judgment. Social Cognition, 16(1), 1-7. 
Wegner, D. M., and Bargh, J. A. (1998). Control and automaticity in social life. In D.

T. Gilbert, S. T. Fiske, and G. Lindzey (Eds.), The handbook of social psychology (pp. 446-496). New York: McGraw-Hill

Whipple, T. W., and McManamon, M. K. (2002). Implications of using male and female voices in commercials: An exploratory study. Journal of Advertising, $31(2), 79-91$.

Whitfield, M., and Jordan, C. H. (2009). Mutual influence of implicit and explicit attitudes. Journal of experimental social psychology, 45(4), 748-759.

Wilson, T. D., Lindsey, S., and Schooler, T. Y. (2000). A model of dual attitudes. Psychological Review, 107(1), 101-126.

Yamauchi, T., andMarkman, A. B. (2000). Inference using categories. Journal of Experimental Psychology: Learning, Memory, and Cognition, 26, 776-795.

Yorkston, E., and De Mello, G. E. (2005). Linguistic gender marking and categorization. Journal of Consumer Research, 32(2), 224-234.

Yoo, B., and Donthu, N. (2001). Developing and validating a multidimensional consumer-based brand equity scale. Journal of Business Research, 52(1), 1-14.

Zaichkowsky, J. L. (1994). The personal involvement inventory: Reduction, revision, and application to advertising. Journal of Advertising, 23(4), 59-70.

Zeithaml, V. A. (1988). Consumer perceptions of price, quality, and value: a meansend model and synthesis of evidence. Journal of Marketing, 52(3), 2-22. 